\title{
Design and Operation of a Passive Neutron Monitor For Assaying the Tru Content of Solid Wastes
}

\author{
R. L. Brodzinski \\ D. P. Brown \\ H. G. Rieck, Jr. \\ L. A. Rogers
}

February 1984

Prepared for the U.S. Department of Energy under Contract DE-AC06-76RLO 1830

Pacific Northwest Laboratory Operated for the U.S. Department of Energy by Battelle Memorial Institute 


\title{
DISCLAIMER
}

This report was prepared as an account of work sponsored by an agency of the United States Government. Neither the United States Government nor any agency thereof, nor any of their employees, makes any warranty, express or implied, or assumes any legal liability or responsibility for the accuracy, completeness, or usefulness of any information, apparatus, product, or process disclosed, or represents that its use would not infringe privately owned rights. Reference herein to any specific commercial product, process, or service by trade name, trademark, manufacturer, or otherwise, does not necessarily constitute or imply its endorsement, recommendation, or favoring by the United States Government or any agency thereof. The views and opinions of authors expressed herein do not necessarily state or reflect those of the United States Government or any agency thereof.

\author{
PACIFIC NORTHWEST LABORATORY \\ operated by \\ BATTELLE \\ for the \\ UNITED STATES DEPARTMENT OF ENERGY \\ under Contract DE-AC06-76RLO 1830
}

\begin{tabular}{|c|c|}
\hline \multicolumn{2}{|c|}{ Printed in the United States of America } \\
\hline \multicolumn{2}{|c|}{$\begin{array}{l}\text { Available from } \\
\text { National Technical Information Service }\end{array}$} \\
\hline \multirow{2}{*}{\multicolumn{2}{|c|}{$\begin{array}{c}\text { United States Department of Commerce } \\
5285 \text { Port Royal Road } \\
\text { Springfield, Virginia 22161 }\end{array}$}} \\
\hline & \\
\hline \multirow{2}{*}{\multicolumn{2}{|c|}{$\begin{array}{l}\text { NTIS Price Codes } \\
\text { Microfiche A01 }\end{array}$}} \\
\hline & \\
\hline \multicolumn{2}{|c|}{ Printed Copy } \\
\hline Paras & Price \\
\hline & \\
\hline $001-025$ & $\mathrm{~A} 02$ \\
\hline $026-050$ & $\mathrm{~A} 03$ \\
\hline $051-075$ & A04 \\
\hline $076-100$ & A05 \\
\hline $101-125$ & A06 \\
\hline $126-150$ & A07 \\
\hline $151-175$ & $\mathrm{~A} 0 \mathrm{~B}$ \\
\hline $176-200$ & $A 09$ \\
\hline $201-225$ & A010 \\
\hline $226-250$ & A011 \\
\hline $251-275$ & A012 \\
\hline $276-300$ & A013 \\
\hline
\end{tabular}


PNL-4966

UC $-79 c$

DESIGN AND OPERATION OF A PASSIVE NEUTRON MONITOR FOR ASSAYING THE TRU CONTENT OF SOLID WASTES
R. L. Brodzinski
D. P. Brown
H. G. Rieck, Jr.
L. A Rogers

February 1984

Prepared for the U. S. Department of Energy under Contract DE-AC06-76RLO 1830

Pacific Northwest Laboratory Richland, Washington 99352 


\section{TABLE OF CONTENTS}

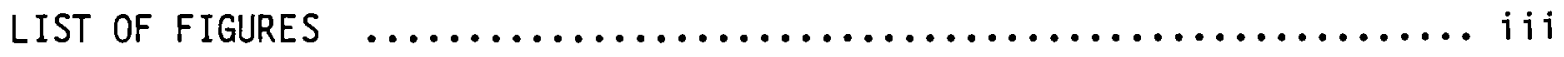

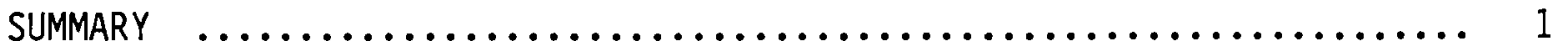

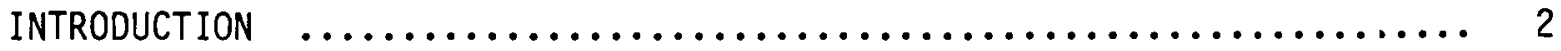

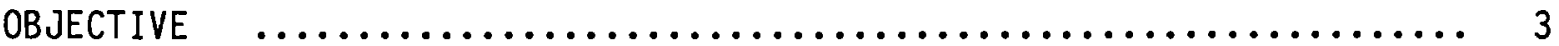

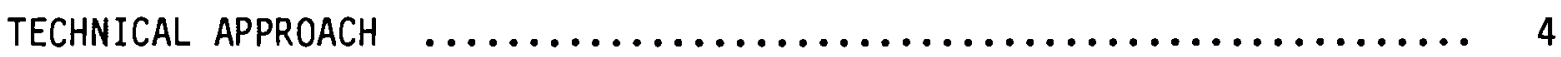

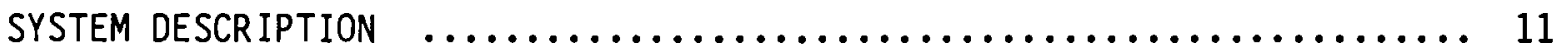

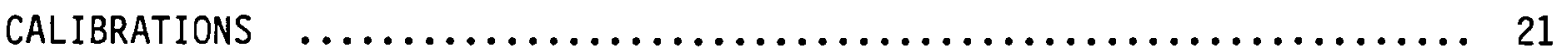

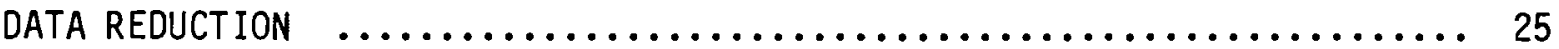

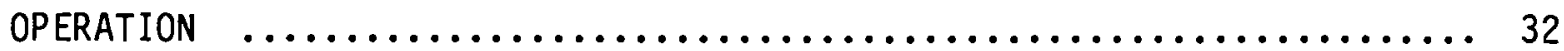

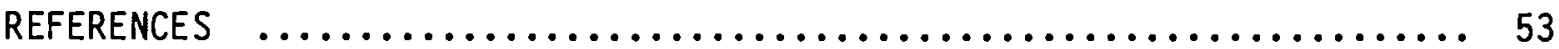

APPENDIX A - ELECTRONIC SYSTEM DATA SHEETS

APPENDIX B - CALIBRATION DATA 


\section{LIST OF FIGURES}

1 PFMP Hulls Monitor Prototype Assembly $\ldots \ldots \ldots \ldots \ldots \ldots \ldots, 12$

2 PFMP Hulls Monitor Lead Shield Assembly $\ldots . . . \ldots \ldots \ldots . . . . .13$

3 PFMP Hulls Monitor Moderator Assembly $\ldots . \ldots \ldots \ldots \ldots \ldots . . . \ldots$

4 Preamplifier/Discriminator Circuit Board Panels and Diagram .................................. 16

5 Preamplifier/Discriminator Housing Assembly,

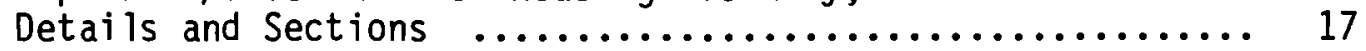

6 PFMP Hulls Monitor Instrumentation $\ldots \ldots \ldots \ldots \ldots \ldots \ldots . . . . . .6$

7 Block Diagram of Electronic Circuitry $\ldots \ldots \ldots \ldots \ldots \ldots \ldots . . . \ldots 34$

8 Sample Spatial Background Log Sheet $\ldots \ldots \ldots \ldots \ldots \ldots \ldots \ldots . . \ldots, 38$

9 Sample Coincidence Background Log Sheet $\ldots \ldots \ldots \ldots \ldots \ldots \ldots . . . .40$

10 Sample Spatial Calibration Log Sheet $\ldots . . . \ldots \ldots . . . . . . . .41$

11 Sample Coincidence Calibration Log Sheet $\ldots . . . \ldots . \ldots . . . . .43$

12 Sample Coincidence Assay Log Sheet $\ldots . \ldots \ldots \ldots \ldots \ldots \ldots . . . .45$

13 Sample Spatial Assay Log Sheet $\ldots . . \ldots \ldots \ldots \ldots \ldots \ldots \ldots . . . . .47$

14 Sample Diagnostic Data Sheet $\ldots \ldots \ldots \ldots \ldots \ldots \ldots \ldots \ldots \ldots . . . \ldots$. 49

15 Typical Pulse Shapes for Normal Events, Noise, and HV Breakdown 
DESIGN AND OPERATION OF A PASSIVE NEUTRON MONITOR FOR ASSAYING THE TRU CONTENT OF SOLID WASTES

\author{
R. L. Brodzinski \\ D. P. Brown \\ H. G. Rieck, Jr. \\ L. A. Rogers
}

\title{
SUMMARY
}

A passive neutron monitor has been designed and built for determining the residual transuranic (TRU) and plutonium content of chopped leached fuel hulls and other solid wastes from spent Fast Flux Test Facility (FFTF) fuel. The system was designed to measure as little as $8 \mathrm{~g}$ of plutonium or $88 \mathrm{mg}$ of TRU in a waste package as large as a $208 \ell$ drum which could be emitting up to $220,000 \mathrm{R} / \mathrm{hr}$ of gamma radiation. For practical purposes, maximum assay times were chosen to be 10,000 seconds.

The monitor consists of $9610 \mathrm{BF}_{3}$ neutron sensitive proportional counting tubes each $5.08 \mathrm{~cm}$ in diameter and $183 \mathrm{~cm}$ in active length. These tubes are embedded in a solid polyethylene moderator which thermalizes the fast neutrons emitted by spontaneous fission of some of the transuranic isotopes present or by $(\alpha, n)$ reactions on 170 or 180 present in the matrix. A $12.7 \mathrm{~cm}$ thick lead annulus shields the $10_{B_{3}}$ tubes from the garmma radiation emitted by the waste package. Specially designed preamplifier/discriminators further reduce gamma-ray pulse "pile-up" from the large array of neutron counters.

The data acquisition system is capable of measuring the total neutron flux, the coincidence neutron counting rate up to eight simultaneous coincidences, and the spatial neutron flux in eight different "octants" for measuring inhomogenieties in the distribution of transuranics in the sample or matrix composition changes. A single switch allows changeover between the coincidence and spatial counting modes, and the total neutron flux is measured simultaneously with either. Computer integration capability is provided for system operation and control, data acquisition and reduction, and quality assurance checks. Complete details of the electronic components and circuits are given.

Tables of neutron emission rates from both spontaneous fission and $(\alpha, n)$ reactions on oxygen are given for all contributing isotopes expected 
to be present in spent FFTF fuel. Tables of neutron yields from isotopic compositions predicted for various exposures and cooling times are also given. Methods of data reduction and sources, magnitude, and control of errors are discussed. Backgrounds and efficiencies have been measured and are reported. A section describing step-by-step operational procedures is included. Guidelines and procedures for quality control and troubleshooting are also given.

The total uncertainty in determining $88 \mathrm{mg}$ of TRU at the $90 \%$ confidence limit in a 1000 second counting period from $1 \frac{1}{2}$-year old spent fuel exposed to 60,000 MWD/MTHM is $+28.93 \%$ (25.46 mg) or $-17.04 \%$ (15.00 mg) based on the total neutron flux count. Using the 2-coincidence measurement method and a 10,000 second counting period, the total uncertainty is $\pm 17.33 \%$. The detection limit for 60,000 MWD/MTHM fuel cooled for $1 \frac{1}{2}$ years is $1.7 \mathrm{mg}$ of TRU in a 10,000 second count period at the $90 \%$ confidence level.

\section{INTRODUCTION}

The measurement of the transuranic content of nuclear waste products or process residue has become increasingly important for the recovery of fissionable material from spent fuel elements, for the determination of the transuranic content in high gamma activity waste material scheduled for disposal, and for the satisfaction of accountability requirements.

The measurement of the transuranic content in nuclear waste is complicated by the fact that transuranics include a broad spectrum of radioactive decays without any single feature in common. Only a few emit relatively high energy gamma-rays, and most of these are very low yield. Most decay by alpha particle emission accompanied by the corresponding $x$-rays, but none of these radiations can be measured in the high gamma-ray environments encountered in this application. In fact, the only radiations from transuranics which are unequivocally measurable by nondestructive techniques in wastes from the head end of the Process Facility Modification Project (PFMP) are the neutrons emitted from fission or from $(\alpha, n)$ interactions in light isotopes which may be present. These neutron emissions are commonly categorized passive (those emitted spontaneously by the transuranics) or active (those emitted following interrogation of the sample with a pulsed neutron or photon source). 
Active neutron interrogation techniques measure either the prompt fission neutrons or the beta delayed neutrons from fission products following induced fission. These techniques normally measure only fissile transuranics (235u, 239pu, and 241Pu) and are commonly applied only to contact handleable waste. (1-8) Application of the technique to high gamma activity wastes has been considered( 9 ) but not reduced to practice.

Passive neutron interrogation techniques, on the other hand, have been demonstrated $(8,10-12)$ to be capable of measuring all transuranics except $235 \mathrm{U}$ with adequate sensitivity and will work on both contact handleable and high gamma activity wastes. A smaller scale hulls monitor $(10,11)$ was designed and built for assaying the residual TRU content of chopped leached hulls from reprocessed commercial nuclear power reactor spent fuel. These cladding hulls were generated during the Commercial Nuclear Waste Vitrification Project demonstration using spent light water reactor fuel from the Point Beach power station. Another embodiment of similar technology is the N-Reactor fuel segregation instrumentation(12) which is used to measure the plutonium isotopic composition in spent fuel elements. This operational system can determine the isotopic composition of $240 \mathrm{Pu}$ to the nearest $0.1 \%$ by weight in spent fuel elements.

The general approach utilizes $10_{\mathrm{BF}_{3}}$ or $3 \mathrm{He}$ filled neutron sensitive proportional counters to record the total spontaneous neutron emission rate of the package and compare that to known standards for quantitative determination of the transuranic concentrations in the unknown.

Since the passive techniques are sensitive to a wider spectrum of transuranic isotopes than the active techniques, and since they are substantially less complex and less expensive than the active systems, and since they are proven techniques for measuring small quantities of TRU in high gama activity packages, the passive neutron TRU assay technology was chosen for development of a PFMP prototype hulls monitor.

\section{OBJECT IVES}

The main objective of this program was to design and fabricate a prototype monitor for the measurement of residual TRU in spent cladding hulls from irradiated Fast Flux Text Facility (FFTF) fuel elements. These mea- 
surements are anticipated to be made directly on the dissolver basket which will be approximately $11 \mathrm{~cm}$ in diameter by 2 meters high; however, design considerations included the capability to measure other (larger) dissolver baskets or standard $208 \ell$ drums of solid waste. Following successful testing this unit would be installed in PFM.

Other design requirements included sufficient sensitivity to measure as little as $88 \mathrm{mg}$ of TRU in a drum or basket having a gamma dose rate up to $220,000 \mathrm{R} / \mathrm{hr}$. Overall accuracy had to be better than $20 \mathrm{mg}$ of TRU. Since high throughput was not required, and for practical purposes, the maximum assay time was set at 10,000 seconds.

\section{TECHNICAL APPROACH}

In order to accurately measure the TRU content of a large package such as a dissolver basket or $208 \ell$ drum, it is necessary to detect a statistically significant net neutron signal from the sample and to relate that signal to the composition of the transuranics. The total recorded signal is composed of a background signal from ambient neutrons in the environment, a true signal from neutrons emitted or generated by the transuranics, and noise, or recordable signals from sources other than neutrons. Each of these will be dealt with separately.

NOISE

Noise or false signals can originate from many sources including microphonics, electrical impulses, radio waves, and reactions in the neutron detectors from other particles which generate a detectable signal. Some of these can be adequately eliminated by appropriate electronic circuit designs and electrical line isolators. In this system, the major potential source of noise is from gamma-ray interactions in the neutron detectors which may generate an electrical pulse indistinguishable from a neutron signal. The gas proportional counters used in this technology detect neutrons via the reaction $10_{B}(n, \alpha)^{7} i$ in the ${ }^{10} B_{B} F_{3}$ fill gas. The recoiling alpha particle and $7_{\mathrm{Li}}$ nucleus deposit $2.79 \mathrm{MeV}$ of energy in the counter through ionization of the gas. A high voltage potential applied across the fill gas leads to the commonly understood electron avalanche in the 
counter. The collection of the resulting ions generates an electrical pulse which is amplified, separated from the high voltage, and recorded by generally accepted electronic techniques. Gamma-rays also interact with the fill gas and produce ionization which results in a noise signal. However, the interaction cross section for gamma-rays in the counter gas is much smaller than for the alpha particle, and gamma-rays deposit only a very small fraction of the energy deposited by the neutron reaction products. Consequently, the interaction of gamma-rays in the proportional counter can be discriminated against by setting an energy threshold above the gamma pulse energy but below the neutron pulse energy. At low gamma-ray interaction rates, the use of an electronic discriminator is all that is necessary to prevent gamma-ray induced pulses from entering the counting circuit. However, at very high gamma-ray fluxes, many of the small gamma-ray produced ionization pulses can arrive within the resolving time of the counteramplifier combination and "pile-up" to produce a signal as large as a neutron generated signal. This "pile-up" cannot be eliminated with a pulse height discriminator. The problem of "pile-up" is further magnified in systems using a large array of proportional counters which combines the output signals from many detectors. In this case, "pile-up" pulses will exceed the discriminator threshhold when the combined gamma signal from all counters sums within the resolving time of the electronics. Thus if an array of 100 counters is used, gamma noise will produce erroneous signals at gamma fluxes on the order of $1 \%$ of that required to produce false signals from a single counter. Since this TRU monitor design incorporates a large array of neutron counters, each individual counter was coupled to a Pacific Northwest Laboratory (PNL) designed preamplifier/discriminator which effectively decouples individual tube gamma noise "pile-up" signals from the array. That is, each counter has its own energy threshhold discriminator which requires any "pile-up" pulses to come from gamma-ray interactions all within the same counter. In this manner, the large array of counters can operate within a gamma-ray field of the same intensity as a single counter without generating erroneous garma caused "pile-up" signals. Details of the electronic preamplifier/discriminators will be given in the section on system description.

The use of energy discrimination alone, however, is not adequate to eliminate "pile-up" in the gamma-ray fields anticipated to be present in 
the hulls basket or waste drums from the PFMP. Consequently, a bulk lead shield has been incorporated between the sample and the counter array. A single $10 \mathrm{BF}_{3}$ neutron counter (or in this case, due to the preamplifier/ discriminators, the entire array of counters) can operate in a gamma field of up to $25 \mathrm{R} / \mathrm{hr}$ without showing a significant increase in count rate due to gamma "pile-up".(13) Hence, the lead shield had to reduce the anticipated maximum gamma field from the basket or drum $(220,000 \mathrm{R} / \mathrm{hr})$ to below $25 \mathrm{R} / \mathrm{hr}$. Simple calculations ordinarily used to determine gamma-ray dose reductions as a function of shielding (such as ISOSHLD) are not entirely applicable in the case of gas filled proportional counters since complex interactions within small finite pathways produce pulses not necessarily correlated with total gamma spectral dose. Consequently, the operational experience of two similarly designed TRU assay systems $(11,12)$ was used to estimate the lead shielding requirements for the PFMP hulls monitor. In one case a lead shield $8.57 \mathrm{~cm}$ thick was sufficient to reduce the gamma flux from spent reactor fuel elements to a level such that no noise was detectable from pileup. The gamma-ray energy spectrum from this fuel is expected to be similar to that from FFTF fuel and was estimated to be $130,000 \mathrm{R} / \mathrm{hr}$. In the second case a lead thickness of $10.2 \mathrm{~cm}$ was sufficient to eliminate gamma "pile-up" pulses from a gamma-spectrum generated in a ${ }^{60}$ Co gamma-ray irradiation facility at an estimated dose of $100,000 \mathrm{R} / \mathrm{hr}$. Based on these two operating parameters, it is felt that the $12.7 \mathrm{~cm}$ thick lead shield designed for the PFMP hulls monitor will be more than adequate to eliminate "pile-up" pulses from the maximum anticipated dose of 220,000 $\mathrm{R} / \mathrm{hr}$.

It is a simple matter to demonstrate that a neutron counter is not responding to gamma radiation by changing the thickness of lead (either adding or removing) between the source and the counter without changing the physical positioning of the source and counter. If the counter is generating "pile-up" pulses from gamma radiation, the count rate will increase or decrease as the gamma flux is increased or decreased. If "pileup" is not present, there will be no significant change in the count rate since the neutron flux is not significantly affected by the presence of the lead absorber. The PFMP hulls monitor has been designed to easily perform this attenuation experiment and to easily increase the thickness of the lead absorber if necessary. 
BACKGROUND

The system background is generated by neutrons from sources other than the sample being measured which interact within the neutron counters. This background signal cannot be eliminated in ordinary circumstances. Major sources of background in the PFMP hulls monitor are expected to be from cosmic ray muon spallation interactions in the lead gamma-ray shield and from proximate spent fuel in other compartments within the facility. The background will, however, remain constant for any given set of conditions, and corrections can be made by simply subtracting it from the total signal. That is, the background signal which is measured without the sample in place is subtracted from the total signal with the sample in place to obtain the net signal from the sample. The effect of the background on accuracy of a measurement will be discussed in a later section on error analys is.

\section{TRUE SIGNAL}

Neutrons from the basket or drum being assayed can originate from three sources: 1) spontaneous fission, 2) $(\alpha, n)$ reactions with 170,180 , or other low atomic number isotopes, and 3) neutron-induced fission or self-multiplication. Experience with kilogram quantities of plutonium has shown very little neutron multiplication from loose $\mathrm{PuO}_{2}$ powder; induced fission seems to contribute to the total signal only in plutonium metal or very large, high-density arrays of plutonium oxide. Consequently, for the milligram to gram quantities of TRU expected in the PFMP wastes, self multiplication is not expected to contribute to the true signal, and all neutrons are expected to come from spontaneous fission and $(\alpha, n)$ interactions on light isotopes, primarily oxygen. The number of neutrons emitted by a spontaneously fissioning isotope can be calculated directly from its known spontaneous fission half-life and the average number of neutrons, $\bar{v}$, emitted per spontaneous fission. Similarly, the number of neutrons emitted via $(\alpha, n)$ interactions on oxygen can be calculated from the alpha decay halflife and the interaction cross section. Most of these $(\alpha, n)$ neutron yields have also been empirically verified. The neutron yields for those isotopes expected to contribute to the signal from spent FFTF fuel are given in 
Table I. Multiplying these neutron yields by the expected or known composition of a mixture of transuranics gives the total neutron yield for that mixture. In the case of FFTF fuel, the expected composition of transuranics can be taken from ORIGIN runs representing the burnup and decay of the processed spent fuel. Table II gives examples of the neutron yields for FFTF fuel at different levels of burnup and decay times. These neutron yields are from all isotopes listed in Table $I$ and have been normalized by both the weight and alpha activity of total TRU and of total plutonium. The total neutron flux, corrected for efficiency, is measured by the hulls monitor, and the total TRU or total plutonium in the basket or drum is determined by dividing the flux by the appropriate neutron yield factor. The uncertainty in this measurement will be governed largely by the uncertainty in the predicted isotopic composition of the fuel residues. It should be remembered that errors in the predicted isotopic ratios from ORIGIN will be diminished substantially as soon as laboratory analyses of the first dissolver batch become available, and that subsequent errors in the residual TRU or plutonium as measured by the hulls monitor due to uncertainties in the assumed isotopic ratios will be reduced to minimal levels. Additional sources of error in the determination of the residual TRU or Pu in the baskets or drums will be discussed in the section on error analysis.

Although the case has just been made for measuring the TRU or plutonium composition of an unknown source by gross neutron counting, it is still necessary to determine the system efficiency in order to obtain the total neutron flux from an unknown source. This is readily accomplished by counting sources of known activity and isotopic composition. The results of these experiments are discussed in a later section on calibrations.

A virtually identical procedure used in another operating system measures the plutonium isotopic composition nondestructively in spent fuel elements. (12) In this case, the ORIGIN code generates the expected isotopic compositions at different burnup levels, and the neutron flux is calculated for each composition in the same manner used to generate Table II. The flux is normalized to the percentage of $240 \mathrm{pu}$ (out of total plutonium) rather than total TRU or total plutonium, and a function is generated which relates the flux to the plutonium isotopic composition for a given fuel element configuration. Therefore, a measurement of the flux yields 
TABLE I. Neutron Yields from Transuranic Metals and 0xides

I sotope

$228 \mathrm{Th}$

230Th

$232 \mathrm{Th}$

$231 \mathrm{~Pa}$

$232 \mathrm{U}$

$233 \mathrm{U}$

$234 \mathrm{U}$

$235 \mathrm{U}$

$236 \mathrm{U}$

$238 \mathrm{U}$

$235 \mathrm{~Np}$

$237 \mathrm{~Np}$

236 pu

237pu

238pu

$239 \mathrm{pu}$

240pu

241Pu

242pu

244pu

240Am

241 Am

$242 m_{A m}$

243Am

$242 \mathrm{Cm}$

${ }^{243} \mathrm{Cm}$

$244 \mathrm{Cm}$

$245 \mathrm{~cm}$

$246 \mathrm{~cm}$

$247 \mathrm{Cm}$
Neutrons Per Gram Per Second

\begin{tabular}{c} 
Spontaneous \\
Fission \\
\hline
\end{tabular}

$(\alpha, n)$

oxide

Total

$\begin{array}{cc}6.15 \times 10^{5} & 6.15 \times 10^{5} \\ 14.6 & 14.6 \\ 8.2 \times 10^{-5} & 8.2 \times 10^{-5} \\ 35.4 & 35.4 \\ 1.61 \times 10^{4} & 1.61 \times 10^{4} \\ 7.23 & 7.23 \\ 4.68 & 4.68 \\ 1.62 \times 10^{-3} & 1.95 \times 10^{-3} \\ 4.85 \times 10^{-2} & 5.43 \times 10^{-2} \\ 2.52 \times 10^{-4} & 4.17 \times 10^{-2} \\ 16.8 & 16.8 \\ 0.529 & 0.529\end{array}$

$3.36 \times 10^{4}$

$3.99 \times 10^{5}$

$4.32 \times 10^{5}$

$3.00 \times 10^{2}$

$3.00 \times 10^{2}$

$2.56 \times 10^{3}$

$1.28 \times 10^{4}$

46.6

$1.54 \times 10^{4}$

46.6

$1.70 \times 10^{2}$

1.86

2.95

$1.36 \times 10^{-2}$

$3.66 \times 10^{2}$

$1.10 \times 10^{3}$

1.86

$1.79 \times 10^{3}$

$2.15 \times 10^{3}$

$-$

1.13

$1.42 \times 10^{2}$

$2.57 \times 10^{3}$

35.0

$1.50 \times 10^{2}$

$2.49 \times 10^{6}$

$3.86 \times 10^{4}$

$6.07 \times 10^{4}$

$1.29 \times 10^{2}$

$2.32 \times 10^{2}$

$6.79 \times 10^{-2}$
$1.80 \times 10^{3}$

$2.15 \times 10^{3}$

$3.66 \times 10^{2}$

$2.57 \times 10^{3}$

$1.77 \times 10^{2}$

$1.51 \times 10^{2}$

$2.27 \times 10^{7}$

$3.86 \times 10^{4}$

$1.11 \times 10^{7}$

$1.29 \times 10^{2}$

$8.13 \times 10^{6}$

$6.79 \times 10^{-2}$ 
TABLE II. Neutron Yields from Spent FFTF Fuel Normalized to TRU and Plutonium Based on ORIGIN-2 Predicted Concentrations of all I sotopes $L$ isted in Table I.

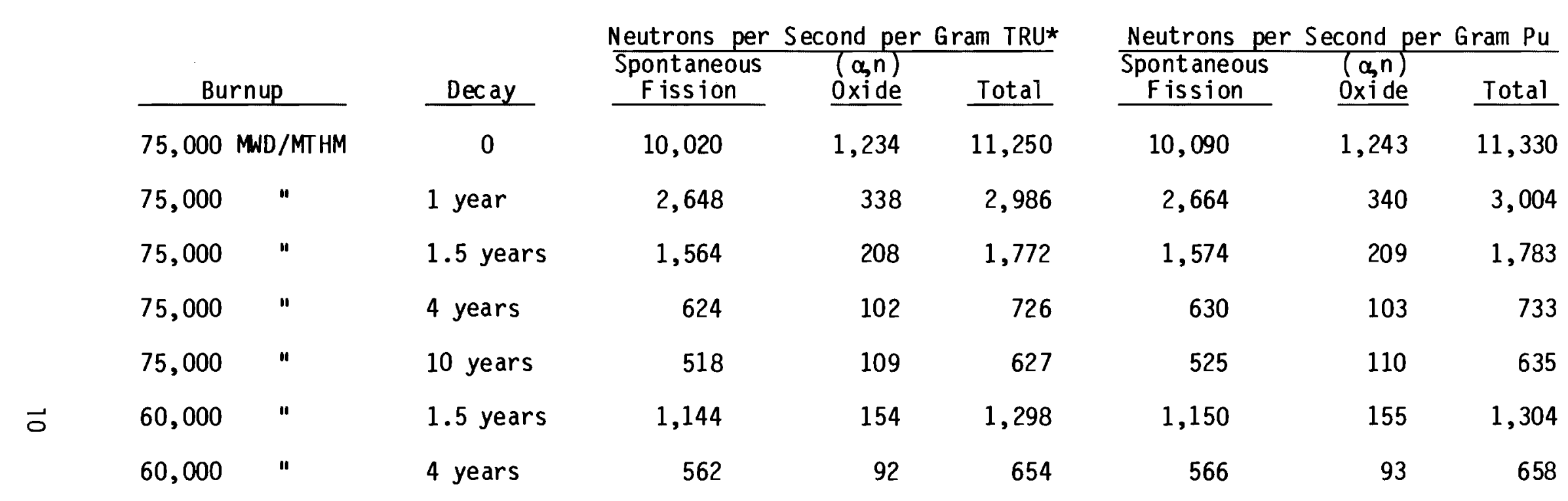

$\star A 11 \mathrm{~Np}, \mathrm{Pu}, \mathrm{Am}$ and $\mathrm{Cm}$ isotopes.

\begin{tabular}{|c|c|c|c|c|c|}
\hline & & & Neutrons pe & econd $p$ & i $\mathrm{TRU}^{+}$ \\
\hline & & & $\begin{array}{c}\text { Spontaneous } \\
\text { Fission }\end{array}$ & $\begin{array}{l}(\alpha, n) \\
\text { Oxide }\end{array}$ & Total \\
\hline 75,000 & MND/MT HM & 1.5 years & 5,648 & 750 & 6,398 \\
\hline 60,000 & $"$ & 1.5 years & 5,568 & 750 & 6,318 \\
\hline 60,000 & $"$ & 4 years & 4,576 & 748 & 5,324 \\
\hline
\end{tabular}

Neutrons per Second per Ci Put \begin{tabular}{lll} 
Spontaneous & $(\alpha, n)$ \\
Fission & oxide & Total \\
\hline
\end{tabular}

$15,088 \quad 2,004 \quad 17,091$

$11,756 \quad 1,583 \quad 13,339$

$\begin{array}{lll}5,757 & 942 \quad 6,699\end{array}$


the plutonium isotopic composition directly. The neutron counter array efficiency for this system was determined by counting a spent fuel element which had been analyzed in the laboratory for isotopic composition.

A more sophisticated and more sensitive method of determining the concentration of transuranics in a sample utilizes coincidence neutron counting of only the spontaneous fission neutrons. This approach overcomes the uncertainty introduced by single $(\alpha, n)$ neutron yields. Although the

efficiency for coincidence neutron counting is much lower than single event counting, there is only a small loss in sensitivity due to lower backgrounds in the coincidence counting mode than in the total neutron counting mode. Since coincidence counting capability could be included in the electronic network at only a very minor increase in cost and space envelope, this feature was incorporated in the design and can be utilized as required in the future.

Another additional feature which required only minor increases in cost and space provides the capability to make spatial measurements of the distribution of transuranics in the event that they are not homogeneously distributed. The spatial feature also provides the capability to determine the moderating capacity of the matrix (i.e., the water content) and is based on an electronic division of the neutron counters into eight groups or "octants." The signal from each of these "octants" can be recorded separately, and the relative values used to obtain spatial distribution or matrix information.

\section{SYSTEM DESCR IPTION}

The monitor, shown in Figure 1, is of modular design to facilitate disassembly for maintenance or relocation as necessary. It consists of an annular internal lead radiation shield, an annular polyethylene neutron moderator, and 96 10 $_{\mathrm{BF}_{3}}$ neutron sensitive proportional counting tubes each $5.08 \mathrm{~cm}$ in diameter and $183 \mathrm{~cm}$ in active length. The tubes are arranged in two concentric rows within the polyethylene moderator. The internal radiation shield, shown in Figure 2, is comprised of 42 layers of specially fabricated lead bricks that have a double offset to prevent gamma-ray "shine" through the cracks. The bottom layer of bricks, however, are fabricated 


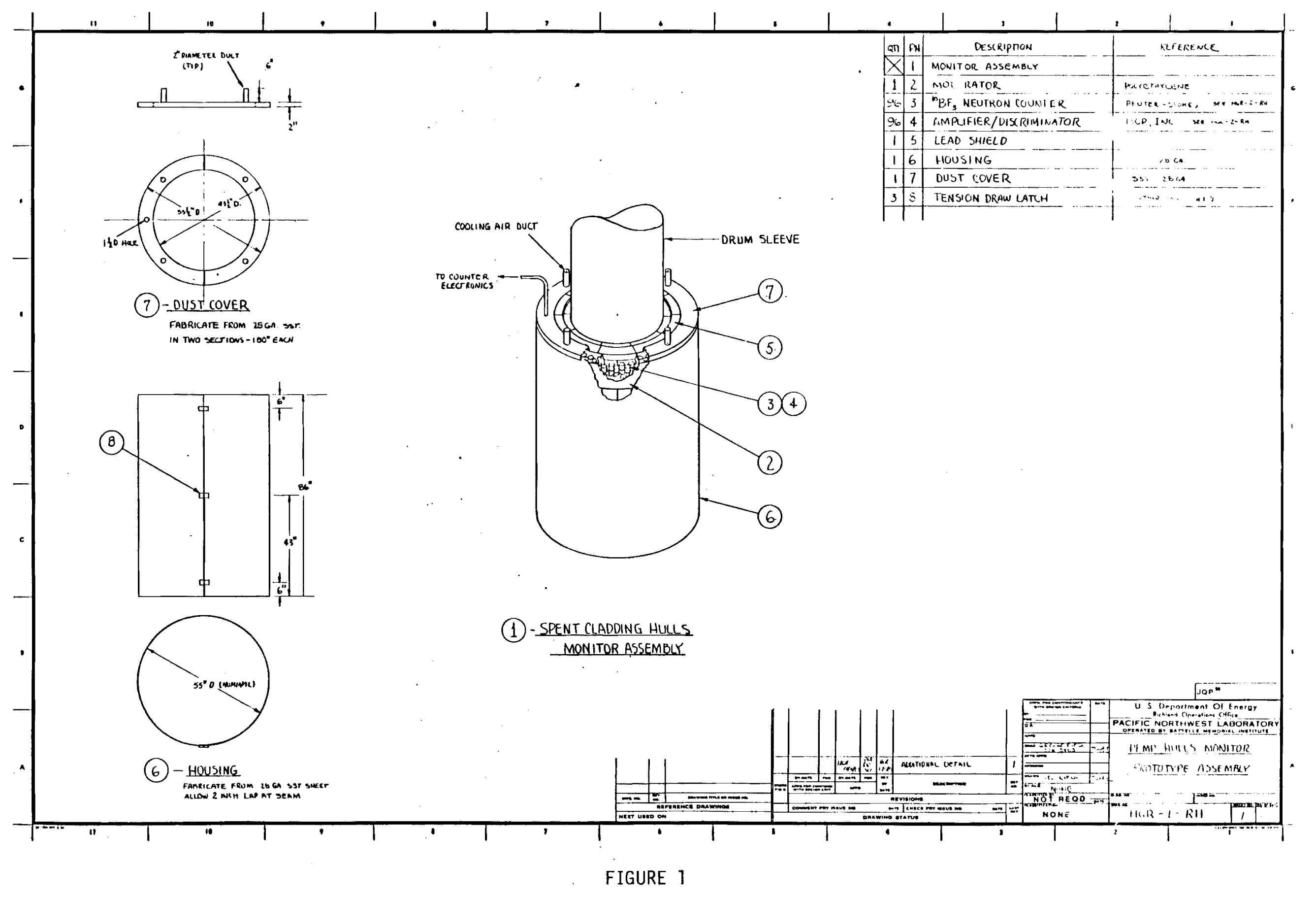


without the bottom offset in order to provide a flat base. All bricks are fabricated with an inside radius of $43 \mathrm{~cm}$ and an outside radius of $55.7 \mathrm{~cm}$ so that the assembled shield has a cylindrical cavity of $86 \mathrm{~cm}$ diameter, large enough to accommodate a 55 gallon drum and its handling grapple.

The fast neutrons emitted from either spontaneous fission or $(\alpha, n)$ interactions pass through the lead shield with only a small loss in flux and enter the moderator/counter assembly. The moderator is composed of polyethylene modules drilled to accept the $1^{10} \mathrm{BF}_{3}$ tubes and is shown in Figure 3. This assembly provides both a support structure for the neutron detectors and moderating capability to slow the neutrons to thermal velocities where they have a high probability of interacting within the ${ }^{10} \mathrm{BF}_{3}$ tube to provide a detectable electronic signal.

The neutron detectors are stainless steel proportional counters filled to $90 \mathrm{~cm} \mathrm{Hg}$ pressure with $96 \%$ enriched $10_{\mathrm{BF}}$ gas and insulated with ceramic to metal seals. All tubes have operating voltage plateaus matched to $\pm 10 \%$ and are internally coated with graphite to prolong the operating life in the presence of gamma radiation. Each tube is coupled to a PNL designed preamplifier/discriminator so that the entire array can operate in the same gamma environment as a single tube. The preamplifier/discriminators are housed in $5.08 \mathrm{~cm}$ diameter by $7.62 \mathrm{~cm}$ high brass cans which provide electrical shielding for the sensitive amplifiers inside. The connectors are taken from the $10_{\mathrm{BF}_{3}}$ tubes, modified, and attached to the brass cans. The preamplifier/discriminators are then attached to the $10 \mathrm{BF}_{3}$ tubes by screwing the original connector body, now attached to the preamp housing, into its original position. The preamp and $10 \mathrm{BF}_{3}$ tube then become virtually an integral assembly. Detailed drawings of these preamplifier/discriminators and their electronic circuitry are shown in Figures 4 and 5.

The ${ }^{10} \mathrm{BF}_{3}$ tubes require a bias voltage of 2700 volts dc which is supplied through an MHV connector attached to the preamplifier/discriminator. In addition, there is a small power jack in the preamplifier/discriminator housing to supply + and $-15 V \mathrm{dc}$. The common ground return for these supplies is through the shield of the high voltage coaxial connector. Each preamplifier/discriminator must be electrically grounded either as described above or through a separate ground wire linking each unit to a common ground in the multiconductor cable used to carry the $15 \mathrm{~V}$ power. It is important 


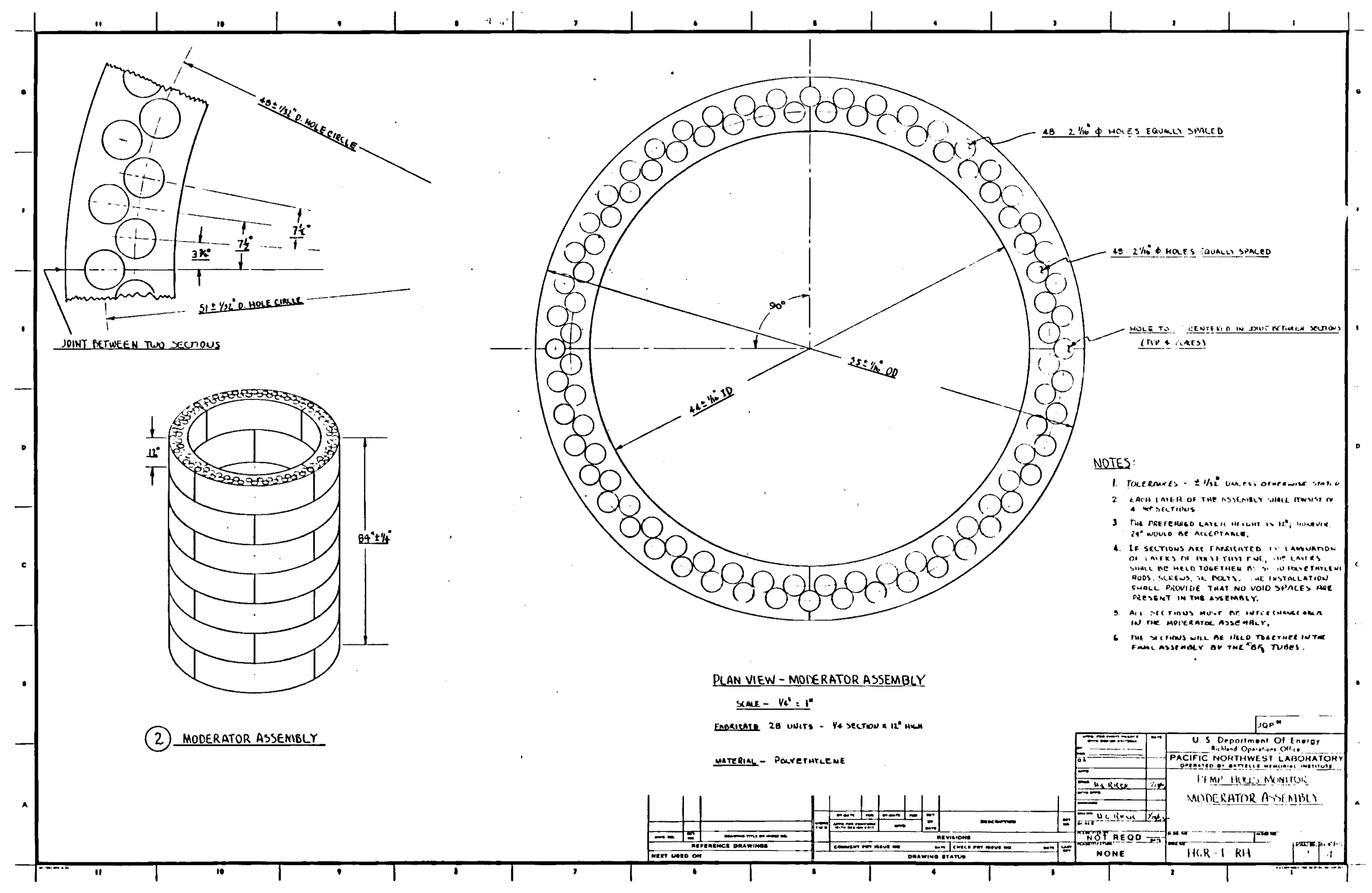

FIGURE 3 


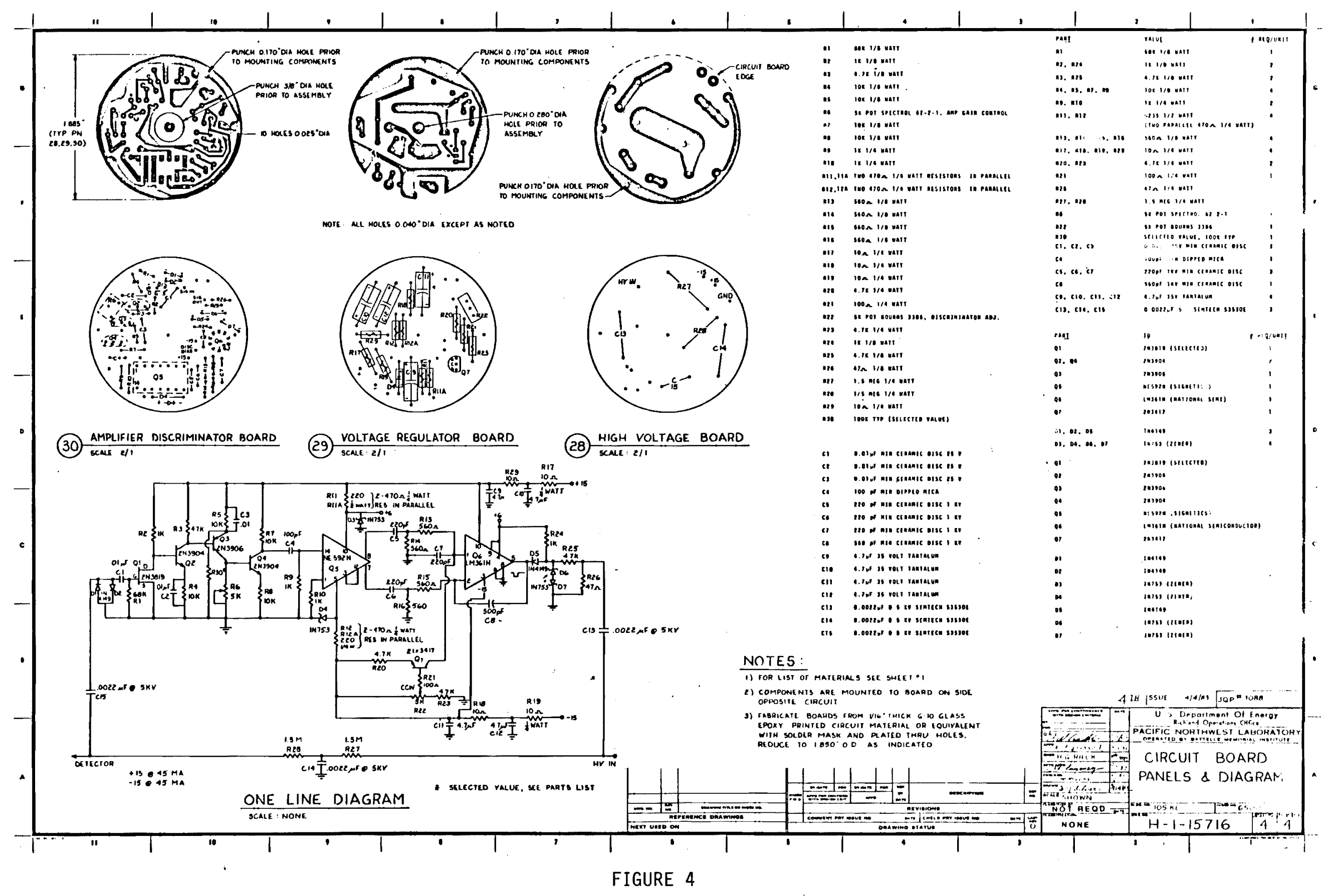




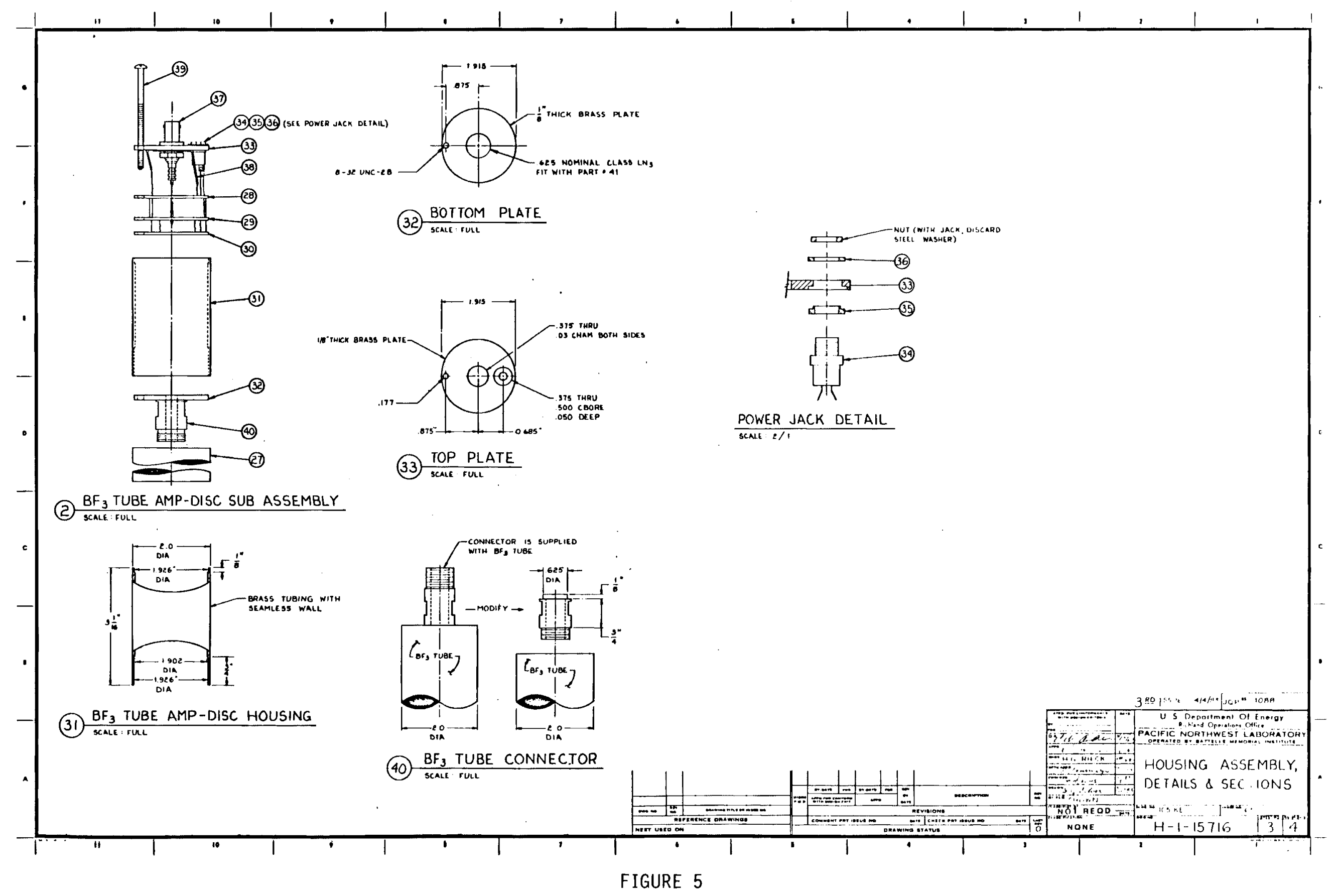


that the conducting stainless stee $10^{10 F_{3}}$ tubes do not become otherwise grounded to building structural components, etc., to avoid ground loops and attendant noise pickup.

The balance of the electronic system for the prototype PFMP Hulls Monitor consists of: (a) eight ORTEC Model 142PC amplifiers, (b) a PNL designed coincidence network, (c) eight ORTEC Model 772 counters, (d) one ORTEC Model 773 timer, (e) one ORTEC Model $4595 \mathrm{kV}$ high voltage bias supply, (f) four ORTEC Model 114 power supplies which feed the 142PC amplifiers, and $(g)$ one Acopian Model VTD15-850 which supplies power to the ninety-six preamplifier/discriminators. The ORTEC scalers, timer, and bias supply are all single width NIM models which plug into a single ORTEC Model $4001 / 4002$ standard size NIM bin and power supply. Data sheets for each of the above units are included in Appendix $A$.

A typical arrangement of some of the components as mounted in a standard 19-inch wide rack is shown in Figure 6 . A power control panel containing a switch for each preamplifier/discriminator allows each unit to be individually switched off. This feature also aids in troubleshooting. The Acopian preamplifier/discriminator power supply is mounted to the rear of this panel which requires $53.3 \mathrm{~cm}$ of vertical space. Four multipin connectors are provided to attach two $13.7 \mathrm{~m} \mathrm{long,} 51$ pair cables which carry the electrical power to the individual preamplifier/discriminators. An additional $76.2 \mathrm{~cm}$ of vertical panel space are required for mounting the eight ORTEC 142PC amplifiers and associated power supplies. Eight $13.7 \mathrm{~m}$ long RG 59/U coaxial cables connect the eight 142PC amplifiers to the eight banks of $1 \mathrm{BF}_{3}$ tubes comprising the eight "octants" of the detector.

The single $5 \mathrm{kV}$ power supply provides the bias voltage for all 96 $10 \mathrm{BF}_{3}$ tubes. This power supply connects to a PNL designed high voltage distribution box which provides eight high voltage output cables (each with a SHV-type connector). Each output cable attaches to the high voltage input of an ORTEC 142PC unit. The preamplifier/discriminators place their output signals on the high voltage cable which also carries the 2700 volt bias voltage to the $1 \mathrm{BF}_{3}$ tubes. Thus, the cable not only provides tube bias but also carries the detector signals back to the counting electronics. This approach reduces the number of coaxial cables needed. The 142PC sepa- 


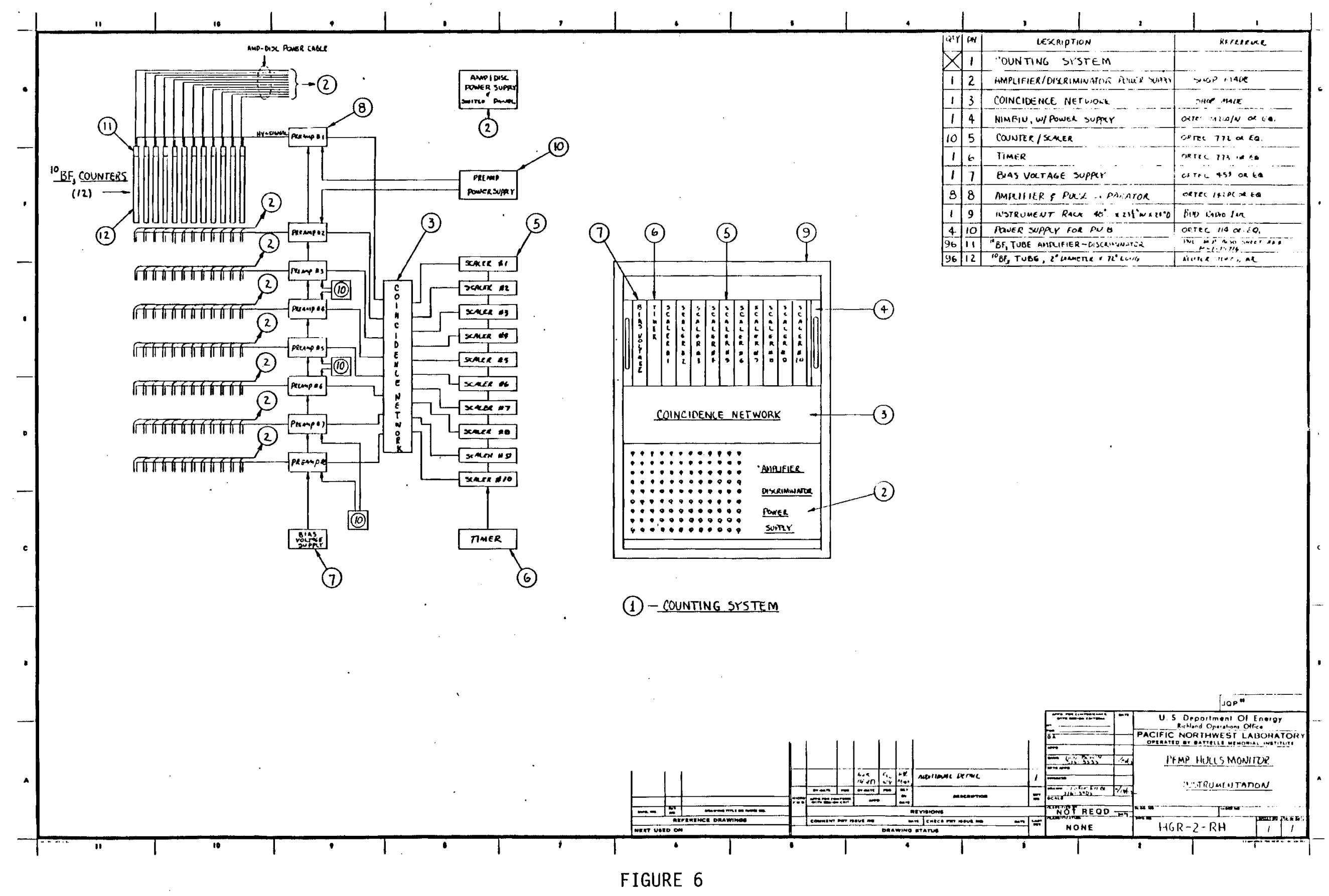


rates the signal from the high voltage, amplifies it, and feeds it to the counting circuitry. This amplifier was chosen for its particular gain characteristics and its ability to provide a full output pulse of $>10$ volts with up to twelve preamplifier/discriminators connected in parallel to its input.

The timer and scalers chosen for the prototype can be daisy chained in ORTEC's "printing loop" and controlled by an ORTEC 779 interface. This unit can serially interrogate each timer and/or scaler and provide the data to an RS232 port for computer access making the accumulation and recording of data by computer possible. Either a main computer or a small dedicated computer, such as an Apple II or IBM PC, could be used. In operation, the computer interrogates the interface and then waits for the data. At the conclusion of the counting period, the interface provides the data after which the computer can restart the whole process.

The data sheet for the ORTEC 779 interface, included in Appendix A, shows it to be a two-wide NIM module, and space has been made available in the NIM bin by limiting the number of scalers to eight.

The coincidence unit occupies $8.9 \mathrm{~cm}$ of vertical panel space and permits measurements to be made in two distinct modes: a coincidence mode for selectively measuring spontaneous fission events and a spatial mode for determining the physical distribution of the transuranics within the sample as well as the moderating capability (hydrogenous content) of the matrix. Both modes provide the total neutron count rate. A block diagram of this circuitry is also shown in Figure 6 . In the coincidence mode, a unique PNL electronic circuit design permits sorting neutron emissions depending on their origin. A special sequencing circuit provides the means to record the number of spontaneous fission multiple coincidence neutrons detected by the counters. Pulses are stored sequentially in up to eight scalers during a preset coincidence time gate. The first pulse to arrive opens an adjustable time window and registers a count in the first scaler. The second pulse to arrive within the window registers in the second scaler. The third pulse registers in the third scaler and so on up to eight pulses within the time window. An instrument calibration procedure determines the optimum time-window. 
In the spatial counting mode, the detector is divided into "octants," eight banks of twelve ${ }^{10} \mathrm{BF}_{3}$ tubes, arranged in an annular array of four inner and four outer quadrants. The neutron count from each octant is recorded in a separate scaler. This arrangement makes it possible to determine the inhomogeneity of the transuranic distribution and, more specifically, the location of hot spots of activity, as well as information on the matrix material. A detailed discussion of the information obtainable in this mode has been given elsewhere. (11)

The preamplifier/discriminators mounted on each $10 \mathrm{BF}_{3}$ tube can operate in a free air environment where the ambient temperature is less than $27^{\circ} \mathrm{C}$. If it becomes necessary to enclose the assembly in an air restrictive housing, cooling air and a means to distribute it about the preamplifier/discriminators must be included. It is estimated that 20 CFM of cooling air at a temperature of less than $15^{\circ} \mathrm{C}$ will provide adequate cooling. Each unit must dissipate approximately $0.08 \mathrm{BTU} / \mathrm{min}$.

Because the counting circuits used in this equipment are very sensitive to noise spikes, it is imperative that the $A C$ power source be free from noise. A well filtered and isolated source of power, such as those available from Gould or Teledynamics, should be used to eliminate any potential noise as may be placed on the power lines by SCR regulators, heavy current relay contact closures, welding machines, etc. Current loops must be avoided.

The total power requirements of the prototype electronics is $125 \mathrm{~V}$ at 3 amps.

\section{CALIBRATIONS}

The system has been calibrated with and without the lead gamma-ray shield in place using point sources of $244 \mathrm{Cm}$ oxide and mixed plutonium/americium oxide and a 208 \& drum standard containing ${ }^{244} \mathrm{Cm}$ distributed in a water matrix. The system backgrounds and efficiencies for both the total neutron count rate and the 2-coincidence only count rate are given in Table III. These measured efficiencies and the general effects of metal matrices reported in reference 11 were used to estimate the efficiencies expected for counting a dissolver basket or a 208 \& drum filled with chopped leached hulls after installation in the PFMP. The actual efficiences for drums or 
baskets in the PFMP will have to be determined experimentally by fabricating and counting calibration standards which contain known amounts of appropriate isotopes after the final design is completed. Large differences in the estimated and experimental values are not anticipated.

Several interesting observations can be made from the data in Table III. First, there is excellent agreement between the measured efficiency using the curium source and that obtained using a mixed plutonium/americium source. This not only lends credence to the values themselves, but supports the accuracy of the neutron yields as listed in Table I. Next, the addition of the lead gamma-ray shield has a negligible effect on the total system efficiency. This observation has also been made on previous occasions $(11,12)$. Third, the presence of large quantities of hydrogenous material (a $208 \ell$ drum filled with water) substantially affects the neutron flux. This phenomenon is expected and was reported earlier(11). The large attenuation of the neutron flux and softening of the neutron energy spectrum by hydrogenous material in the sample matrix can be used to measure the moisture content of the sample by use of the spatial mode feature designed into the data acquisition system. For example, the ratio of counts in the inner ring of ${ }^{10} \mathrm{BF}_{3}$ tubes to those in the outer ring is 1.564 for a ${ }^{244} \mathrm{CmO}_{2}$ source within the counting cavity (the inner ring is geometrically more efficient). When the same source is put in a 19 \& bucket filled with water, the ratio of counts in the inner to outer ring increases to 1.964. This is due to a larger fraction of the neutrons being thermalized before reaching the counting annulus and having a higher probability of interaction within the first row of counter tubes. Finally, the large increase in system background caused by the addition of the lead gamma-ray shield corresponds with previous observations(11). This phenomenon is due to cosmic ray muon spallation reactions in the lead shield.

Both the measured total neutron flux and the 2-coincidence neutron flux can be used to determine the TRU or plutonium content of the sample. In fact, both values can be measured simultaneously and provide independent measures of the source term. The total neutron flux results from both spontaneous fission and $(\alpha, n)$ interactions on oxygen, while the 2-coincidence events are engendered exclusively by spontaneous fission (after correcting for random coincidence events, of course). Those neutrons generated 
by $(a, n)$ interactions on oxygen should contribute in the range of 11-14\% of the total neutron flux from FFTF fuel residues when present as the oxide (see Table II). However, if the TRU to be measured is not present as the oxide or is sufficiently dispersed to give an incomplete yield of $(a, n)$ neutrons, the measured flux will be lower than expected and will yield a calculated source term lower than that actually present in the sample if the determination is based on the total neutron yield from an oxide source. The use of the 2-coincidence neutron count rate circumvents this potential source of error by responding only to the spontaneous fission neutrons. In fact, by determining the source term based on both the total neutron count rate and the spontaneous fission neutron count rate simultaneously, the $(\alpha, n)$ yield can be accurately measured, and the effective fraction of TRU present as the oxide can be determined. This could be very useful in establishing whether the TRU in the sample is present as undissolved fuel or as finely divided powder, for example.

The electronic support system includes the capability to vary the coincidence time gate, as described earlier, from 3-13,000 $\mu \mathrm{sec}$, and the 2-coincidence efficiency reported in Table III was obtained at a coincidence window width of $210 \mu \mathrm{sec}$, the experimentally determined opt imum time for maximizing the signal-to-noise ratio.

Tables of all the calibration data appear in Appendix B.

Since the coincidence efficiency is roughly a function of the square of the total efficiency, it is necessary to maximize the total efficiency (and hence the number of neutron counters) in order to prevent the signal to noise ratio diminishing to the point that the 2-coincidence data will no longer yield statistically significant results. Similarly, the "octant" spatial counting capability requires the use of eight scalers in order to provide information on source distribution or moisture content of the matrix. Since reducing either the number of scalers or the number of neutron counters would result in no savings in the space envelope and only minor savings in cost, such reductions are not recommended.

After installation in the PFMP it will be necessary to have a calibration source available for quality control checks to insure that all parts of the system continue to function properly. Any sealed neutron emitting transuranic source can be used for this purpose. 


\section{DATA REDUCTION}

The TRU or plutonium content of a sample can be absolutely determined from the measured total neutron count by dividing the count rate by the total system efficiency to get the total neutron flux emitted by the sample and then dividing this flux by the appropriate neutron yield factor from Table II. Similarly, the measured 2-coincidence count rate can be divided by that efficiency factor to yield the spontaneous fission neutron count rate. This value can then be divided by the appropriate spontaneous fission neutron yield from Table II to also yield the TRU or plutonium content of the sample. Any disparity between these two values would probably indicate an incomplete conversion of $(\alpha, n)$ yields from the oxide. Ordinarily, calibration factors are obtained using standards containing known concentrations of transuranic isotopes, and the total number of counts obtained during a sample assay are multiplied by the appropriate calibration factor to yield the TRU or Pu content directly.

In actual practice, the neutron yield functions given in Table II would be generated into a family of curves as a function of burnup and decay times. These curves would be described by mathematical algorithms such that the yield could be obtained for any given burnup and decay time. This entire data reduction sequence can be readily accomplished with a desktop calculator or within a small computer which could also be used to control the interrogation sequence and the data acquisition function.

The total uncertainty of any single determination is the geometrical sum of all components of potential error propagated normally. Sources of error associated with this measurement technique are listed below along with their approximate magnitude.

1) The uncertainty in the activity levels of the calibration standards: nominally $\pm 2 \%$ National Bureau of Standards referenceable sources are used.

2) System efficiency: $\leq \pm 2 \%$ since the same isotopes are used to calibrate the system as are being measured by it.

3) Nuclear decay scheme data, such as half-lives, average spontaneous fission neutron yields, $(\alpha, n)$ neutron yields, etc.: $\leq \pm 2 \%$ 
since the same isotopes are used to calibrate the system as are being measured.

4) Counting statistics: variable but controllable by choosing the length of the count and, hence, the total number of events observed.

5) Uncertainty in burnup or age and, hence, isotopic composition of the source: completely dependent on the magnitude of error in predicting burnup or knowing the age, as well as choice of normalization factor, i.e. weight or activity of the TRU or Pu; for example, from Table II, an error in the estimated burnup from 60,000 to 75,000 MWD/MTHM (25\%) would result in an uncertainty in the activity of TRU of only $\pm 1 \%$ but an uncertainty of $\pm 37 \%$ in the weight of TRU.

6) $(\alpha n)$ component of the neutron yield: $\leq 14 \%$ depending on the conversion efficiency. This uncertainty can be eliminated by coincidence counting.

7) Uncertainty in the ORIGIN code predictions of the isotopic composition: $\leq \pm 30 \%$ which will be reduced to the order of $\pm 5 \%$ after the code can be verified against the laboratory analysis of spent fuel.

Errors introduced by counting statistics are governed by the standard mathematical principles of Poisson distributions. One standard deviation, corresponding to a $68.27 \%$ confidence limit, in the number of events observed in a given counting period is equal to the square root of the number of events. In order to assure that any particular number of events observed above background are real, it is necessary to demonstrate that they cannot belong to a randomly high background reading or a randomly low sample measurement at any chosen level of significance. That is, the net number of counts must exceed the statistical uncertainty of the observation. The following example will demonstrate the statistical error determination for a reference measurement using the background and efficiency of the PFMP hulls monitor measuring $88 \mathrm{mg}$ of TRU from 4-year old 75,000 MWD/MTHM FFTF fuel in a 10,000 second count period having also measured the background for a 10,000 second period. The confidence limit will be chosen at $90 \%$ ( 1.645 standard deviations). 
Total number of background events $=$ $(182.1 \mathrm{c} / \mathrm{s})\left(10^{4} \mathrm{~s}\right)=1.821 \cdot 10^{6}$

Uncertainty in number of background events $=$ $1.645 \sqrt{1.821 \cdot 106}=2220$

Number of counts from TRU $=$

$(726 \mathrm{n} / \mathrm{s} / \mathrm{g})(0.088 \mathrm{~g})(20.11 \%$ efficiency $)(104 \mathrm{~s})=1.285 \cdot 105$

Total number of counts during measurement $=$

$\left(1.821 \cdot 10^{6}\right.$ from background $)+\left(1.285 \cdot 10^{5}\right.$ from TRU $)=1.949 \cdot 10^{6}$

Uncertainty in number of events during measurement $=$ $1.645 \sqrt{1.949 \cdot 10^{6}}=2297$

Uncertainty in net events at the $90 \%$ confidence 1 imit $=$ $(2220+2297) \div 1.285 \cdot 10^{5}= \pm 3.515 \%$

This statistical uncertainty can be controlled by counting either the background or the sample or both for different periods of time. A tabulation of the statistical uncertainties involved in measuring various combinations of the reference cases of 8 grams of plutonium or $88 \mathrm{mg}$ of TRU aged for 1 and 4 years is given in Table IV for various counting periods. For comparison, a similar listing is given utilizing the 2-coincidence counting data.

As an example of the total propagation of errors, consider the reference case used to demonstrate the statistical uncertainty. This example was chosen since it is essentially a worst-possible case. Geometrically summing the uncertainties numbered 1-4, the total uncertainty in the measurement itself is:

$$
\left[(2 \%)^{2}+(2 \%)^{2}+(2 \%)^{2}+(3.5)^{2}\right]^{\frac{1}{2}}= \pm 4.9 \% .
$$

Additionally, the ORIGIN code could be off in predicting the isotopes by $30 \%$ in which case:

$$
\left[(4.9 \%)^{2}+(30 \%)^{2}\right]^{\frac{1}{2}}= \pm 30 \% .
$$


TABLE IV. The Statistical Uncertainty at the $90 \%$ Confidence Limit of Measuring $8 \mathrm{Grams}$ of Plutonium or $88 \mathrm{mg}$ of TRU from FFTF Fuel Having Cooled One and Four Years Fol lowing 75,000 MD/MTHM Exposure. Both the Background and the Sample are Counted for the Same Length of Time

Source

Bkgd.

Bkgd. + $8 \mathrm{~g} \mathrm{Pu}$

Bkgd. + $8 \mathrm{~g} \mathrm{Pu}$

$8 \mathrm{~g} \mathrm{Pu}$

Bkgd. $+88 \mathrm{mg}$ TRU

$88 \mathrm{mg}$ TRU

Bkgd . + $88 \mathrm{mg}$ TRU

$88 \mathrm{mg}$ TRU

Counts from Total Neutron F lux

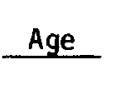

$1.821 \times 10^{4} \pm 222$

$1.821 \times 10^{5} \pm 702$

$5.016 \times 10^{5} \pm 1165$

$5.016 \times 10^{6} \pm 3684$

$4.834 \times 10^{7} \pm 13,870(0.0296)$

1-year

$4.834 \times 10^{5} \pm 1867(0.39 \%)$

$1.362 \times 10^{5} \pm 607$

$1.362 \times 10^{6} \pm 1920$

$1.362 \times 10^{7} \pm 6071$

4-years

$1.18 \times 10^{5} \pm 829(0.70 \%)$

$1.18 \times 10^{6} \pm 2622(0.22 \%)$

$2.349 \times 10^{5} \pm 797$

$2.349 \times 10^{6} \pm 2521$

1-year $5286 \pm 474(4.2 \%)$

$1.949 \times 10^{4} \pm 230$

4 -years $1285 \pm 452(35 \%)$
$5.286 \times 10^{4} \pm 1499(2.8 \%)$

$1.949 \times 10^{5} \pm 726$

$1.285 \times 10^{4} \pm 1428(11 \%)$
$1.821 \times 10^{6} \pm 2220$

$5.016 \times 10^{7}+11,651$

$1.18 \times 10^{7} \pm 8291(0.070 \%)$

$5.286 \times 10^{5} \pm 4741$ (0.90\%)

Counts from

Spont aneous $F$ ission

Neutron Flux

$10,000 \mathrm{Sec}$. Count

\section{$2.635 \times 10^{5} \pm 844$}

$5.589 \times 10^{6} \leq 3889$

$4.192 \times 10^{6} \pm 4733(0.089 \%)$

$1.523 \times 10^{6} \pm 2030$

$1.259 \times 10^{6} \pm 2874(0.23 \%)$

$3.217 \times 10^{5} \pm 933$

$5.823 \times 10^{4} \pm 1777(3.1 \%)$

$1.949 \times 10^{6} \pm 2297$

$2.772 \times 10^{5} \pm 866$

$1.285 \times 10^{5} \pm 4516(3.5 \%)$ 
However, this source of error should be reduced to on the order of $\pm 5 \%$ following verification of ORIGIN predictions with laboratory analyses of spent fuel. The major source of error from uncertainties in predicting isotopic composition should then be due to uncertainties in the burnup or age of the spent fuel. If the magnitude of this error is given by $x \times \%$ then the total uncertainty is given by:

$$
\left[(4.9 \%)^{2}+(x \times \%)^{2}\right]^{\frac{1}{2}} .
$$

Finally, the $(\alpha, n)$ yield could be nonexistent while the TRU or Pu concentration is being determined based on the total flux data. This is a one directional error resulting in a negative bias by as much as $14 \%$. That is, the true value would be uncertain by $+14 \%$ and $-0 \%$. Hence, in the worst case, the results of a determination would be uncertain by:

$$
\left[(4.9 \%)^{2}+(x \times \%)^{2}\right]^{\frac{1}{2}}+14 \%
$$

This $(\alpha, n)$ uncertainty can be eliminated by using the 2-coincidence counting data instead of the total counting data. In this case, the statistical uncertainty is changed and the $(\alpha, n)$ uncertainty eliminated so that the worst-possible-case uncertainty is the geometrical sum of the uncertainties numbered 1-5 including the $12 \%$ uncertainty in the 2-coincidence counting statistics:

$$
\left[(2 \%)^{2}+(2 \%)^{2}+(2 \%)^{2}+(12 \%)^{2}+(x \times \%)^{2}\right]^{\frac{1}{2}} .
$$

The total statistical uncertainty associated with coincidence counting must include the uncertainty added by the random coincidence component of the background events. In the worst-possible-case example above, the system background constitutes $95 \%$ of the total signal, and the number of random events due to the $88 \mathrm{mg}$ TRU will be very small and not measureably increase the total statistical uncertainty. If the true signal is much higher (i.e. from $8 \mathrm{~g} \mathrm{Pu}$ ), then the uncertainty added to the background from increased random events will become larger, but the uncertainty in the number of net events will become smaller because of the larger net signal. The net effect 
is such that the $12 \%$ uncertainty used in the example is indeed a worstpossible case.

The components of and the total uncertainty associated with a determination of $88 \mathrm{mg}$ TRU are given in Table $V$ for various counting scenarios.

One other parameter of general interest which can be calculated from the above data is the detection limit of the system. Assuming the same reference scenario and a 10,000 second count, the detection limit for $1 \frac{1}{2}$-year old fuel at the $90 \%$ confidence limit is given by

$$
S=1.645[\sqrt{B}+\sqrt{B+S}]
$$

where the detection limit is defined as that point where the net signal equals the uncertainty. In the above equation, $S$ is the net signal counts and $B$ is the total background counts. Substituting for $B$ and solving for $S, S=0.4442 \mathrm{c} / \mathrm{s}$. Dividing by the efficiency yields a detection limit for the neutron flux of $2.209 \mathrm{n} / \mathrm{s}$ which corresponds to $1.2 \mathrm{mg}$ of TRU. The corresponding detection limit for 4-year old fuel is $3.0 \mathrm{mg}$ of TRU. 
TABLE V. Uncertainty in Measuring $88 \mathrm{mg}$ TRU at the $90 \%$ Confidence Limit

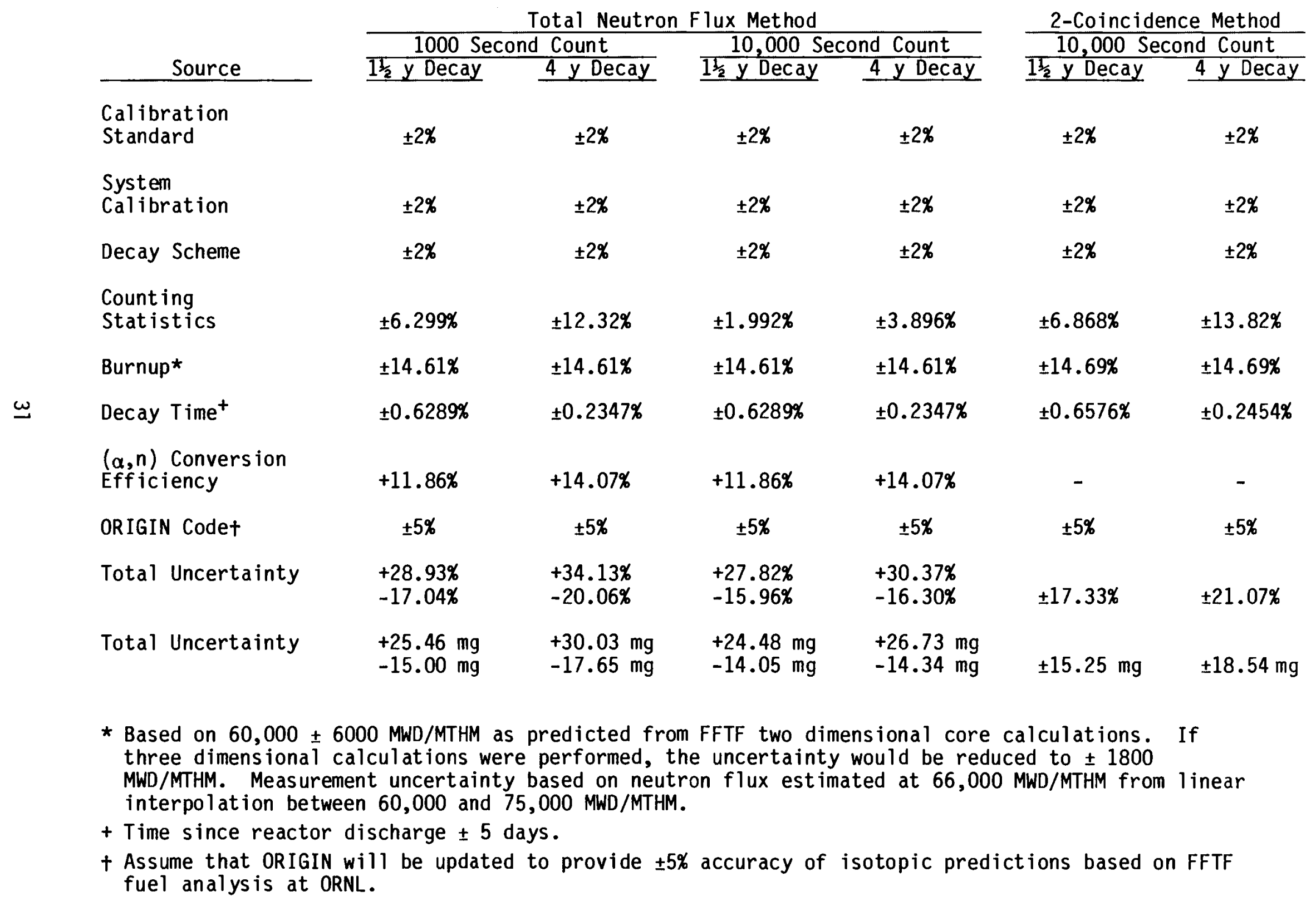




\section{OPERATION}

This section provides operational procedures for using the system to assay baskets of spent fuel cladding (hulls) or barrels of waste for transuranic content. A short description of the system is repeated so that this section can be used as a stand-alone operations manual. Stepwise procedures are given so that an operator can start up the system, make background and calibration measurements, assay baskets of hulls or barrels of waste, and perform diagnostic and troubleshooting operations.

The two major components of the system are the neutron detector assembly and the remotely located instrument rack of associated electronics. The neutron detector assembly consists of a polyethylene annulus which is $55 \mathrm{in.}(140 \mathrm{~cm})$ in outside diameter, $44 \mathrm{in} .(112 \mathrm{~cm})$ in inside diameter, and $84 \mathrm{in}$. $(213 \mathrm{~cm})$ high and which contains two concentric rings of ${ }^{10} \mathrm{BF}_{3}$ neutron detection proportional counting tubes. Each ring consists of 48 tubes equally spaced within the moderator. The inner row is on a 48 in. $(114 \mathrm{~cm})$ diameter hole circle, and the outer row is on a 51 in. $(129.5 \mathrm{~cm})$ diameter hole circle. This spacing provides a minimum thickness of 1 in. $(2.5 \mathrm{~cm})$ of polyethylene between the tubes and the sample to assure optimum moderation of the fast neutrons and maximum sensitivity of the $10_{\mathrm{BF}}$ detectors.

A lead annulus, 43-3/4 in. (111 cm) outside diameter, 33-3/4 in. $(85.7 \mathrm{~cm})$ inside diameter, and $84 \mathrm{in.}(213 \mathrm{~cm})$ high, shields the ${ }^{10} 0_{\mathrm{BF}_{3}}$ tubes from the intense gamma flux emitted by the hulls or wastes. This shield is assembled around a $33 \mathrm{in.}(83.8 \mathrm{~cm})$ diameter drum sleeve using single lead bricks, 2 in. $(5.1 \mathrm{~cm})$ thick, each having offsets on top, bottom, and ends to provide high integrity shielding. Each layer is composed of 10 bricks which are machined on all surfaces to provide a nearly perfect fit. Each brick weighs 50 pounds $(22.7 \mathrm{~kg})$, and the total shield weight is 21,000 pounds $(9545 \mathrm{~kg})$.

The electronics instrument rack contains the necessary circuitry for obtaining and recording signals from neutron interactions within the $10_{\mathrm{BF}}$ tubes. From top to bottom the rack contains the coincidence network chassis, a NIM bin, a preamplifier/discriminator power supply switch panel, and several blank panels which serve as mounting surfaces for eight preamplifiers 
and four amplifier power supplies. The NIM bin contains a bias voltage supply, eight counters, and a counter timer. A block diagram of the circuitry is shown in Figure 7 .

The $961_{10} \mathrm{BF}_{3}$ tubes are connected in eight banks of 12 tubes each. A common high voltage/signal line connects each bank of 12 tubes to an ORTEC Model 142PC charge sensitive preamplifier. This unit separates the signal from the high voltage and amplifies the signal to $>10$ volts. The ORTEC Model 114 preamp power supplies each support two preamplifiers. The common high voltage bias supply provides the 2700 volts required for operation of all 96 detectors. The output signals from the preamplifiers go to the input connectors of the Battelle coincidence chassis. This component provides for data to be accumulated in either a spatial or coincidence mode. In the coincidence mode, the number of coincidence events occurring within a preset time window are stored sequentially in the scalers from left to right. In the spatial mode, each scaler stores the signals from a bank of $12{ }^{10} \mathrm{BF}_{3}$ tubes. A digital timer allows counts to be acquired for a preset length of time. $A \pm 15 \mathrm{~V}$ dc power supply and associated switch panel provides the power to operate a preamplifier/discriminator mounted on each $10_{\mathrm{BF}_{3}}$ tube. Each of these units is supplied power through a separate switch so that it can be turned off individually. The switches are arranged in eight rows of twelve. Each row controls power to one quadrant of the inner or outer ring of $10_{\mathrm{BF}_{3}}$ tubes (an "octant"). Adjacent rows control "octants" in corresponding inner and outer rings. The columns of switches are labeled \#1 through \#12 from left to right. The rows of switches are labeled "WEST INNER", "WEST OUTER", "NORTH INNER", "NORTH OUTER", "EAST INNER", "EAST OUTER", "SOUTH INNER", and "SOUTH OUTER" from top to bottom. The corresponding scalers (when used in the spatial mode) are labeled from left to right. The moderator should be oriented to correspond with the compass points to facilitate diagnostic and troubleshooting steps as well as spatial data acquisition. Tubes in each octant are numbered clockwise from the top starting with \#1 in the first hole and ending with \#12 in the last hole. The seam between sections of moderator intersects a hole in the outer ring, and this hole is designated \#1 with \#12 being the last full hole. For example, NORTH INNER \#6 would be the sixth tube in the inner ring of the north quadrant. This arrangement provides a convenient method for quickly checking proper operation of all 10BF 3 tubes. All \#1 tubes, for example, 


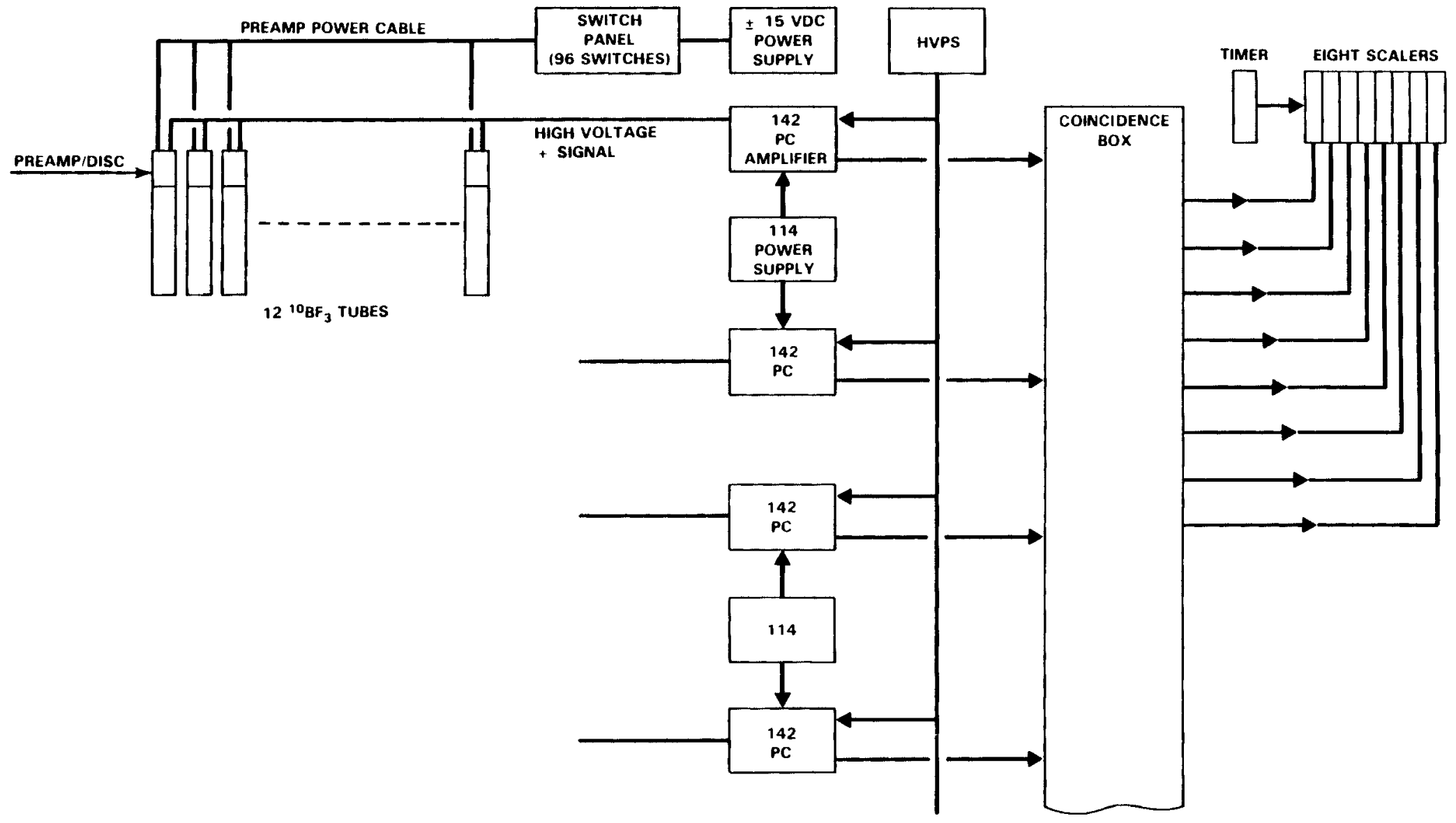

FIGURE 7 
can be checked by setting the switches in column \#1 to "on" with all other switches set to "off". The counts accumulated in each scaler will represent the response of the $\# 11_{10} \mathrm{BF}_{3}$ tube in a specific ring and quadrant.

During operation of the system in the manual mode, operator interaction with the counter-timer and subsequent tabulation of the scaler readouts will be required. If the system is interfaced to a computer, operator interaction with the computer will be required.

\section{SYSTEM START-UP}

This procedure will insure an orderly start-up of the detector and electronic systems. The procedure commences with the instrument rack power cable unplugged.

1. Check to see that the following power switches are turned to the "OFF" position:

A. Coincidence Network - front panel, left side

B. NIM bin - front panel, right side

C. $10 \mathrm{BF}_{3}$ Tube Power Supply - front panel, 96 switches on the top part of the panel

D. Preamplifier Power Supply (ORTEC \#114) - inside on back of lower front panel, four units

E. Bias Supply (ORTEC \#459) - left side of NIM bin

2. Adjust the Bias Supply (left side of NIM bin) output voltage potentiometer (near center) to 000 .

3. Set the following switches on the 8 scalers (ORTEC \#772) located in the NIM bin:
A. "Master-Norm-Slave" to "Slave"
B. "Count-Stop" switch to "Count"

4. Set the following switches on the Counter Timer (ORTEC \#773) located in the NIM bin:
A. "Master-Norm-Slave" switch to "Master
B. "Timer-Min-Counter" switch to "Timer-0.1 sec"

5. Plug instrument rack power cord into a $115 \mathrm{~V}$ ac conditioned power source. 
6. Set NIM bin power switch - front panel, right side to "On". The "Count" light should be illuminated on all Counters and the CounterTimer should start timing the preset count.

7. Set Preamplifier Power Supply (ORTEC \#114) "On-0ff" switches to "On" -inside lower back of front panel - 4 units. Verify that the four Power Indicator Lights are on.

8. If a cover is installed over the detector system, verify that cooling air has been turned on.

9. Set all switches on the AMP-DISC Power Supply to "On" (up position).

10. Set the Concidence Network power switch to "On". Set the "Coincidence-Spatial" switch to "Spatial".

11. Set the Counter-Timer "Preset $M \times 10^{N}$ " rotary switches to $62(M=6$, $N=2$ ).

12. Press "Reset" on the Counter-Timer. This action will initiate a 60 second (600 tenth second) counting interval for each counter. Verify that the "Count" light is illuminated on each counter.

13. Observe the accumulated counts on each counter and if that number is 1 or less, proceed to Step 14. If the count is greater than 2 , refer to the diagnostics procedures for instructions.

14. Set the Bias Supply power switch to "On".

15. Adjust the "Output Voltage" potentiometer on the Bias Supply front panel to 2700 . Lock the potentiometer.

16. Wait approximately 30 seconds.

17. Press "Reset" on the Counter-Timer. All scalers should be accumulating background counts. If certain scalers are not registering counts or if the accumulated counts in each scaler after the 60 second counting interval are not similar, refer to the diagnostic procedures for instructions.

This completes the start-up procedures for the system.

\section{BACKGROUND MEASUREMENT}

This procedure is used to determine the background neutron counting rates for the detector system and to identify any malfunctions. (The count- 
ing interval used in the procedure will depend on the type of sample being assayed and the confidence level requirements. A 1000 second counting interval is used to demonstrate the procedural requirements for making a background measurement.)

1. Remove all sample materials from the drum sleeve. Install all required shielding plugs in the cell floors.

2. Set the "Spatial-Coincidence" switch on the Coincidence Network to "Spatial".

3. Set "Preset $M \times 10^{N "}$ on the Counter-Timer to 14 (1000 seconds).

4 At the end of the counting interval, read and record the accumulated counts in each counter. Add the accumulated counts and record the total. This value is designated the Spatial Mode Background. Record the date and time of measurement, and the length of count. Record the location of any $10 \mathrm{BF}_{3}$ tubes that were off during the measurement. A sample log sheet is shown in Figure 8 .

5. Compare the observed counts with previous values. If they are within the $90 \%$ confidence limit ( \pm 1.645 standard deviations), the background measurement is acceptable. If the observed counts are outside this limit, repeat the background measurement. If the accumulated count in each scaler is low or high, suspect that a source of neutrons has been removed or brought to the vicinity of the detector system. If the count in only one or two scalers is high or low, suspect a system malfunction and refer to the diagnostic procedures for instructions. The counts in each scaler should be approximately 23,000.

6. Set the "Spatial-Coincidence" switch on the Coincidence Network to "Coincidence".

7. Adjust the Gate Width potentiometer on the Coincidence Network to 200 and set the lock. Set the "X1-X10-X100" switch to "X10".

8. Press "Reset" on the Counter-Timer to initiate a new 1000 second background measurement.

9. At the end of the counting interval, read and record the counts in eight scalers. Record the location of any $10_{\mathrm{BF}_{3}}$ tubes that were off during the measurement in the remarks column. Sum the 


\section{BACKGROUND DATA}

SPATIAL MODE

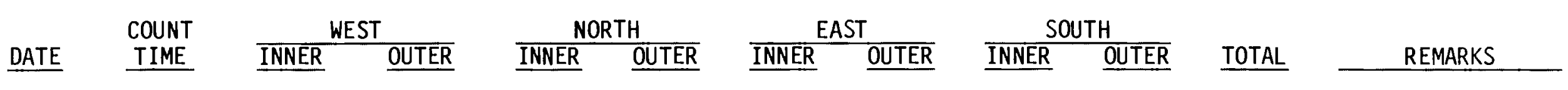


counts and record the total. These values are designated the Coincidence Mode Background. A sample log sheet is shown in Figure 9. The coincidence sum should agree with the spatial sum within the $90 \%$ confidence limit. The sum should be approximately 182,000 . If the sum agrees with the previous average within the 90\% confidence limit, the background measurement is acceptable. If the value is consistently low or high, refer to the diagnostic procedures for instructions.

This completes the procedure for making a background measurement.

\section{CALIBRATION MEASUREMENT}

This procedure is used to check the counting efficiency of the detector system. Several standards may be used depending on the type of sample being assayed. The calibration standard should be approximately the same geometry as the sample being measured, i.e. the same size and composition, and should be counted in the same location in the drum sleeve. (The counting interval used in the procedure will depend on the type of sample being assayed and the confidence level requirements. A 1000 second counting interval is used to demonstrate the procedural requirements for making a calibration measurement.)

1. After a background measurement has been made, position the calibration standard in the drum sleeve.

2. Set the "Preset $M \times 10^{N "}$ on the Counter-Timer to $14 \quad(M=1, N=4)$.

3. Set the "Spatial-Coincidence" switch on the Coincidence Network to "Spatial".

4. Press "Reset" on the Counter-Timer.

5. At the end of the counting interval, read and record the counts which have been accumulated in each scaler (eight starting from the left). Record the location of any $10 \mathrm{BF}_{3}$ tubes that were of $f$ during the measurement in the remarks column. Record the date and time of the measurement, length of count, and the calibration standard designation. A sample log sheet is shown in Figure 10.

6. Sum and record the accumulated counts. Compare the total counts with the previous average for that calibration standard. If it 


\section{CALIBRATION DATA}

SPATIAL MODE

COUNT CALIBRATION

DATE TIME STANDARD

WEST

OUTER

SOUTH

OUTER TOTAL REMARKS 
falls within the $90 \%$ confidence 1 imit, the measurement is acceptable. If it is outside this limit, verify proper location and designation of the calibration standard, and make a recount. If it remains outside the $90 \%$ confidence limit, refer to the Diagnostic Procedures and Troubleshooting Guide.

7. Calculate and record the net count - calibration count total minus background total. Using the weight of Pu or TRU in the standard, calculate and record the efficiency factor - grams of Pu or TRU divided by net counts. This efficiency factor is grams per count and is designated the Spatial Mode Efficiency Factor.

8. Set the "Spatial-Coincidence" switch on the Coincidence Network to "Coincidence".

9. Press "Reset" on the Counter-Timer to initiate a new 1000 second measurement .

10. At the end of the counting interval, read and record the counts which have been accumulated in each scaler. Record the location of any $10 \mathrm{BF}_{3}$ tubes that were off during the measurement in the remarks column. Record the date and time of the measurement, length of count, and the calibration standard designation. A sample log sheet is shown in Figure 11.

11. Sum and record the accumulated counts. Compare the total counts with the previous average for that calibration standard. If it falls within the $90 \%$ confidence limit, the measurement is acceptable. If it is outside this limit, verify proper location and designation of the calibration standard, and make a recount. If it remains outside the $90 \%$ confidence limit, refer to the Diagnostic Procedures and Troubleshooting Guide.

12. Remove the calibration standard from the drum sleeve and position a single-only neutron emission source (such as $241_{A m B e)}$ in the drum sleeve such that the total neutron count rate is the same as that for the calibration standard.

13. At the end of the counting interval, read and record the counts which have been accumulated in each scaler on the log sheet directly under the data for the calibration standard. This row of data represents the random coincidence events associated with the coinci- 
CALIBRATION DATA

COINCIDENCE MODE

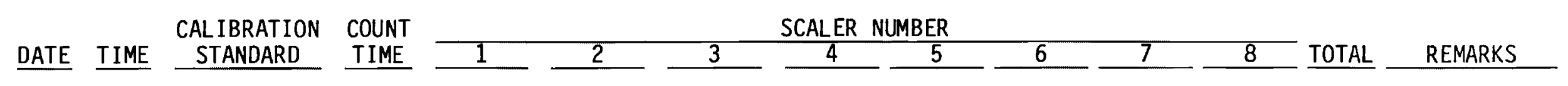


dence window width and total neutron count rate. In practice, this data should be obtained empirically, as a function of count rate, prior to routine operation.

14. Calculate and record the new counts, calibration counts minus random, in scaler \#2 through \#8. Using the weight of Pu or TRU in the standard, calculate and record the coincidence efficiency factor - grams of PU or TRU divided by net 2-coincidence counts. This efficiency factor is grams per count and is designated the 2-Coincidence Mode Efficiency Factor. Similar efficiency factors can be calculated for 3-, 4-, etc. coincidence events, if desired, to provide redundant data checks.

This completes the procedure for system calibration.

\section{SAMPLE ASSAY}

This procedure is used to perform an assay on a sample. (The counting interval used in the procedure will depend on the type of sample being assayed and the confidence level requirements. A 1000 second counting interval is used to demonstrate the procedural requirements of a sample assay operation.)

1. After a background measurement has been made, position the sample in the drum sleeve.

2. Set the "Preset $M \times 10^{N "}$ on the Counter-Timer to $14 \quad(M=1, N=4)$.

3. Set the "Coincidence-Spatial" switch on the Coincidence Network to "Coincidence".

4. Press "Reset" on the Counter-Timer to initiate a 1000 second counting interval.

5. At the end of the counting interval, observe and record the accumulated counts in each scaler.

6. Sum and record the total count. Record the date and time of measurement, length of count, and the sample designation. Record the location of any $10 \mathrm{BF}_{3}$ tubes that were off during the measurement in the remarks column. A sample log sheet is shown in Figure 12. 
ASSAY DATA

COINCIDENCE MODE

COUNT

DATE TIME SAMPLE COUNT

$\frac{1}{1}-2 \quad \begin{aligned} & \text { SCALER NUMBER } \\ & -\frac{4}{5}-\frac{5}{5}\end{aligned}$

DATE TIME SAMPLE TIME. 6 $7-8$ TOTAL REMARKS 
7. Record the Spatial Mode Background (same as Total Coincidence Mode Background) and Spatial Mode Efficiency factor (same as total Efficiency factor in the Coincidence Mode) to be used in the calculation.

8. Calculate the Pu or TRU content - sample count total minus background count total multiplied by the Spatial Mode Efficiency factor (efficiency factor is grams Pu per count or grams TRU per count depending on which assay is being made).

9. Remove the sample from the drum sleeve and position a single-only neutron emission source in the drum sleeve such that the total neutron count rate is the same as that for the sample.

10. At the end of the counting interval, read and record the counts which have been accumulated in each scaler on the log sheet directly under the data for the sample. This row of data represents the random coincidence events associated with the coincidence window width and total neutron count rate. In practice, this data should be obtained empirically, as a function of count rate, prior to routine operation.

11. Repeat the Pu or TRU calculation using the net 2-Coincidence counts, sample counts minus random in scaler \#2, and the corresponding 2Coincidence Mode Efficiency factor. The Pu or TRU content determined in this step should agree with that calculated in Step \#8. If it is lower than measured in Step \#8 the $(\alpha, n)$ conversion efficiency is less than $100 \%$.

12. The Pu or TRU content calculation may be repeated using higher order coincidence data if desired. This would be particularly informative if the concentrations calculated in Step \#8 and Step \#11 do not agree.

13. If information regarding the distribution of $\mathrm{Pu}$ or TRU in the sample or regarding the moderating capacity of the sample matrix (i.e. water content) is desired, the assay procedure can be repeated in the Spatial Mode. A sample log sheet is shown in Figure 13. The net counts in each octant will define any inhomogeneities in the Pu or TRU distribution and the ratio of the new inner ring to outer ring totals can be compared to standard matrix ratios to determine changes in the moderating capacity of the matrix. 
ASSAY DATA

SPATIAL MODE

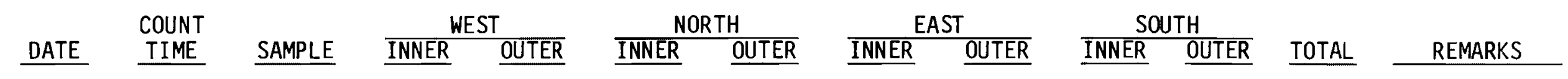


This completes the procedure for performing a HULLS or Waste Barrel assay.

DIAGNOSTICS AND TROUBLESHOOTING

These procedures are used to locate malfunctions. Experience with the prototype detector system indicates that when abnormal counts are obtained during background or calibration measurements, a single $10 \mathrm{BF}_{3}$ tube circuit is usually the cause. If the accumulated count appears abnormally low, an offending $10 \mathrm{BF}_{3}$ tube circuit has probably stopped counting due to a component failure, usually in the preamplifier/discriminator circuit. If the accumulated count appears abnormally high, the offending ${ }^{10} \mathrm{BF}_{3}$ tube circuit has become noisy, either in the high voltage network or the preamplifier/discriminator circuit. A background measurement $c$ an be used to locate the malfunction.

1. Remove all sample and calibrations material from the drum sleeve. Install all required shielding plugs.

2. Set "Preset $M \times 10^{N "}$ on the Counter-Timer to $62(M=6, N=2)$.

3. Set the "Coincidence-Spatial" switch on the Coincidence Network to "Spatial".

4. Set all $10_{\mathrm{BF}_{3}}$ tube power switches to "Off" (down) except in the \#1 column.

5. Press "Reset" on the Counter-Timer to initiate a 60 second count.

6. At the end of the counting interval, observe and record the accumulated counts from the scalers. A sample log sheet is shown in Figure 14.

7. Set all 10 $\mathrm{BF}_{3}$ tube power switches to "Off" (down). Move to the next column to the right and set those switches to "On" (up). Repeat Steps 5 and 6.

8. Repeat Step 7 until all columns have been measured.

9. Inspection of the data sheet should reveal malfunctioning ${ }^{10} \mathrm{BF}_{3}$ tube circuits by either an abnormally high or low count. Once the malfunctioning unit has been found, the preamplifier/discriminator should be replaced. First turn off the bias supply and allow 


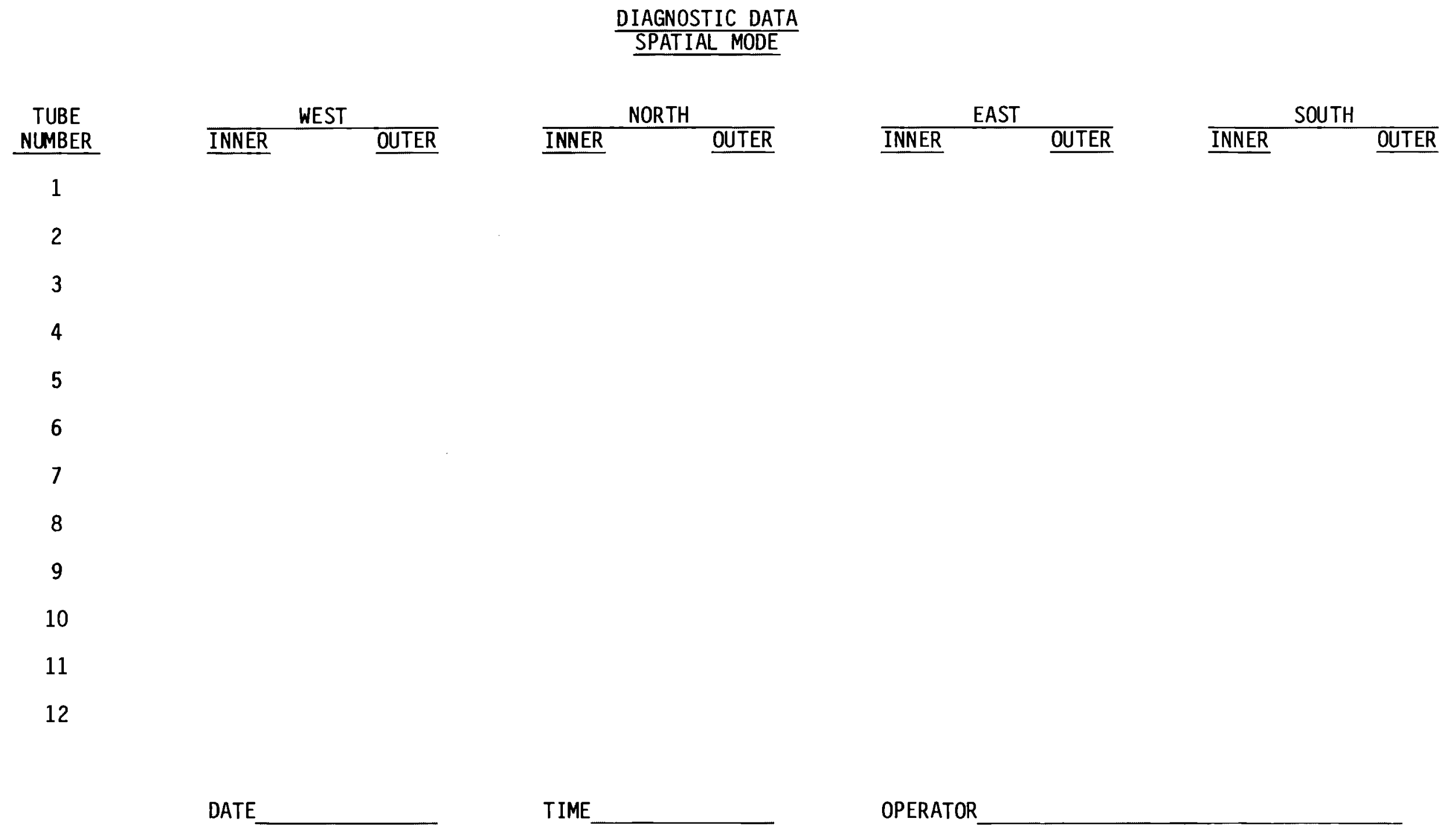

FIGURE 14 
sufficient time (up to 5 minutes) for HV to dissipate. Then disconnect the offending unit, remove it, and replace with a new one. Turn on the HV and rerun the test. Be sure and al low sufficient time for the high voltage to fully establish itself and for the new unit to become fully stressed before conducting the test. This could take up to $1 / 2$ hour. If problem persists the $10_{\mathrm{BF}_{3}}$ tube is probably at fault. Replace the $10 \mathrm{BF}_{3}$ tube.

10. If all counts from a specific scaler appear to be abnormally high or low, the malfunction is associated with a device common to all tubes in that row, i.e. Preamplifier, Coincidence Network or Counter. If :

A. A single scaler stops counting

1. The scaler has failed - replace

2. The 142PC amplifier feeding the scaler has failed

a. Most likely problem is a blown input Field Effect Transistor (FET) which can be replaced.

b. The power supply feeding the amplifier could have failed or have a blown fuse. This failure will cause two scalers to cease counting since each power supply feeds two amplifiers. The cause of the blown fuse should be found and repaired.

3. The coincidence box has failed

a. Check for the presence of input and corresponding output signals.

b. Identify the bad component and replace.

B. Background is high in a single scaler

1. High voltage breakdown external to preamplifier/discriminator including preamplifier connector and high voltage cable

a. Confirm by attaching an oscilloscope in parallel with the input to the scaler. Normal signal will be as shown in Figure 15a. External high voltage breakdown produced pulses are like those illustrated in Figure 15c. 


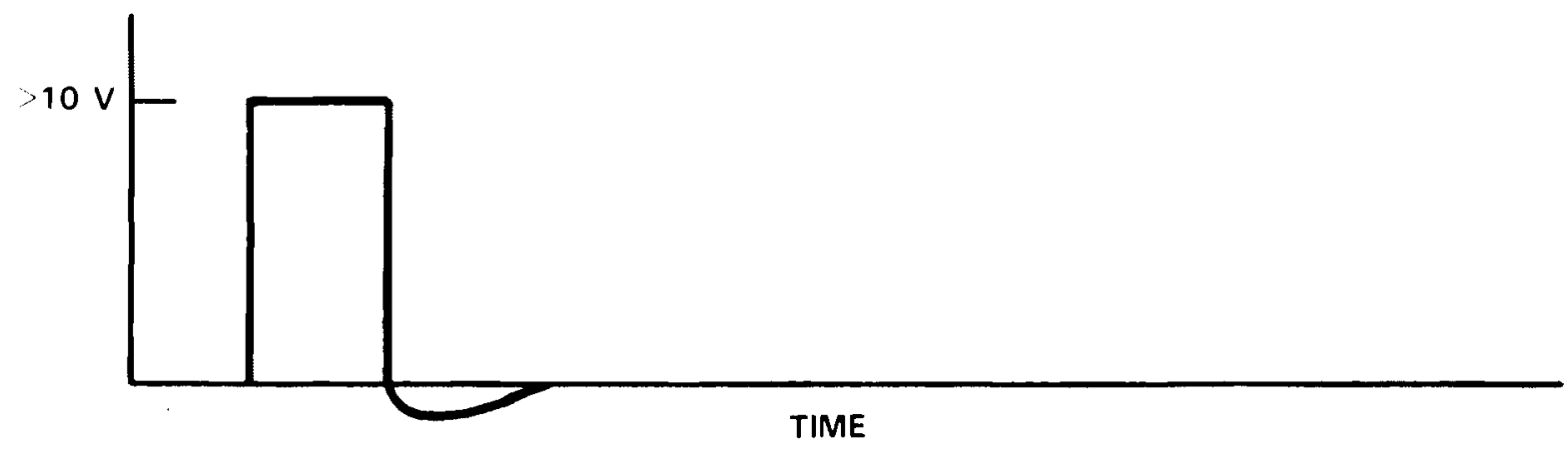

(a) NORMAL PULSE AT INPUT TO SCALER

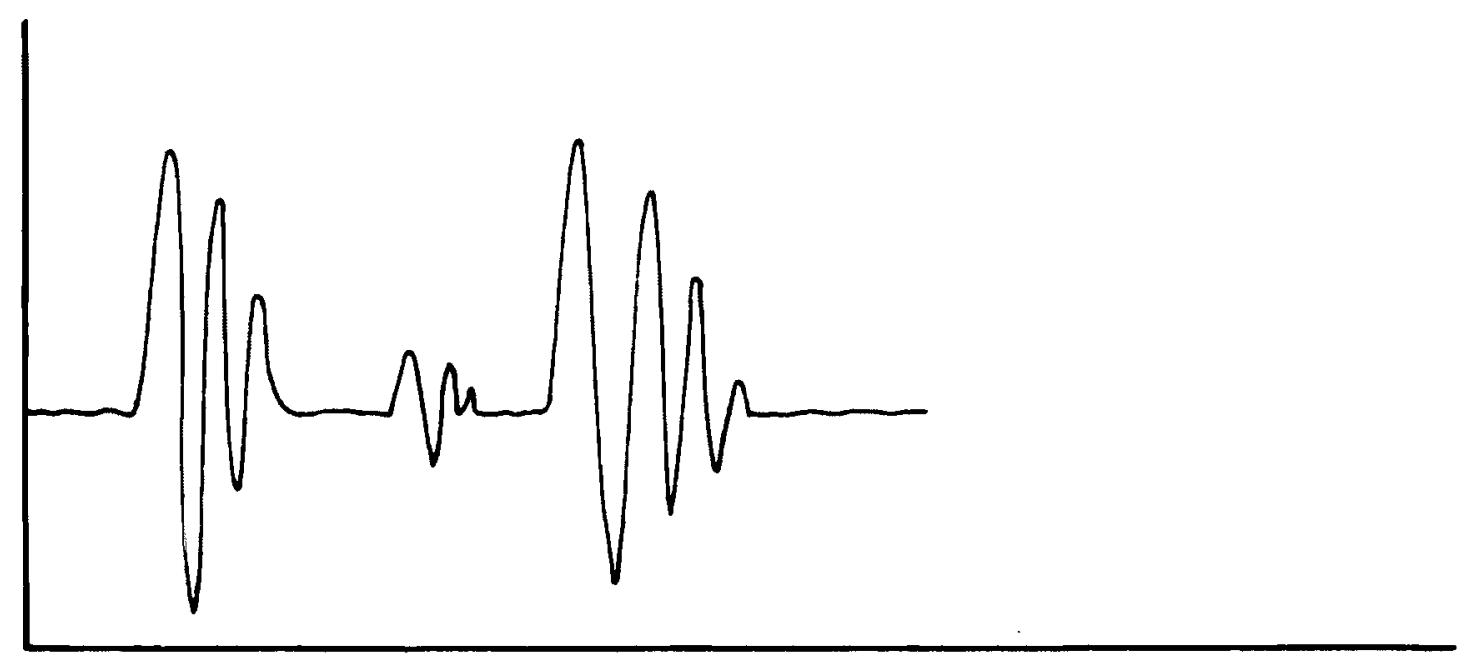

(b) TYPICAL NOISE BURSTS

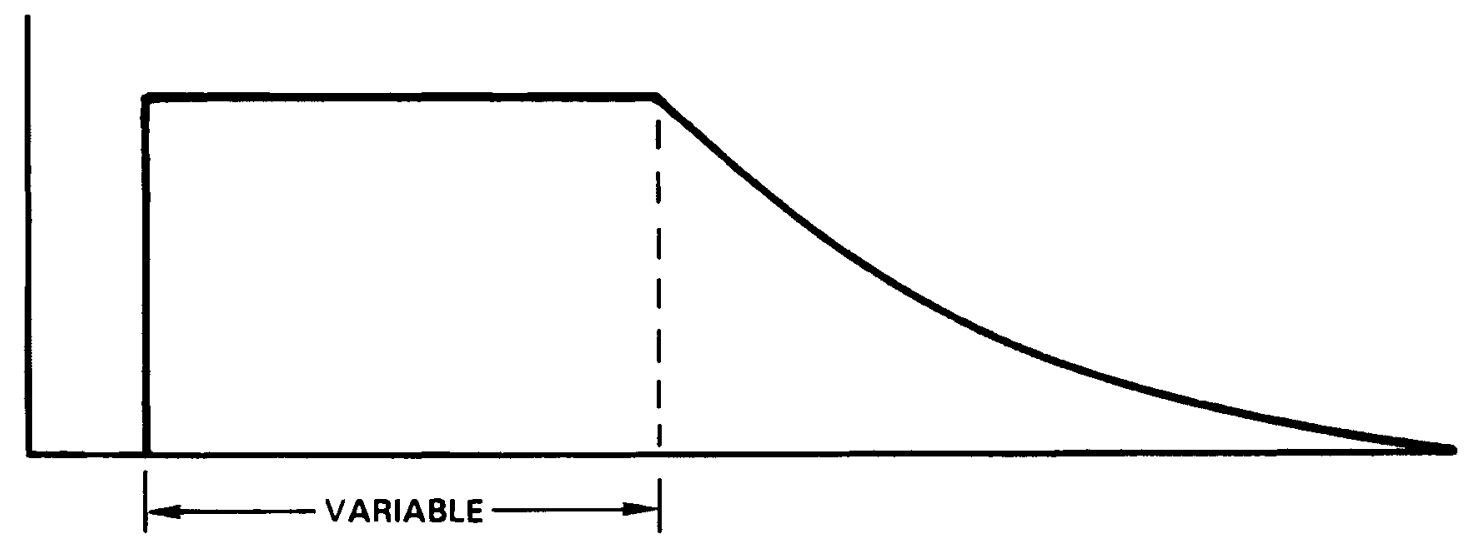

(c) PULSE CAUSED BY EXTERNAL HV BREAKDOWN

FIGURE 15 
b. This type of problem can only be eliminated by disconnecting the offending contributor. The problem could be in any connector or cable making up the high voltage distribution to that bank of detectors and can only be found by trial and error by removing various components until the problem is found.

11. If all counts from all scalers appear to be abnormally high or low, the malfunction is associated with a device common to the entire system. If:

\section{A. All scalers stop counting}

1. The high voltage supply has failed - replace or repair

2. The low voltage supply to the preamplifier/disc has failed or blown its fuse - determine cause of failure and repair

3. The timer has malfunctioned and fails to gate the scalers on - find cause and repair

4. The NIM bin power has failed - replace or repair

5. The coincidence box has failed - determine cause and repair

B. Background count is high in all scalers

1. A true increase of neutron background will be indicated if all scalers increase their background count about the same. This condition can only be remedied by removing the source of background.

2. A noise source has contributed to the count. An oscilloscope connected to one of the scaler inputs could aid in identifying a noise contribution. Normal pulses should appear as in Figure 15a, while noise would have the general appearance of Figure 15b. Remedial action would be to eliminate the noise source. Alternatively it might be possible to increase the discriminator setting of the scalers to eliminate the noise contribution. Care must be used, however, to avoid setting the discriminator above the level of the input pulses.

The use of this diagnostic procedure is recommended at least twice per week and records should be maintained on a continuing basis. 


\section{REFERENCES}

1. W. E. Kunz, J. D. Atencio, W. Bernard, G. C. Herrera, J. C. Pratt, and J. T. Caldwell, "A 1-mg-Sensitivity Fissile Assay System," LA-UR81-1358, Los Alamos, New Mexico.

2. W. E. Kunz and J. T. Caldwe11, "Current Status of the Multi-I sotopic Transuranic Waste Assay System," LA-UR-82-787, Los Al amos, New Mexico.

3. W. B. Bremner, K. C. Macleod, and P. C. Prentice, "The Design and Operation of Non-destructive Solid Waste Measurement Systems at DNPDE," TRG Memorandum 7342 (D), 1977, Windscale, United Kingdom.

4. W. E. Kunz, "Differential Dieaway Technique: Current Status of Los Al amos National Laboratory Work," Proceedings of TRU Waste Assay Instrumentation Workshop, May 23-24, 1983, Los Alamos.

5. L. A. Franks and S. M. Kocsimski, "LINAC Based TRU Assay," Proceedings of TRU Waste Assay Instrumentation Workshop, May 23-24, Los Alamos.

6. R. J. Critchley, N. Gardner, and G. B. Armitage, "Application of Differential Dieaway and Other NDA Nondestructive Assay Techniques to Selected Measurement Problems in the United Kingdom Nuclear Fuel Cycle," Proceedings of TRU Waste Assay Instrumentation Workshop, May 23-24, 1983, Los Alamos.

7. G. B. Armitage, "Harwell Experience with Dieaway Chamber Design, 208liter Barrel Effects, Neutron Tube Development, and Package Monitors," Proceedings of TRU Waste Assay Instrumentation Workshop, May 23-24, 1983, Los Al amos.

8. T. W. Crane, "Measurement of Uranium and Plutonium in Solid Waste by Passive Photon or Neutron Counting and I sotopic Neutron Source Interrogation," LA-8294-MS, 1980, LoS Alamos, New Mexico.

9. J. T. Caldwell and W. E. Kunz, "Experimental Evaluation of the Differential Die-Away Pulsed-Neutron Technique for the Fissile Assay of Hot Irradiated Fuel Waste," LA-UR-82-788.

10. R. L. Brodzinski, N. A. Wogman, H. L. Nielson, and D. P. Brown, "An Instrument for Determining the Transuranic Element Content of Chopped Leached Fuel Hulls and Other Materials," Proceedings of the 20th Annual Meeting of the Institute of Nuclear Materials Management, p. 438 (1979).

11. L. A. Rogers, D. P. Brown, and R. L. Brodzinski, "A Passive Neutron Counter for Determination of Transuranics in High Gamma Activity Samples," PNL-SA-11338, to be published in the Proceedings of the 1983 IEEE Nuclear Science Symposium.

12. R. L. Brodzinski, "TRU Assay System and Measurements," Proceedings of TRU Waste Assay Instrumentation Workshop, May 23-24, 1983, Los Alamos. 
13. D. P. Brown, "Optimization of the Clipping Time Constant for $\mathrm{BF}_{3}$ Neutron Detectors Operated in a High Level Ganma Environment," IEEE Transactions on Nuclear Science, Vol. 21, February, 1974. 
APPENDI X A 

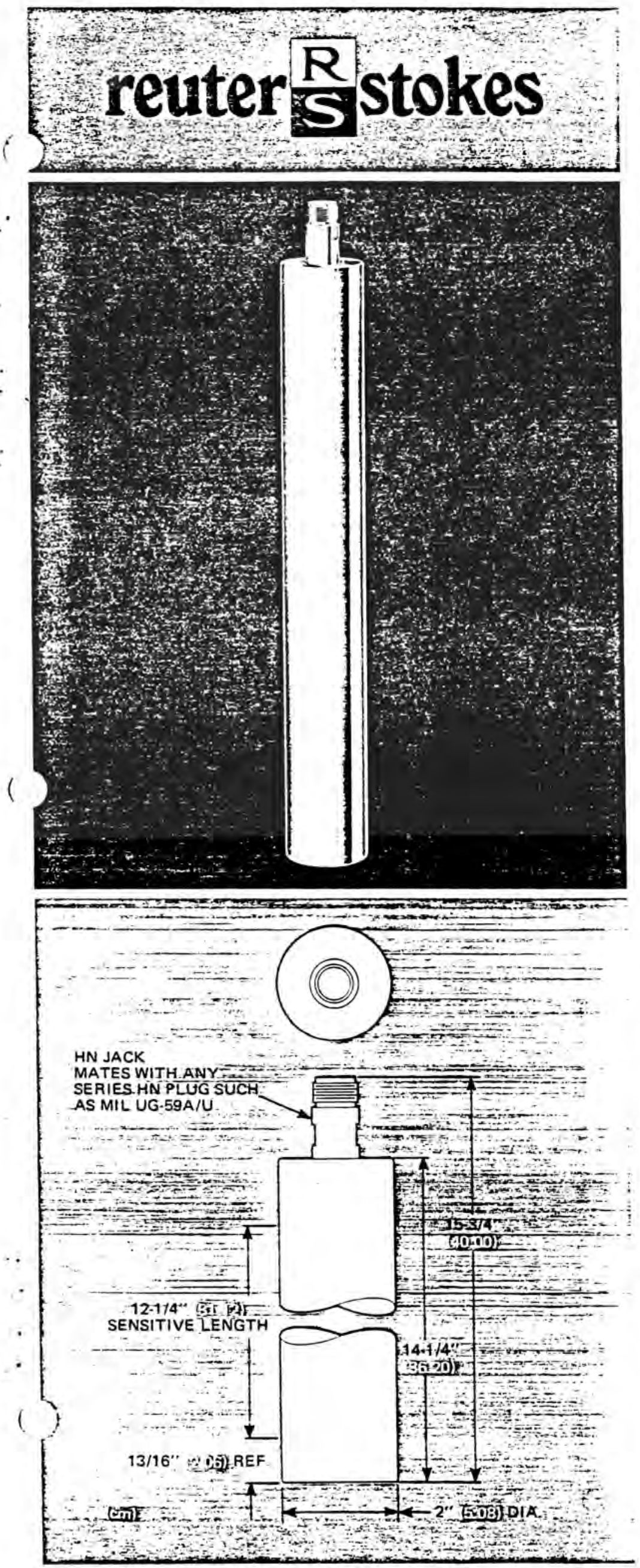

Engineering Data Sheet

\section{for Thermal Neutron Counting}

This is our standard $5.08 \mathrm{~cm}$ diameter ${ }^{10} \mathrm{BF}_{3}$ filled thermal neutron detector normally used in industrial gaging, failed fuel element detection, and nuclear safeguard.

The detector has a sensitive length of $31.12 \mathrm{~cm}$ and outer diameter of $5.08 \mathrm{~cm}$, filled with $70 \mathrm{~cm}$ $\mathrm{Hg}$ pressure $\mathrm{BF}_{3}$ gas. The filling gas is enriched to greater than $96 \%$ in ${ }^{10} \mathrm{~B}$ isotope. Typical sensitivity of the detector is $28 \mathrm{cps} / \mathrm{nv}$.

The design of this detector has been qualified to MIL specifications for shock and vibration requirements.

RDT specifications C15-11T " $B F_{3}$ Gamma Tolerant Neutron Detector Tubes", which is part of LMFBR instrumentation development, was written around the performance of the aluminum version of this $\mathrm{BF}_{3}$ detector. The detector can be provided to the exacting $\mathrm{QA}$ and testing requirements of this specification.

Aluminum construction minimizes weight and neutron absorption. The background counting rate due to inherent alpha contamination is $\sim 2 \mathrm{cpm}$. Stainless steel is recommended for high temperature and/or lower background $(\sim 0.2 \mathrm{cpm})$ requirements.

The standard detector is filled with $70 \mathrm{~cm} \mathrm{Hg}$ pressure $\mathrm{BF}_{3}$ gas; other fill pressures between 10 $\mathrm{cm} \mathrm{Hg}$ and $90 \mathrm{~cm} \mathrm{Hg}$ can be provided. Neutron sensitivity varies linearly with sensitive length and fill pressure. The required operating voltage increases with increase in fill pressure, and $90 \mathrm{~cm} \mathrm{Hg}$ pressure is generally considered as a practical maximum for standard construction. In special applications, anode size can be adjusted to achieve desired pressure/voltage relationship.

These $\mathrm{BF}_{3}$ filled neutron detectors are provided with our special MG process of carbon coating $\left({ }^{*}\right)$ the cathode to improve resistance to high radiation fields.

\footnotetext{
"Improved Performance of $\mathrm{BF}_{3}$ Neutron Counters in High Gamma Fluxes" conference paper presented at The Institute of Electrical and Electronic Engineers Nuclear Science Symposium. San Francisco, October 18-20, 1965, by Arthur J. Stokes, Thomas J. Meal and John E. Myers, Jr
} 


\section{Specifications}

\section{RS-P1-1613-144 - ALUMINUM RS-P1-1613-203 - STAINLESS STEEL \\ MECHANICAL}

Maximum diameter

Maximum overall length (See Note 1)

Connector

Net weight: $A L$ S.S.

$5.16 \mathrm{~cm}$ $40.32 \mathrm{~cm}$ HN fernale $0.3 \mathrm{~kg}$ $0.4 \mathrm{~kg}$

MATERIAL

Outer shell: Model - 144

$1100 \mathrm{AL}$. Model - 203

Connectar

. . .

Insulation: Detector

Connector

Neutron sensitive material

Fill pressure (See Note 1) $\mathrm{BF}_{3}$ enriched to $96 \%$ in ${ }^{10} \mathrm{~B}$

CAPACITANCE

$70 \mathrm{~cm} \mathrm{Hg}$

$\sim 8 \mathrm{pf}$

RESISTANCE @ $25^{\circ} \mathrm{C}$

$10^{12}$ ohms (minimum) MAXIMUM RATINGS

Voltage

Temperature:

$$
\text { AL. }
$$

3000 volts

$$
\text { S.S. }
$$

$100^{\circ} \mathrm{C}$

Burn-up life:

for $10 \%$ decrease in sensitivity.

$2 \times 10^{19}$ nvt (thermal)

\section{OPERATING CHARACTERISTICS}

Thermal neutron sensitivity (unperturbed)

Thermal neutron flux range

$28 \mathrm{cps} / \mathrm{nv}$

Voltage range to $4 \times 10^{3} \mathrm{nv}$

Resolution (FWHM) See plateau curve

Output pulse characteristics (average)

$$
\text { Charge output . . } \sim 5 \times 10^{-14} \text { coulombs @ } 2400 \mathrm{~V}
$$

NOTE 1: Other lengths from 15 to $142 \mathrm{~cm}$ available; other pressures from 10 to $90 \mathrm{~cm} \mathrm{Hg}$ available.

NOTE 2: $\quad \mathrm{BF}_{3}$ detectors are operable in $10 \mathrm{R} / \mathrm{hr}$ gamma field without any significant loss of sensitivity. With proper choice of electronics, and some loss of sensitivity these detectors can be used in gamma field up to $100 \mathrm{R} / \mathrm{hr}$.

TYPICAL PLATEAU CURVE

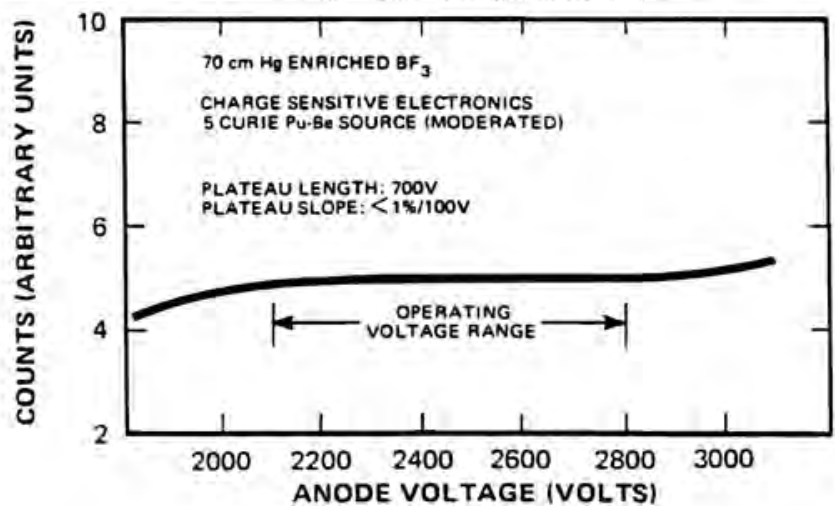

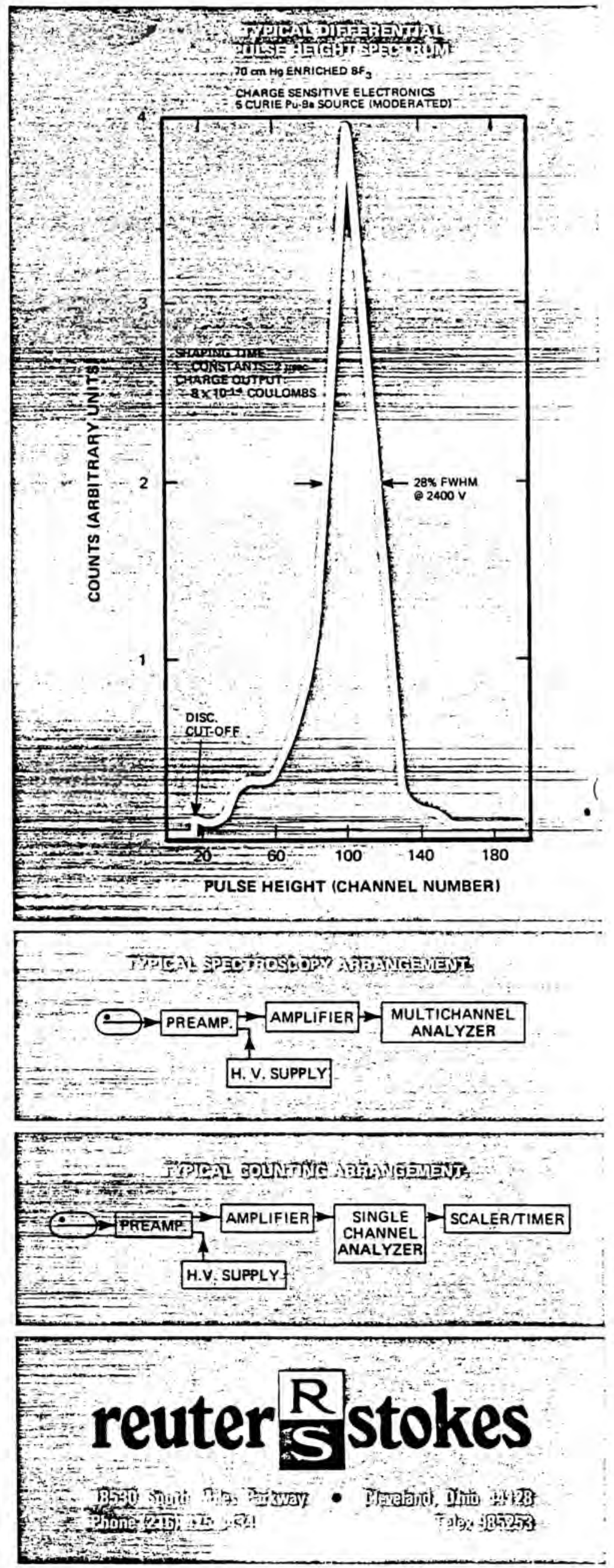




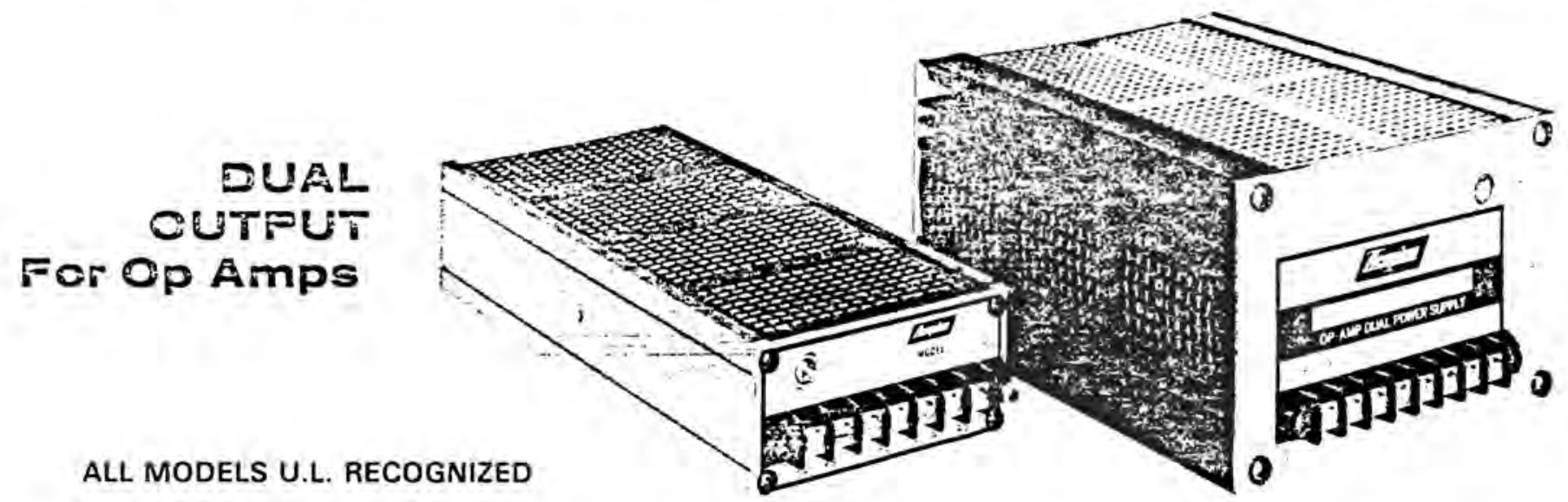

Series D dual output power supplies are a convenient source of the tracking voltages required for powering operational amplifiers and related circuits. Their positive/common/negative output termi- nal configuration minimizes system wiring. Provision for remote sensing permits compensation of load line effects. Although moderately priced, they are sturdily constructed and conservatively rated.

\section{SPECIFICATIONS}

Input Voltage: 105-125 VAC, $50-400 \mathrm{~Hz}$, single phase.

Output Voltages: Tracking within 1\%. See tables. Output Currents:

Output Voltage Adjustment Ranges:

Load Regulation: $\pm 0.1 \%$.

Line Regulation: $\pm 0.1 \%$.

Ripple: $1.5 \mathrm{mv}$ RMS.

Polarity: Positive output, common, and negative output.

Remote Voltage Sensing: Standard.

Ambient Operating Temperature: -10 to $+71^{\circ} \mathrm{C}$.

Storage Temperature: -55 to $+85^{\circ} \mathrm{C}$.

OPTIONS

Overvoltage Protection: A built-in preset overvoltage protection circuit is available on all models. If either output fails, both outputs are "crowbarred." To order, add prefix " $V$ " to the model number, and increase standard price by $\$ 30.00$.

230 Volt Input: All models can be alternately furnished for operation on inputs of 210-250 VAC. $50-400 \mathrm{~Hz}$. To order, add suffix " -230 " to model number and $\$ 25.00$ to price.

- Connections:

$$
c
$$

(Supplies for Op Amps)
V S M $\vec{S} \vec{V}$ AC GND

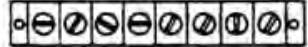

\begin{tabular}{|c|c|c|c|c|c|c|c|}
\hline \multirow{2}{*}{$\begin{array}{c}\text { Nominal } \\
\text { Output } \\
\text { Voltages }\end{array}$} & \multirow{2}{*}{$\begin{array}{c}\text { Adjust } \\
\pm V .\end{array}$} & \multicolumn{3}{|c|}{ CurrentOutput Amps. at } & \multirow[b]{2}{*}{ Price } & \multirow[b]{2}{*}{ Model } & \multirow[b]{2}{*}{ Size" } \\
\hline & & $40^{\circ} \mathrm{C}$ & $55^{\circ} \mathrm{C}$ & $71^{\circ} \mathrm{C}$ & & & \\
\hline \pm 5 & .5 & .750 & .650 & .550 & $\$ 170$ & TDS-75 & TGS \\
\hline \pm 5 & .5 & 1.5 & 1.25 & 1.0 & 200 & TD5-150 & TG6 \\
\hline \pm 5 & .5 & 2.5 & 2.0 & 1.5 & 235 & TD5-250 & TG9 \\
\hline \pm 12 & 1 & 1.0 & .900 & .800 & 170 & TD12-100 & TGS \\
\hline \pm 12 & 1 & 1.6 & 1,4 & 1.0 & 200 & TD12-160 & TG6 \\
\hline \pm 12 & 1 & 2.5 & 2.0 & 1.5 & 235 & TD12.250 & TG9 \\
\hline \pm 12 & .5 & 4.5 & 3.7 & 3.0 & 290 & TD12-450 & TG13 \\
\hline \pm 12 & .5 & 8.5 & 7.0 & 5.5 & 375 & TD12-850 & TH11 \\
\hline \pm 15 & 1 & .400 & .400 & .400 & 125 & TD15-40 & TG5 \\
\hline \pm 15 & 1 & 1.0 & .900 & .800 & 170 & TD15-100 & TG5 \\
\hline \pm 15 & 1 & 1.6 & 1,4 & 1.0 & 200 & TD15-160 & TG6 \\
\hline \pm 15 & 1 & 2.5 & 2.0 & 1.5 & 235 & TD15-250 & TG9 \\
\hline \pm 15 & .5 & 4.5 & 3.7 & 3.0 & 290 & TD15.450 & TG13 \\
\hline \pm 15 & .5 & B.5 & 7.0 & 5.5 & 375 & TD15.850 & TH11 \\
\hline
\end{tabular}

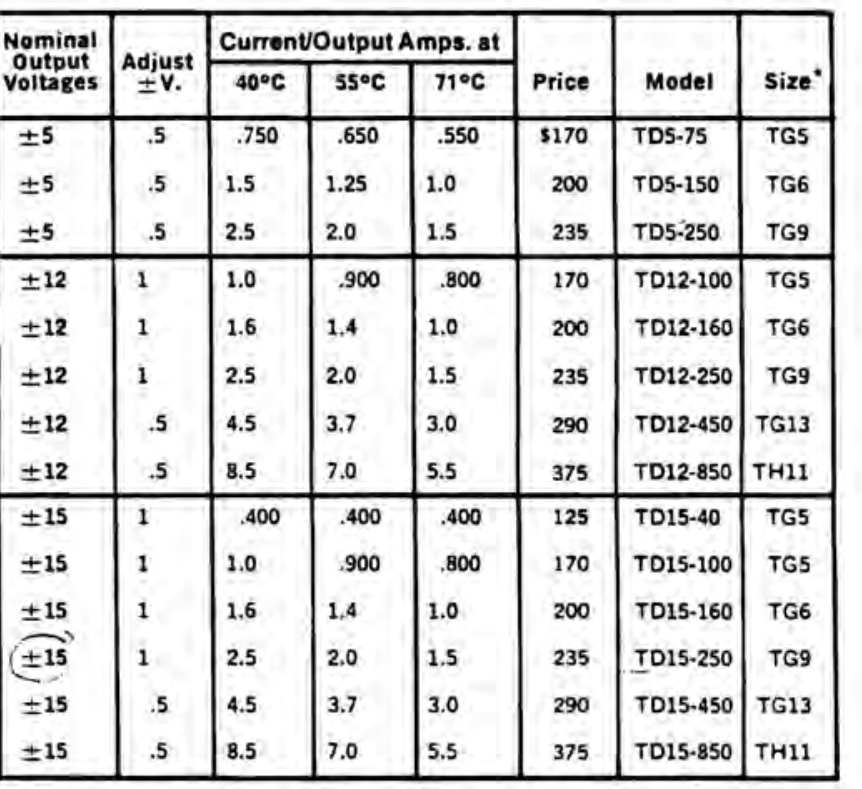

\begin{tabular}{|c|c|c|c|c|c|c|c|}
\hline \multirow{2}{*}{$\begin{array}{l}\text { Nominal } \\
\text { Output } \\
\text { Voltage }\end{array}$} & \multirow{2}{*}{$\begin{array}{c}\text { Adjust } \\
\pm \mathbf{v} .\end{array}$} & \multicolumn{3}{|c|}{ Currentoutput Amps. at } & \multirow[b]{2}{*}{ Price } & \multirow[b]{2}{*}{ Model } & \multirow[b]{2}{*}{ Size* } \\
\hline & & $40^{\circ} \mathrm{C}$ & $55^{\circ} \mathrm{C}$ & $71^{\circ} \mathrm{C}$ & & & \\
\hline \pm 12 & 1 & .500 & .500 & .400 & $\$ 140$ & FD12-50 & TN6 \\
\hline \pm 12 & .5 & 1.0 & .900 & .800 & 185 & LD12-100 & TNBH \\
\hline \pm 15 & 1 & .500 & .500 & .400 & 140 & FD15-50 & TNG \\
\hline \pm 15 & .5 & 1.0 & .900 & .800 & 185 & LD15-100 & TNBH \\
\hline
\end{tabular}




\section{DUAL OUTPUT \\ General Purpose}

\section{ALL MODELS U.L. RECOGNIZED}

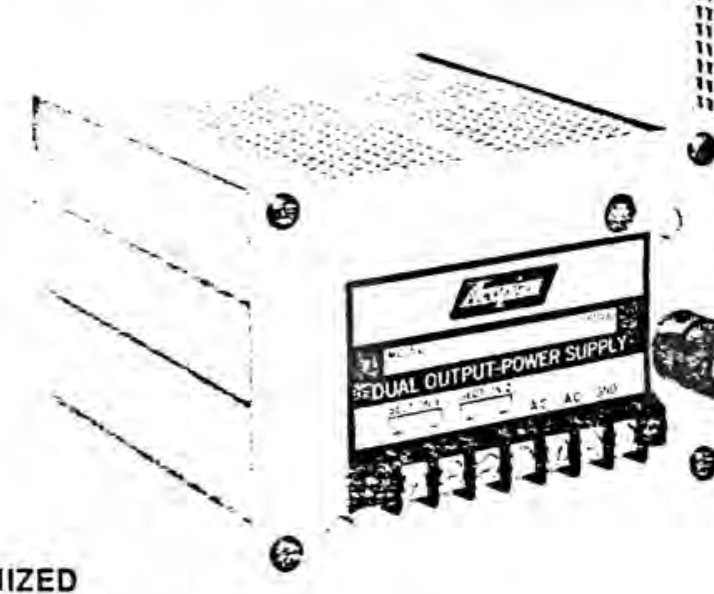

(2)

Acopian general purpose duals furnish two completely independent outputs, either identical or different, in less space and at less cost than two equivalent single output supplies. Thousands of out- put voltage/current rating combinations are available. Mounting and system wiring are simplified. Quality components, generously derated, insure long-term reliability.

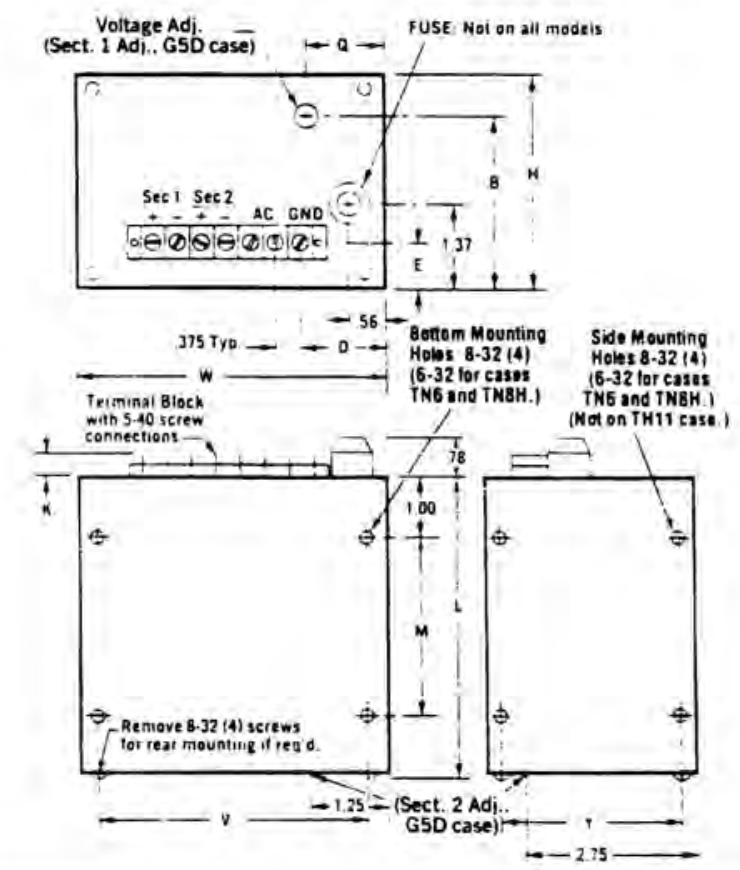

\begin{tabular}{|c|c|c|c|c|c|c|c|c|c|c|c|c|c|}
\hline Size & L & $w$ & $H$ & $M$ & $v$ & $r$ & E & a & B & K & D & \multicolumn{2}{|c|}{$\begin{array}{l}\text { Approx. } \\
\text { weight }\end{array}$} \\
\hline$G 50$ & 509 & 5.12 & 3.44 & 3.00 & 4,50 & 200 & .75 & 1.25 & 2.73 & .39 & 2,44 & \multicolumn{2}{|l|}{410} \\
\hline TGS & 5.09 & 5.12 & 3.44 & 3.00 & \$so & 2.00 & 75 & 1.25 & 2.73 & j8 & 1.48 & 310 & $40 z$ \\
\hline TG6 & $=.59$ & $\$ .12$ & $3 \div 4$ & 400 & 250 & 3.20 & .75 & 1.25 & 2.73 & .35 & 1.44 & 410 & 402 \\
\hline TG9 & 925 & 512 & $3<4$ & 5.00 & 650 & 3.00 & 75 & 1,25 & 2.73 & 38 & 1.44 & 610 & $5 \circ z$ \\
\hline$T G 13$ & 1325 & 5,12 & 3.44 & 10,00 & $\div \leq 0$ & $3=0$ & .75 & 1.25 & 2.73 & 38 & $1: 4$ & \multicolumn{2}{|c|}{1210} \\
\hline-411 & 0.25 & 7.37 & 5.12 & 8.00 & 475 & $=36$ & .75 & 2.73 & 4.36 & 38 & 2.38 & 1810 & $60 z$ \\
\hline$+N 6$ & $5 \leq 5$ & $3: 2$ & 1.68 & $=00$ & 3.12 & i. 31 & .62 & 287 & 1.31 & 53 & .59 & 210 & $40 x$. \\
\hline TNEH & 3.47 & 4.68 & $1.6 \varepsilon$ & 500 & 3.12 & 1.31 & 62 & 2.87 & 1,31 & 53 & 59 & 3101 & $140 x$ \\
\hline
\end{tabular}

HOW TO ORDER: Select two sections from one of the three tables on pages 18 and 19. The complete model number is the combination of the two sections selected. Example: The combination of section 5GT20D and section 8GT50D is Model 5GT20D-8GT50D. Always assign the lower voltage section first. For pricing purposes, add the cost of the individual sections selected.

\section{SPECIFICATIONS}

Input Voltage: $105-125$ VAC, $50-400 \mathrm{~Hz}$, single phase.

Output Specifications: See pages 18 and 19. No derating required through ambient temperature range of -10 to $+71^{\circ} \mathrm{C}$.

Short Circuit Protection: Delivers current surges without damage - built-in fuse protects supply against prolonged overloads and shorts.

Polarity: Outputs are floating. Each output may be independently connected to provide any combination of positive and negative voltages. Outputs may be floated up to $300 \mathrm{~V}$ above ground.

Ambient Operating Temperature: -10 to $+71^{\circ} \mathrm{C}$.

Storage Temperature: -55 to $+85^{\circ} \mathrm{C}$.

Dimensions and Weight: Case size G5D.

\section{OPTIONS}

Cvervoltage Protection: Separate preset overvoltage protection circuit for each output. To order, add prefix " $V$ " to model number. When both outputs are in the range of 3 to $28 \mathrm{~V}$, add $\$ 20.00$ to the standard price. An additional $\$ 5.00 /$ output charge applies for outputs from 30 to $70 \mathrm{~V}$. Not available for other voltages.

230 Volt Input: All models can be alternately furnished for operation on inputs of $210-250$ VAC, $50-400 \mathrm{~Hz}$. To order, add suffix "-230" to the model number and $\$ 25.00$ to the standard price. 


\section{Preamplifier Power Supply}

- Powers two EGag ORTEC preampilfiers

- Short-circult protected

- $117 \mathrm{~V}$ or $230 \mathrm{~V}$ ac operation
The EG\&G ORTEC 114 Preamplifier Power Supply provides remote power for two EG\&G ORTEC preamplifiers.

Output power connections are compatible with the power cable that is furnished with each EG\&G ORTEC transistorized preamplifier.

All outputs are short-circuit protected.

The 114 is self-contained in a small box and accepts its input power directly from a nominal $117 \mathrm{~V}$ or $230 \mathrm{~V}$ ac power source.

\section{Specifications}
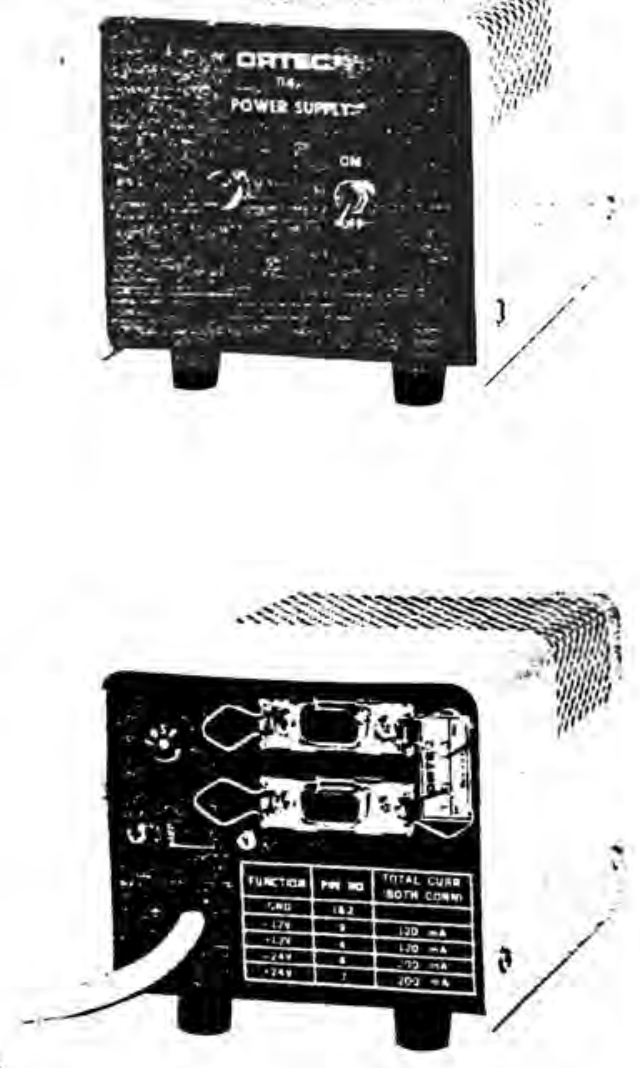

\section{INPUT}

103-129 V ac or 206-258 V ac, switchselectable; $50-65 \mathrm{~Hz}$; captive $1.6 \mathrm{~m}(5.5 \mathrm{ft})$ 3-wire power cord with NEMA standard connector.

\section{OUTPUTS}

Two Amphenol 17-10090 preamplifier power connectors: all power levels duplicated in both connectors.

\section{ELECTRICAL AND MECHANICAL}

POWER REQUIRED $+24 \mathrm{~V}, 0-200 \mathrm{~mA}$ : $-24 \mathrm{~V}, 0-200 \mathrm{~mA} ;+12 \mathrm{~V}, 0-120 \mathrm{~mA}:-12 \mathrm{~V}$. $0-120 \mathrm{~mA}$

WEIGHT

Not $1.6 \mathrm{~kg}(3.5 \mathrm{lb})$.

Shipping $2.5 \mathrm{~kg}(5.5 \mathrm{lb})$.

DIMENSIONS $16.5 \times 10.2 \times 8.4 \mathrm{~cm}(6.5 \times$ $4.0 \times 3.3 \mathrm{in}$.) plus $1.6 \mathrm{~m}(5.5 \mathrm{ft})$ power cord. 


\section{$142 P C$ Preamplitier}

- Ideal for proportional counters

- Very low noise for solt $x$-ray and low-energy gammaspectroscopy

- Improves resolution and prolongs counter life
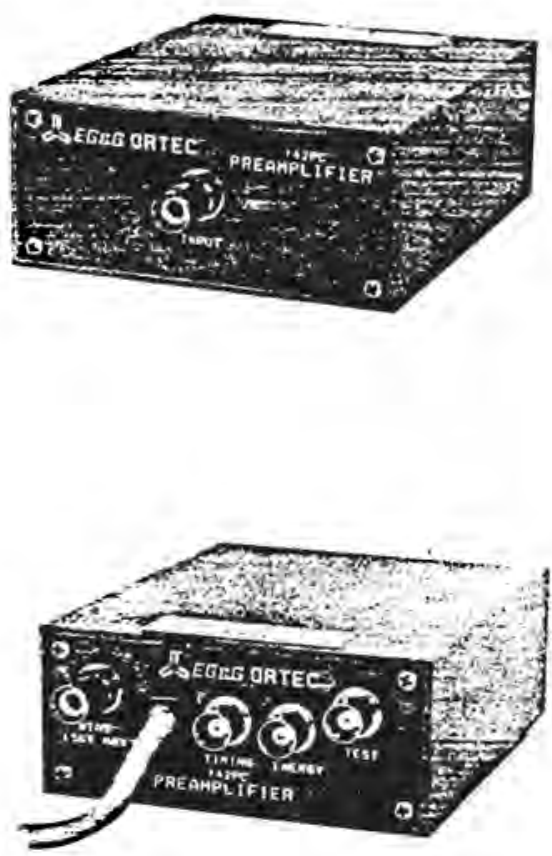

The EG\&G ORTEC 142PC Preamplifier is a low-noise charge-sensitive unit especially designed for use with proportional counters requiring up to $\pm 3000 \mathrm{~V}$ detector bias.

The high gain of this unit often allows operating the proportional counter at reduced voltages, thus greatly minimizing peak position shifts and peak broadening with changing count rates. This will also extend the tube lifetime.

The low-noise performance for this type of preamplifier greatly improves the resolution of the spectroscopy system. The separate energy and timing outputs enhance instrument flexibility.

The 142PC incorporates a protection circuit for the input FET to prevent damage from inadvertently applied overvoltages. The unit is shipped with the protection circuit in-place; better resolution, however, will be obtained when the protection is removed (Fig. 1).

\section{Specifications}

\begin{tabular}{|c|c|}
\hline \multicolumn{2}{|c|}{ PERFORMANCE } \\
\hline \multicolumn{2}{|l|}{ NOISE } \\
\hline $\begin{array}{cc}\text { Typical } \\
\text { O pF } & 295 \mathrm{rms} \text { electrons } \\
100 \mathrm{pF} & 450 \mathrm{rms} \text { electrons }\end{array}$ & $\begin{array}{c}\text { Guaranteed } \\
340 \text { rms electrons } \\
485 \text { rms electrons }\end{array}$ \\
\hline \multicolumn{2}{|c|}{$\begin{array}{l}\text { RISE TIME Based on a }+0.5 \mathrm{~V} \text { signal through } \\
\text { either output into a } 93-\Omega \text { circuit and meas - } \\
\text { ured from } 10 \% \text { to } 90 \% \text { of peak amplitude; } 25 \\
\text { ns at } 0 \mathrm{pF} \text { and } 150 \mathrm{~ns} \text { at } 100 \mathrm{pF} \text {. }\end{array}$} \\
\hline \multicolumn{2}{|c|}{$\begin{array}{l}\text { SENSITIVITY Nominal, measured through } \\
\text { either output, } 6.5 \mathrm{~V} / \mathrm{pC} \text {. }\end{array}$} \\
\hline \multicolumn{2}{|c|}{ DYNAMICINPUT CAPACITANCE $1000 \mathrm{pF}$. } \\
\hline $\begin{array}{l}\text { INTEGRAL NONLINEARI } \\
\text { to } \pm 7 \text { V open circuit or } \pm \\
93 \Omega \text {. }\end{array}$ & ITY $\leqslant \pm 0.05 \%$ for 0 \\
\hline
\end{tabular}

\author{
OUTPUT LINEAR RANGE $\pm 7 \mathrm{~V}$. \\ TEMPERATURE INSTABILITY $\leqslant \pm 50 \mathrm{ppm} /$ \\ ${ }^{\circ} \mathrm{C}, 0$ to $50^{\circ} \mathrm{C}$. \\ DETECTOR BIAS ISOLATION $\pm 3000 \mathrm{~V}$. \\ OPEN LOOP GAIN $\geqslant 40,000$.
}

\section{INPUTS}

INPUT Accepts input signals from a proportional counter and extends operating bias to the proportional counter.

BIAS Accepts the bias voltage for the proportional counter from a bias supply.

TEST Accepts input voltage pulses from a pulse generator for instrument and system check and calibration; $R_{i n}=93 \Omega$.

\section{OUTPUTS}

ENERGY AND TIMING 2 connectors furnish identical signals through 2 output paths; either or both of these outputs can be used as required, and they are interchangeable. $R_{0}=93 \Omega$ through each connector and the output polarity is opposite from the input pulse polarity (output pulse polarity is the same as bias polarity).

\section{CONNECTORS}

INPUT AND BIAS SHV

TEST, ENERGY, AND TIMING BNC.

POWER CABLE $3 \mathrm{~m}(10 \mathrm{ft})$ captive power cable. EG\&G ORTEC 121-C1; longer lengths available on special order.

\section{ELECTRICAL AND MECHANICAL}

POWER REQUIRED $+24 \mathrm{~V}, 30 \mathrm{~mA} ;-24 \mathrm{~V}$, $10 \mathrm{~mA} ;+12 \mathrm{~V}, 15 \mathrm{~mA} ;-12 \mathrm{~V}, 15 \mathrm{~mA}$. Furnished from NIM bin and power supply through any EG\&G ORTEC main amplifier or from the 114 Preamplifier Power Supply; built-in captive cable is compatible with either source.

WEIGHT

Net $0.65 \mathrm{~kg}(1.5 \mathrm{lb})$.

Shipping $1.3 \mathrm{~kg}(3.0 \mathrm{lb})$.

DIMENSIONS $4.5 \times 13.2 \times 10.0 \mathrm{~cm}(1.75 \times$ $5.2 \times 4.0 \mathrm{in}$.) plus $3 \mathrm{~m}$ (10 ft) cable.

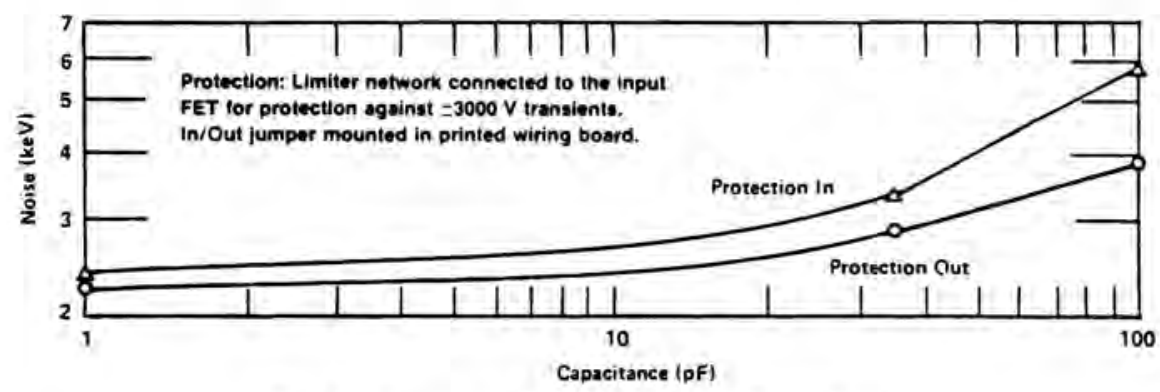

Fig. 1. Noise as a Function of Input Capacitance, Measured with an EG\&G ORTEC 572 Amplifier and $2 \mu \mathrm{s}$ Time Constant. 


\section{5-kV Detector Bias Supply}

The EG\&G ORTEC $4595-k V$ Detector Bias Supply provides a bias voltage from a NIM package of positive or negative polarity for a semiconductor detector or for any type of detector requiring bias currents $<0.1 \mathrm{~mA}$; this includes proportional counters and ionization chambers. Two simultaneous outputs are provided: one for a range of 0 to $5 \mathrm{kV}$ and the other for a range of 0 to $500 \mathrm{~V}$. Both output voltages are controlled by a 5-turn direct-reading potentiometer located on the front panel. Either polarity is available through both outputs. with the polarity selected by an internal switch and indicated by a light on the front panel. A panel meter also monitors the polarity and the approximate voltage available through the output.

The $\mathbf{4 5 9}$ receives its necessary operating power from the EG\&G ORTEC $4001 \mathrm{C} /$ 4002A Bin and Power Supply in which it is installed for operation. All of the input power is supplied through the rear panel module connector.

\section{Specifications}

\section{PERFORMANCE}

BIAS VOLTAGE OUTPUTS 2 output circuits; ranges 0 to $5 \mathrm{kV}$ and 0 to $500 \mathrm{~V}$.

BIAS CONTROL 5-turn direct-reading precision potentiometer.

BIAS POLAAITY Either positive or negative for both outputs, selected by an internal switch and indicated on the front panel.

NOISE AND RIPPLE $<10 \mathrm{mV}$ peak-to-peak from $5 \mathrm{~Hz}$ to $50 \mathrm{MHz}$.

\section{TEMPERATURE INSTABILITY}

$< \pm 0.02 \% /{ }^{\circ} \mathrm{C}$ through 0 to $50^{\circ} \mathrm{C}$ operating range.

VOLTAGE INSTABILITY $< \pm 0.1 \% / h$ output voltage variation with constant input voltages from bin supply, constant temperature, and constant load.

OUTPUT CURRENT $1-100 \mu \mathrm{A}$.

OUTPUT VOLTAGE RISE TIME $5 \mathrm{~s}$.

OVERLOAD PROTECTION Internal overload and short-circuit protection with automatic output restoration.

RESETTABILITY Output voltage can be reset to within $0.2 \%$

\section{CONTROLS}

OUTPUT VOLTAGE 5-turn direct-reading potentiometer with 500 dial divisions adjusts output levels for both outputs simultaneously.

HIGH VOLTAGE ON/OFF Toggle switch and indicator lamp show when the instrument circuits are turned on to provide an output.

POLARITY +/- Internal switch selects either polarity for both outputs.

\section{INPUTS}

POWER All input power is furnished through the rear panel module connector from the bin and power supply.

REMOTE SHUTDOWN Rear panel BNC connector; output voltage is reduced to zero by shorting the center contact to ground: $Z$.... of grounding circuit $<30 \Omega$

\section{OUTPUTS}

0-5 KV $\left(Z_{0}=2 \mathrm{Mn}\right)$ Rear panel SHV connector furnishes the adjusted output voltage in the 0 to $5 \mathrm{kV}$ range through an output impedance of approximately $2 \mathrm{M} \Omega$.

$0-500 \mathrm{~V}\left(Z_{1}=700 \mathrm{k} \Omega\right)$ Rear panel SHV connector furnishes the adjusted output voltage in the 0 to $500 \mathrm{~V}$ range through an output impedance of approximately $700 \mathrm{ks}$.

FRONT PANEL METER Edge-reading meter monitors the polarity and output level for the 0 to $5 \mathrm{kV}$ output range.

\section{ELECTRICAL AND MECHANICAL} POWER REQUIREMENTS +24 V, $57 \mathrm{~mA}$ $-24 \mathrm{~V}, 57 \mathrm{~mA} ;+12 \mathrm{~V}, 75 \mathrm{~mA} ;-12 \mathrm{~V}, 75 \mathrm{~mA}$. WEIGHT

Net $0.9 \mathrm{~kg}(2.0 \mathrm{lb})$.

Shipping $1.8 \mathrm{~kg}(4.0 \mathrm{lb})$.

DIMENSIONS Standard single-width NIM module $3.43 \times 22.13 \mathrm{~cm}(1.35 \times 8.714 \mathrm{in}$. $)$ per TID-20893 (Rev)

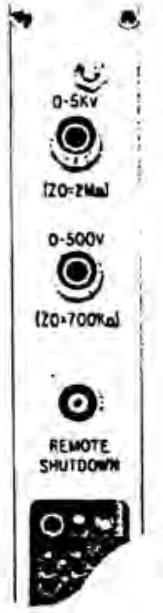

- NIM BIn package

- Positive or negative polarity

- 0 to $5 \mathrm{kV}$ and 0 to $500 \mathrm{~V}$ simultaneous outputs

- 5-turn direct-reading control

- Front panel meter

- Recelves power from NIM bin supply

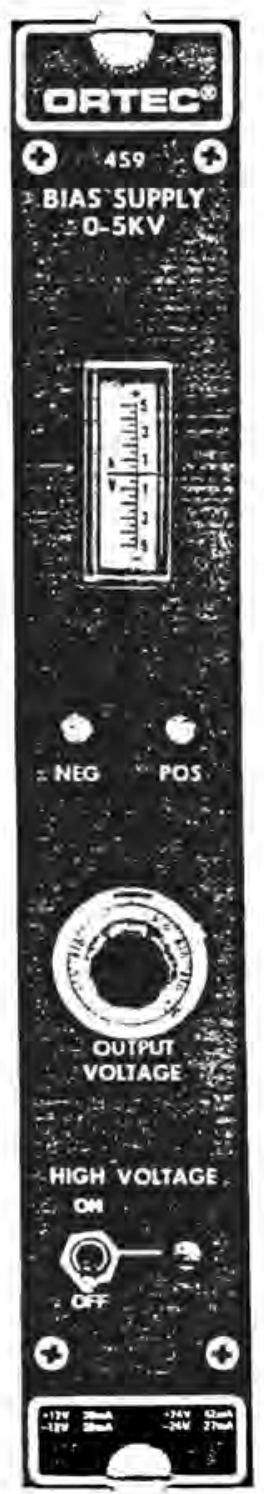




\section{2 counter}

- High speed, printing Counter

- Economical

- 6-decade LED display with leading zeros suppressed and positive display test

- $100 \mathrm{MHz}$ negative and $20 \mathrm{MHz}$ positive input counting capability

- Wide range positive input variable discriminator

- Negative input protected for $\pm 100 \mathrm{~V}$, positive input protected for $\pm 25 \mathrm{~V}$

- LED gate and overflow indicators

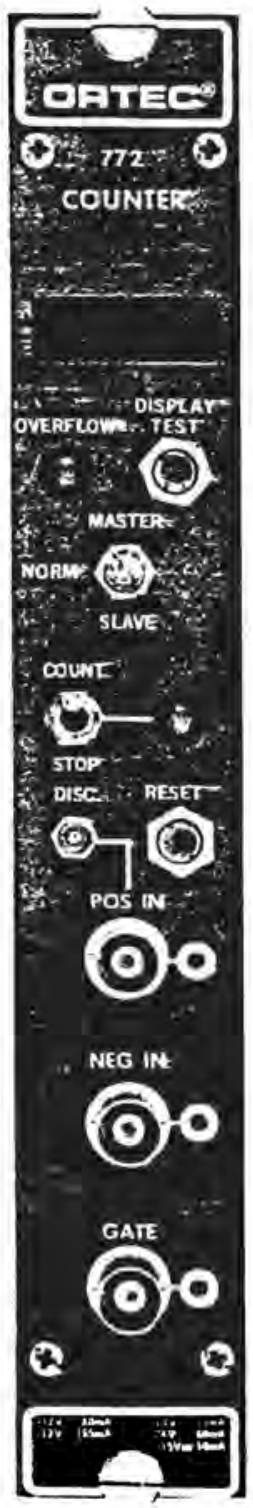

The EG\&G ORTEC 772 is a single NIM width, 6-decade, high-speed printing Counter that accepts both positive and negative NIM-standard input signals. The unit combines the utilization of integrated circuits with a light-emitting diode (LED) display for unprecedented operational reliability at an economical cost. The 6-decade LED display provides a highly legible count indicator that is further enhanced by the leading-zerosuppression circuitry. The LED display and leading-zero suppression features minimize the errors commonly made when the readout information is monitored or taken manually. Display test circuitry is included to increase operator confidence. Depression of the front panel Display Test switch illuminates all " 8 s," thereby verifying operation of all display segments.

The 772 accommodates inputs at rates up to 100 million counts/s $(100 \mathrm{MHz})$ at the negative input and 20 million counts/ s $(20 \mathrm{MHz})$ at the positive inputs. This ensures applicability to a wide range of operational requirements. The negative pulses need be only $4 \mathrm{~ns}$ wide, and the positive input pulses need only exceed the discriminator threshold level for 20 ns to be counted.

The positive input discriminator is variable from the front panel control within the $100 \mathrm{mV}$ to $10 \mathrm{~V}$ range. The wide $\mathrm{dy}$ namic range of this discriminator permits counting only signals of interest. with total freedom from extraneous noise or other unwanted pulses. The negative input discriminator is fixed at $-250 \mathrm{mV}$. The inputs are protected from any application of high level signals up to $\pm 100 \mathrm{~V}$ at the negative input and $\pm 25 \mathrm{~V}$ at the positive inputs. The 772 is totally compatible with all other EG\&G ORTEC printing modules.
An additional operational feature of the 772 is its LED Gate and Overtlow indicators. The Gate indicator is illuminated when counting is enabled either by an externally applied gate input or by the front panel Count/Stop switch. The Overflow indicator is illuminated by the first overflow of the sixth decade and remains illuminated until the counter is reset. A rear panel connector supplies a standard NIM positive logic output signal each time the counter overflows. This allows cascading of additional counters to expand the maximum count capacity of the counting system.

\section{Specifications}

\section{PERFORMANCE}

COUNT CAPACITY 6 decades, for 0 through 999,999.

MAXIMUM COUNTING RATES Negative input $100 \mathrm{MHz}$; positive input $20 \mathrm{MHz}$.

DISCRIMINATOR Negative input trigger level is fixed at $-250 \mathrm{mV}$ : positive input trigger level is adjustable over a range of $100 \mathrm{mV}$ to $10 \mathrm{~V}$. Orift is $<0.1 \mathrm{mV} /{ }^{\circ} \mathrm{C}$ from 0 to $50^{\circ} \mathrm{C}$ for both.

PULSE PAIR RESOLUTION Positive input $50 \mathrm{~ns}$; negative input $10 \mathrm{~ns}$; minimum duty cycle $40 \%$ at either input at maximum count rate. 


\section{2 (Continued)}

AUTOMATIC CLEAR Generated when power is turned on initially or after a power failure.

\section{INDICATORS}

DISPLAY 6 direct-reading 7-segment LED digits with leading zeros suppressed.

OVERFLOW LED, illuminated from first overflow until reset, either manually or remotely, through the printing system control lines.

GATE LED illuminated while unit is in the counting condition.

\section{CONTROLS}

DISPLAY TEST Pushbutton switch illuminates all 7 segments of each count display digit when depressed for a reading of 888,888 .

MASTER/NORMAL/SLAVE 3-position locking toggle switch selects the counter function when the module is connected in a data acquisition system:

Master Allows control over all slaves within the data acquisition system through the gate and reset lines.

Slave Subordinates this module to some other module in the system loop that is operating as a master.
Normal Isolates the gate and reset lines from the system lines even when connected in a printing system. This permits the counter to be used independently of the rest of the system. The unit will, however, print out when the total system prints out.

DISCRIMINATOR Sets positive input trigger level over the range of $100 \mathrm{mV}$ to $10 \mathrm{~V}$.

RESET Pushbutton switch resets the display and internal circuitry to proper initial conditions when depressed.

COUNT/STOP Toggle switch selects counting or noncounting condition of the module.

\section{CONNECTORS}

POSITIVE INPUT Front and rear panel BNC connectors accept positive unipolar or positive leading bipolar signals to $\pm 25 \mathrm{~V}$ maximum. Input amplitude must exceed the adjusted discriminator level for a minimum of 20 ns to be counted. $Z_{\text {in }}=1 \mathrm{k} \Omega$ to ground, $d c$ coupled.

NEGATIVE INPUT front panel BNC connector accepts NIM-standard fast negative signals, $14 \mathrm{~mA}$ into $Z_{\text {in }}$ of $50 \mathrm{~s}$, with $4 \mathrm{~ns}$ minimum width at $40 \%$ duty cycle. Fixed input discriminator level at $-250 \mathrm{mV}$. Input protected to $\pm 100 \mathrm{~V}$.

GATE Front and rear panel BNC connectors accept NIM-standard positive logic signals to control the counter gate and the gate indicator. An open circuit or application of signal $\geqslant+3 \vee$ in amplitude enables counting: a signal $\leqslant+1.5 \mathrm{~V}$ in amplitude inhibits counting: input protected for $25 \mathrm{~V}$ maximum; driving source must be capable of sinking $0.5 \mathrm{~mA}$ of positive current.

RESET Rear panel BNC connector accepts standard positive logic signal to reset the unit to initial zero condition. A signal $\geqslant+3 \mathrm{~V}$ causes reset; $\leqslant+1.5 \vee$ does not reset; input protected for $\pm 25 \mathrm{~V}$ maximum; minimum pulse width $100 \mathrm{~ns}$. $Z_{\text {in }}=2 \mathrm{k} \Omega$ to ground, dccoupled.

OVERFLOW Rear panel BNC connector furnishes standard positive logic output, $+5 \mathrm{~V}$ for $2 \mu \mathrm{s}$ when the counter overflows from 999,999 to 0 . Driving source impedance $\leqslant 10 \Omega$ to ground, dc-coupled.

IN/OUT Rear panel Amphenol 57-40140 connector includes four common data lines and all system logic for the standard EG\&G ORTEC printing and/or counting system interconnections through a fan-out adapter.

\section{ELECTRICAL AND MECHANICAL}

POWER REQUIRED + $12 \mathrm{~V}, 155 \mathrm{~mA} ;-12 \mathrm{~V}$. $265 \mathrm{~mA} ;+24 \mathrm{~V}, 0 \mathrm{~mA} ;-24 \mathrm{~V}, 80 \mathrm{~mA} ; 117 \mathrm{Vac}$, $50 \mathrm{~mA}, 47-63 \mathrm{~Hz}$

WEIGHT

Net $1.3 \mathrm{~kg}(3.0 \mathrm{lb})$

Shipping $2.25 \mathrm{~kg}(5.0 \mathrm{lb})$.

DIMENSIONS NIM-standard single-width module $3.43 \times 22.13 \mathrm{~cm}(1.35 \times 8.714 \mathrm{in}$.) per TID-20893 (Rev).

ACCESSORIES INCLUDED Printing system control cable for use in a standard EG \&G ORTEC printing loop and an adapter from a single 57-40140 connector to two 57-40140 connectors, In and Out.

RELATED EQUIPMENT in a standard EG\&G ORTEC data acquisition system one or more 772 Counters may be interconnected with other EG\&G ORTEC printing counters, timers, digital ratemeters, etc., with output to other peripherals through an EG\&G ORTEC 779 Interface Controller or directly to an EG\&G ORTEC 777A Line Printer.
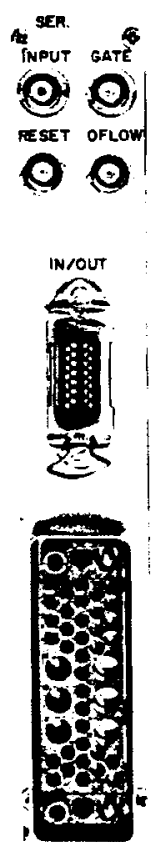


\section{Timer-counter}

- Presettable printing counter or timer

- $1 \mathrm{MHz}$ crystal oscillator time base

- Timing intervals from $0.1 \mathrm{~s}$ to $900,000 \mathrm{~min}$

- $20 \mathrm{MHz}$ positive input counting capability

- 6-decade LED time or count display with leading zeros suppressed and positive display test

- LED gate and overflow indicators

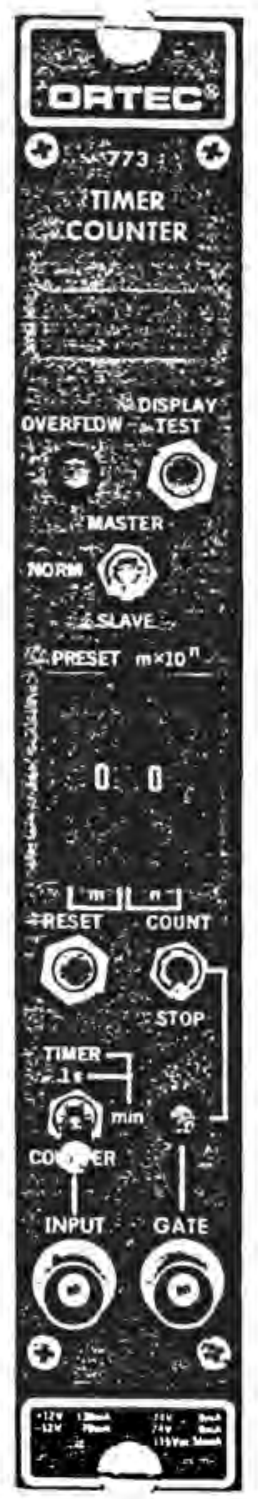

The EG\&G ORTEC 773 Timer-Counter is a single, NIM-width unit that can be used as a presettable printing counter or alternately as a highly accurate timer. The unit combines the utilization of integrated circuits with a light-emitting diode (LED) display for unprecedented operational reliability at a very economical cost. A $1 \mathrm{MHz}$ crystal oscillator is the standard time base in the unit, thereby resulting in substantially improved timing accuracy compared with that of a timer using a line frequency time base. Two thumbwheel switches allow either a preset count or time in an $m \times 10^{n}$ format. A 3-position Timer-Counter switch selects unit operation as either a timer or a counter and also selects the time base of either $0.1 \mathrm{~s}$ or $1.0 \mathrm{~min}$. Timing intervals from $0.1 \mathrm{~s}$ to $900.000 \mathrm{~min}$ are thus available. In the counter mode of operation the 773 accepts up to 20 million positive pulses/s $(20 \mathrm{MHz})$ at its front or rear panel Input connectors. The unit does not accept negative input signals.

The 6-decade 7-segment LED display provides an easily read time or count monitor which is further enhanced by the leading-zero-suppression circuitry. The LED display and leading-zero-suppression features minimize the errors commonly made when the readout information is monitored visually or taken manually. Positive display test circuitry is included to increase operator confidence. Depression of the front panel Display Test switch illuminates all "8s," thereby actively testing all segments of the display.

Single LED devices are also utilized as indicators for count enable and overflow. The Gate indicator is illuminated at all times when the module is in a counting (or timing) condition, which is determined by the input at the Gate connectors, or by the Count/Stop switch.
The Overflow indicator is illuminated by the 1st overflowing count from the 6th decade. In this case the front panel Preset switch must be disabled by setting $m=0$. When the preset circuitry is enabled, the unit functions as a preset counter (or timer) and no overflows can occur. Each time the counter overflows, a carry pulse is generated and is available at the rear panel Overflow connector. which allows several units to be cascaded to expand the maximum count capacity.

The 773 may be incorporated in a complete data acquisition system with other EG\&G ORTEC printing modules as it is compatible with all existing units. It can be selected as a Master or Slave in the system, or may be isolated from system control by selection of the Normal position on the front panel switch.

\section{Specifications}

\section{PERFORMANCE}

NOTE: This unit can be used as a Timer or Counter but not as both simultaneously.

COUNT CAPACITY 6 decades for 0 through 999.999.

TIME BASE $0.1 \mathrm{~s}$ or 1.0 min counting increments; time base is derived from $1 \mathrm{MHz}$ crystal controlled oscillator.

COUNTING RATE (Counter Mode) $20 \mathrm{MHz}$. TIME BASE INACCURACY Within $< \pm 0.0005 \%$. 
TIME BASE INSTABILITY

Within $\angle \pm 0.0001 \% /{ }^{\circ} \mathrm{C}$.

PULSE PAIR RESOLUTION (Counter Mode) Minimum 50 ns with minimum $50 \%$ duty cycle at $20 \mathrm{MHz}$ maximum count rate.

SYNCHRONIZING ERROR $<0.2 \mu \mathrm{s}$.

AUTOMATIC CLEAR Generated when power is turned on initially or after a power failure.

\section{INDICATORS}

READOUT DISPLAY 6-decade direct-reading, 7-segment LED digits and a decimal point with leading zeros suppressed.

OVERFLOW LED illuminates from 1st overflow until reset.

GATE LED illuminates while unit is in the counting (or timing) condition.

\section{CONTROLS}

DISPLAY TEST Pushbutton switch illuminates all 7 segments of each digit in the display when depressed for a reading of 888,888 .

MASTER/SLAVE/NORMAL 3-position locking toggle switch selects the timer-counter function when the module is connected in a data acquisition system:

Master Allows control over all slaves within the data acquisition system through the gate and reset lines.

Slave Subordinates this module to some other module in the data acquisition system that is operating as a Master.

Normal Isolates the gate and reset lines from the system lines even when connected in a printing system. This permits the unit to be used independently of the rest of the system. The unit will, however, print out when the system prints out.
PRESET 2 thumbwheel switches select a count (or time) level within the capacity of the module with an $\mathrm{m} \times 10^{n}$ format as a preset level. Setting $m=0$ disables the preset signal generation circuitry.

RESET Pushbutton switch resets the display and internal circuitry to the initial condition when depressed.

COUNTER/TIMER 3-position locking toggle switch selects the source of the puises to be counted:

Counter Selects the input pulses applied through the adjacent or rear panel input connector.

$.1 \mathrm{~s}$ Selects the timer pulses furnished by the internal timing system at $0.1 \mathrm{~s}$ intervals. min Selects the internal timer pulses that are furnished at $1.0 \mathrm{~min}$ intervals.

COUNT/STOP Toggle switch selects counting (timing) or noncounting (timing off) condition of the module.

\section{CONNECTORS}

INPUT Front and rear panel BNC connectors accept NIM-standard slow positive logic signals, $\geqslant 3 \vee$ to count or $\leqslant 1.5 \mathrm{~V}$ to not count: $\pm 25 \mathrm{~V}$ maximum, $\geqslant 25 \mathrm{~ns}$ width. $Z_{\text {in }}=2 \mathrm{k} \Omega$ to ground, dc-coupled.

GATE Front and rear panel BNC connectors accept NIM-standard slow positive logic signais to control the counting register input gate and the associated indicator. An open circuit, or application of a signal of $\geqslant 3 \mathrm{~V} \mathrm{am}$ plitude, enables counting (or timing); a signal of $\leqslant 1.5 \mathrm{~V}$ amplitude inhibits counting: input is protected for a maximum of $\pm 25 \mathrm{~V}$; driving source must be capable of sinking $0.5 \mathrm{~mA}$ of positive current.

INTERVAL Rear panel BNC connector furhishes a $+5 \mathrm{~V}$ output level when the 773 is in a counting condition. Nominally $0 \mathrm{~V}$ for noncounting (timing off).

RESET Rear panel BNC connector accepts standard positive logic signal to reset the unit to an initial zero condition. A signal $\geqslant 3 \mathrm{~V}$ causes reset; $\leqslant 1.5 \mathrm{~V}$ does not reset; input is protected for $25 \mathrm{~V}$ maximum; minimum pulse width $=100 \mathrm{~ns} . Z_{\text {in }}=2 \mathrm{k} \Omega$ to ground, dccoupled.
OVERFLOW Rear panel BNC connector furnishes standard positive logic output, $-5 \mathrm{~V}$ for $2 \mu \mathrm{s}$, when the counter overflows from 999,999 to 0 . Driving source impedance $\leqslant 10 \Omega$ to ground, dc-coupled.

IN/OUT Rear panel Amphenol 57-40140 connector includes 4 common data lines and all system logic for the standard EG\&G ORTEC printing and/or counting system interconnections through an adapter.

\section{ELECTRICAL AND MECHANICAL}

POWER REQUIRED $+12 \mathrm{~V}, 130 \mathrm{~mA}:-12 \mathrm{~V}$. $70 \mathrm{~mA}: 117 \mathrm{~V}$ ac. $55 \mathrm{~mA}, 50-60 \mathrm{~Hz}$.

\section{WEIGHT}

Net $1.3 \mathrm{~kg}(3.0 \mathrm{lb})$.

Shipping $2.25 \mathrm{~kg}(5.0 \mathrm{lb})$

DIMENSIONS NIM-standard single-width module $3.43 \times 22.13 \mathrm{~cm}(1.35 \times 8.714 \mathrm{in}$. $)$ per TID-20893 (Rev).

ACCESSORIES INCLUDED Printing system control cable for use in a standard EG\&G ORTEC printing loop and an adapter from a single 57-40140 connector to two 57-40140 connectors, in and Out.

RELATED EOUIPMENT In a standard EG\&G ORTEC data acquisition system one or more 773 Timer-Counters may be interconnected with other EG\&G ORTEC printing counters, timers, digital ratemeters, etc., with output to other peripherals through an EG\&G ORTEC 779 Interface Controller or directlv to a 777 A Line Printer.

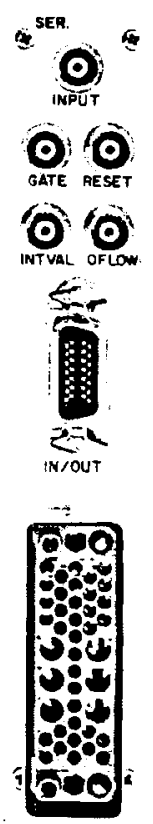




\section{9 controler/lntertace}

- Printing controller for up to $\mathbf{5 0}$ printing counters or timers

- Data transfer to RS-232-C or 20 mA current loop communications links

- Control information transfer from peripherals to scaler loop

- LSI integrated circuitry including microprocessor

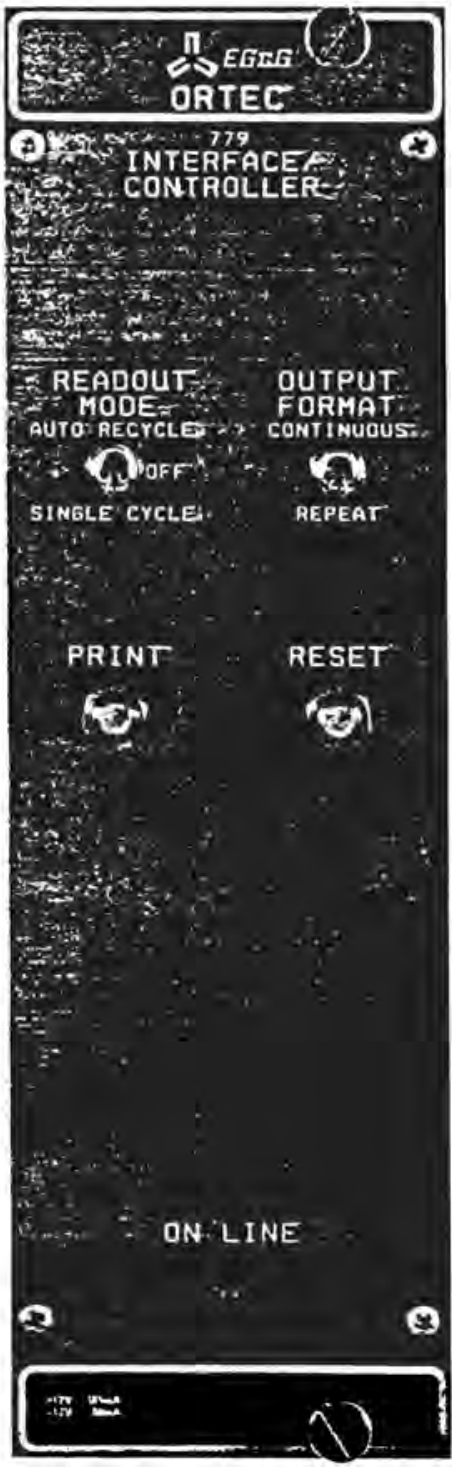

The EG\&G ORTEC 779 Controller/Interface interconnects EG\&G ORTEC NIM printing scaler or timer modules to computers, printers, recorders, and calculators over short or long distances. It is designed as part of a standard EG\&G ORTEC printing system and is connected into the system loop. Interfacing and software are simplified by the use of two accepted communications interface standards and ASCII-coded data.

The 779 controls the readout of data from up to 50 printing modules with digital outputs that match the EG\&G ORTEC printing scaler loop standards, transfers the digital information to one of two communications links, RS-232-C or $20 \mathrm{~mA}$ current loop, and transfers control information from the communications links to the scaler loop.

The 779 is very useful in laboratory areas using small computers and calculators as well as in environmental monitoring. surveillance, waste management, and fuel processing facilities where nuclear data in very diverse areas must be measured and transferred to a centralized computer.

The 779 is contained in a standard NIM double-width module for operation in an EG\&G ORTEC Bin and Power Supply or equivalent. Its power requirements are derived from the bin power supply. The 779 is composed mostly of LSI integrated circuitry including a microprocessor and support chips. The firmware to control the printing loop logic and to output the data is contained in an ultraviolet erasable read-only memory (ROM) chip.
Printing cycles can be initiated either automatically or manually. The cycle is initiated automatically by a signal through the system preset line; this signal can originate in any module capable of being preset and will affect all modules in the system simultaneously. The cycle can originate manually at the 779 either when the Print switch is pressed or when a signal is furnished through a connector on the rear panel. The signal is extended to the printing system through the system preset line to stop counting in all modules.

After all the data have been fed to the readout device, the 779 provides a selectable system cycle mode control to stop or recycle the function of data accumulation.

The 779 allows the user to provide some commands to the printer loop from the terminal such as generation of a system gate, system preset, and system reset. This will allow the user to start counting or stop counting, reset the system, and generate a readout as desired.
EG\&G ORTEC PRINTING SYSTEM MODULES

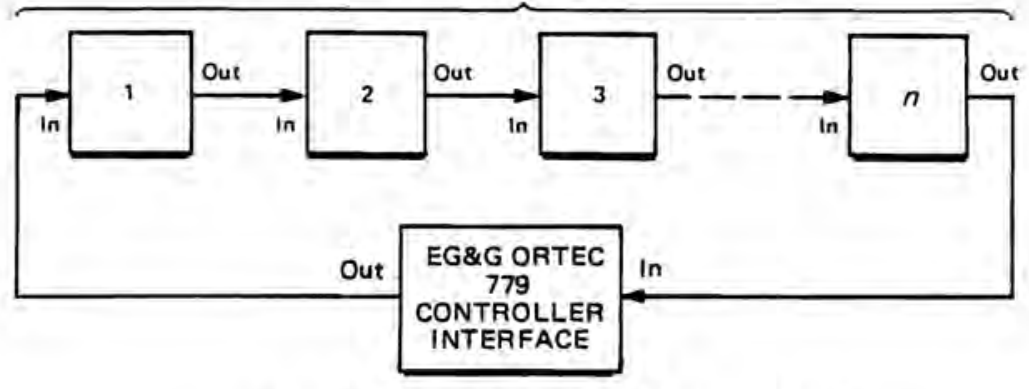

Serial Printing System Loop Interconnections. 


\section{Specifications}

\section{PERFORMANCE}

SCALER CAPACITY From one to 50 standard EG\&G ORTEC printing modules can be connected into a single printing data acquisition system and can be arranged in any combination within the system loop.

BAUD RATE Adjustable in 14 most-oftenused steps from 50 to $19.2 \mathrm{k}$ Baud from a single crystal-controlled bit rate generator.

OPERATING TEMPERATURE RANGE 273 to $323 \mathrm{~K}\left(0\right.$ to $\left.50^{\circ} \mathrm{C}\right)$.

AUTOMATIC CLEAR Generated when power is turned on to initialize the internal circuitry.

CONTROL FUNCTIONS AcceptS ASCI control codes from output device to generate System Preset. System Gate, and System Reset signals.

\section{CONTROLS}

READOUT MODE 3-position toggle switch selects the system control at the end of a data transfer cycle.

Auto Recycle Provides an automatic reset to the control circuit and to all the modules in the system so that a new counting interval is initialized.
Single Cycle Does not generate the automatic reset, and the system remains static after the printout cycle is complete until a reset signal is furnished on the system reset line by a master module in the system or by a reset signal through the 779 . The 779 includes both manual reset by a switch on the front panel and a BNC connector to accept an external reset signal.

Off When the switch is set at its center position, the data transfer function is disabled.

OUTPUT FORMAT 2-position toggleswitch selects either of 2 basic formats for a Teletype Page Printer or equivalent output device.

Continuous Carriage return and line feed are generated only after a full line has been printed, regardless of the total number of data words available from the system.

Repeat Carriage return and line feed are generated at the end of each full line and also after the last data word that has been printed. so that each new set of data starts at the left margin of the printed page.

PRINT Pushbutton switch initiates a data transfer cycle manually if the Readout Mode switch is set at either Single Cycle or Auto Recycle.

RESET Pushbutton switch resets the internal logic and generates a system reset to all modules in the system.

\section{CONNECTORS}

EXT READOUT INPUT Rear panel BNC connector accepts NIM slow positive logic signal to initiate a printout when Readout Mode switch is at either Single Cycle or Auto Recycle.

AUTO RECYCLE DELAY IN Reat panel BNC connector accepts $+5 \mathrm{~V}$ level to inhibit recycle; removing the $+5 \mathrm{~V}$ level for a period of $20 \mu \mathrm{s}$ or longer causes system reset and starts a new counting cycle. Active only when Readout Mode switch is set at Auto Recycle. RESET INPUT Rear panel BNC connector accepts a positive-going $10 \mu \mathrm{s}$ signal that will generate a system reset.
BUSY OUT Rear panel BNC connector provides $a+5 \vee$ level while printing and $0 \vee$ when not printing.

RESET OUT Rear panel BNC connector provides a NIM standard positive logic pulse at the end of a printing cycle.

IN Amphenol 57-40140 connector accepts all data and logic signals from the modules of an EG\&G ORTEC printing data acquisition system.

OUT Amphenol 57-40140 connector provides all logic signals out to the EG\&G ORTEC printing data acquisition system.

RS-232-C Rear panel 25-pin connector that contains all signals for an ElA standard RS232-C communication interface.

20 mA LOOP Rear panel 7-pin connector that contains all signals for communicating with devices that use a $20 \mathrm{~mA}$ data loop; may be either active or passive.

\section{ELECTRICAL AND MECHANICAL}

POWER REQUIRED $+12 \mathrm{~V}, 385 \mathrm{~mA} ;-12 \mathrm{~V}$. $80 \mathrm{~mA}$.

WEIGHT

Net $1.36 \mathrm{~kg}(3 \mathrm{ib})$

Shipping $2.72 \mathrm{~kg}(6 \mathrm{lb})$.

DIMENSIONS NIM-standard double-width module $6.90 \times 22.13 \mathrm{~cm}(2.70 \times 8.714 \mathrm{in}$. $)$ front panel per TID-20893 (Rev)

ACCESSORY ONE EG\&G ORTEC 432-C1 printing system loop cable is furnished. Mating connector to the $20 \mathrm{~mA}$ output and the RS-232-C output is supplied.

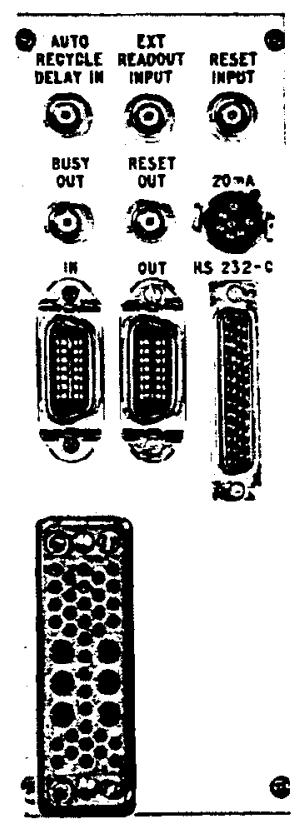




\section{$4001 / 4002 / 402$ Power Supplies}

- Exceeds recommended specifications

- Adjustment-free bin construction

- Low-impedance power distribution

- Use with $100,120,220$, or $240 \mathrm{~V}$ ac power main

- Choice of power supplies

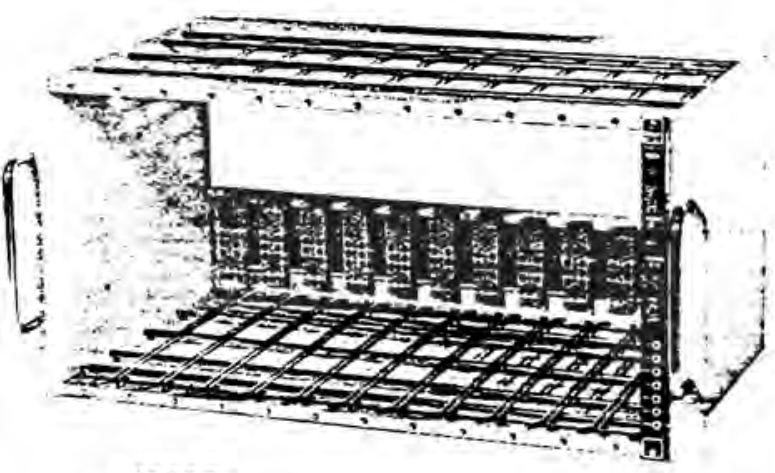

4001C

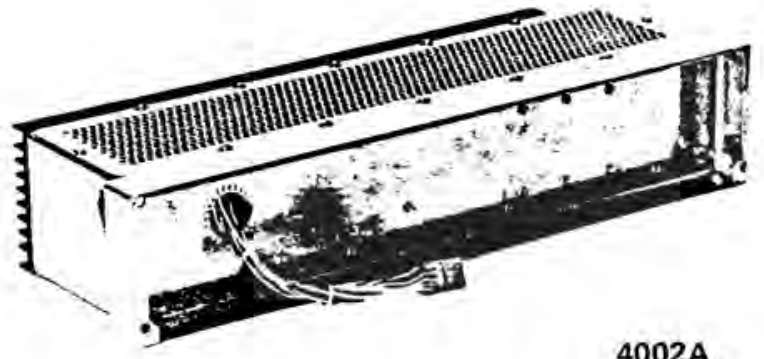

4002A

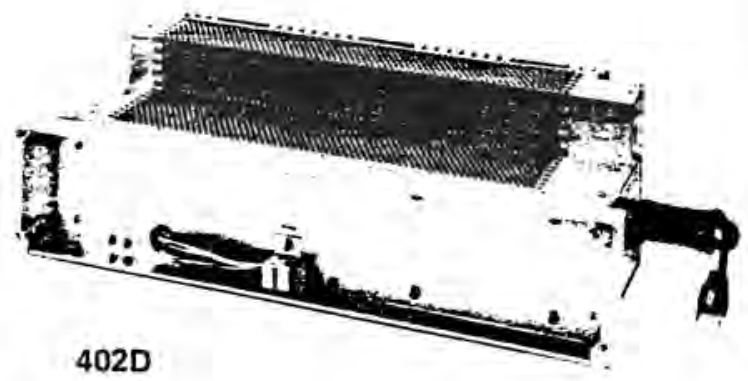

EG\&G ORTEC offers a standard NIM bin and a choice of power supplies to accommodate any equipment modules that have been manufactured to NIM standards as defined in TID-20893 (Rev).

The EG\&G ORTEC $4001 \mathrm{C}$ Bin is constructed of wire-form grids to ensure unimpeded ventilation for the instruments that are operated in the bin. The adjustment-free module guides are superior to the requirements specified in TID-20893 (Rev 4). These hardened steel guides feature generous openings, and because of their highly-polished nickel plating, offer a low friction coefficient. Aluminum alloy side plates are precision-formed and protected with a painted finish. Either the $4002 \mathrm{~A}$ or $402 \mathrm{D}$ power supply may be attached to the precision-stamped plated-steel connector mounting plate.

The EG\&G ORTEC $4001 \mathrm{C}$ Bin distributes all dc and ac power from the power supply to the module connectors. Very low impedance levels are provided by the use of heavy-duty copper bus bars, wire, and printed wiring board (PWB), ensuring a uniform voltage output to even high-power modules. Also available by special order is a wired-bus bin which enables the user to adapt the standard wiring to meet special needs.

Either the $4002 \mathrm{~A}$ or $402 \mathrm{D}$ power supply can be mated to the $4001 \mathrm{C}$ bin for a complete rack-mountable assembly or housed in an optional EG\&G ORTEC 909A Bin Cover for table-top use.

The EG\&G ORTEC 4002A Power Supply complies with specifications for Type 1, Class A power supplies as defined in TID20893 (Rev 4), Appendix A. The input voltage can be 100, 120, 220 , or $240 \mathrm{~V} \mathrm{ac}$, and an internationally-approved primary circuit connector allows the use of many types of power plugs. The dcoutput power levels that are furnished to the mating bin are +12 and $-12 \mathrm{~V}$ at up to $2 \mathrm{~A}$ each and +24 and $-24 \mathrm{~V}$ at up to $1 \mathrm{~A}$ each. The maximum output power is $96 \mathrm{~W}$ at $+50^{\circ} \mathrm{C}$ ambient temperature. A $117-\mathrm{V}$ ac power output is also distributed to the bin. Each dc-output voltage is adjustable over $a \pm 1 \mathrm{~V}$ range from its nominal rating. The outputs are short-circuit protected by current-foldback limiting.

The EG\&G ORTEC 402D Power Supply is designed to exceed recommended power supply specifications for Type $\mathrm{V}-\mathrm{H}$ supplies as defined in TID-20893 (Rev 4), Appendix A. The input power can be either 117 or $230 \mathrm{~V}$, furnished through fused input circuits and a 3-conductor NEMA-standard power cord that is included. The dcoutput power levels furnished to the mating bin are +6 and $-6 \mathrm{~V}$ at up to $8 \mathrm{~A}$ each, +12 and $-12 \mathrm{~V}$ at up to $2 \mathrm{~A}$ each, and +24 and $-24 \mathrm{~V}$ at up to $1 \mathrm{~A}$ each, with a combined maximum rating of $132 \mathrm{~W}$ at $50^{\circ} \mathrm{C}$. Each dc-output voltage is adjustable over $\mathrm{a} \pm 2 \%$ range from its nominal rating by a 20 -turn precision potentiometer. The outputs are regulated, short-circuit protected, current limited, and thermal protected. 


\section{HV Bias/NIM Power Supplies and Bins}

\section{Specifications}

\section{BIN SPECIFICATIONS}

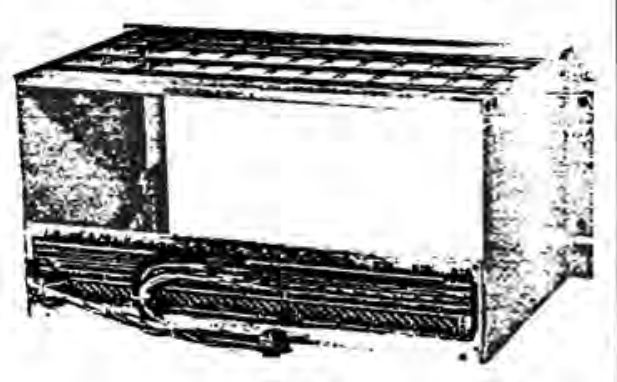

$4001 C$ BIN
MODULE CONNECTORS 12 each as specified by TID-20893 (Rev).

INSTALLED WIRING All connectors wired in parallel for $+12 \mathrm{~V},-12 \mathrm{~V},+24 \mathrm{~V},-24 \mathrm{~V},+6 \mathrm{~V}$. $-6 \mathrm{~V}$. high-quality ground. power-return ground, and $117 \mathrm{~V}$ ac, in accordance with TID-20893 (Rev) pin assignments. An interface connector is supplied as required by TID-20893 (Rev) for connecting control and power supply, Meets specifications for laminated busses as outlíned in TID-20893 (Rev 4) under Section F.F2., "Bussing."

CONTROL PANEL A control panel with On-Off switch, power-indicating lamp, and thermal warning lamp provided for mating power supply. The thermal warning lamp is illuminated when the operating temperature approaches the design limit. Voltage test points are provided for convenient monitoring of the power supply outputs.

CONSTRUCTION Aluminum alloy side plates with nickel-chromium-plated handles on front panel mounting flanges. Top and bottom members are high-tensile steel rod weldments, nickel plated, containing module guides. Rear connector plate is steel, cadmium plated.

\section{POWER SUPPLY SPECIFICATIONS}

\section{A POWER SUPPLY}

INPUT $88-110,103-129,191-239$, or 206$258 \mathrm{~V}$ ac, $47-63 \mathrm{~Hz}$. At nominal input voltages efficiency is typically $44 \%$.

DC OUTPUT $+12 \mathrm{~V}$ at $2 \mathrm{~A}_{1}-12 \mathrm{~V}$ at $2 \mathrm{~A},+24$ $V$ at $1 \mathrm{~A},-24 \mathrm{~V}$ at $1 \mathrm{~A}$, combined maximum output power $96 \mathrm{~W}$ at $+50^{\circ} \mathrm{C}$; derates to $72 \mathrm{~W}$ at $+60^{\circ} \mathrm{C}$.

117-V AC OUTPUT Limited only by supply fuses when operating on $117-\mathrm{V}$ ac mains; limited to 50 VA when dc load is 96 VA when operating on $230-\mathrm{V}$ ac mains.
REGULATION $< \pm 0.05 \%$ over combined range of zero to full load and input voltage of $88 \%$ to $110 \%$ of rated input over any $24-\mathrm{hr}$ period at constant ambient temperature after a 60-min warmup.

INSTABILITY $< \pm 0.3 \%$ over a 6 -month period at constant line, load, and ambient temperature after a 24-hr warmup.

OUTPUT IMPEDANCE $<0.3 \Omega$ at any frequency up to $100 \mathrm{kHz}$.

TEMPERATURE COEFFICIENT $<0.01 \%$ / ${ }^{\circ} \mathrm{C}$ from 0 to $60^{\circ} \mathrm{C}$.

NOISE AND RIPPLE $<3 \mathrm{mV}$ peak-to-peak, as observed on $50-\mathrm{MHz}$ bandwidth oscilloscope.

VOLTAGE ADJUSTMENT $\pm 0.5 \%$ minimum range, resettability $\pm 0.05 \%$ of supply voltage (typical $\pm 1 \mathrm{~V}$ ).

RECOVERY TIME $<50 \mu$ s to return to within $\pm 0.1 \%$ of rated voltage for any change in rated input voltage and load current from $10 \%$ to $100 \%$ full load.

CIRCUIT PROTECTION. Input power line fused; Power Supply is automatically cut off by an internal switch if the temperature exceeds a maximum safe limit; also electronic output current foldback limiting with automatic recovery when demand is removed.

\section{D POWER SUPPLY}

INPUT $100-129 \mathrm{~V}$ ac, $57-63 \mathrm{~Hz}$, or 200$258 \mathrm{~V}$ ac, $47-53 \mathrm{~Hz}$. Input current at $117 \mathrm{~V} \mathrm{ac}$ is $3.5 \mathrm{~A}$ for a $132-\mathrm{W}$ dc output.

DC OUTPUTS +6V, $8 A_{;}-6 \mathrm{~V}, 8 A_{;}+12 \mathrm{~V}$, $2 \mathrm{~A} ;-12 \mathrm{~V}, 2 \mathrm{~A} ;+24 \mathrm{~V}, 1 \mathrm{~A} ;-24 \mathrm{~V}, 1 \mathrm{~A} ;$ max output power, 0 to $50^{\circ} \mathrm{C}$ ambient, $132 \mathrm{~W}$; derates $\leqslant 3 \% /{ }^{\circ} \mathrm{C}$ from 50 to $60^{\circ} \mathrm{C}$.
117-V AC OUTPUT Limited only by supply fuses when operating on $117-\mathrm{V}$ ac mains: limited to 50 VA when dc load is $132 \mathrm{~W}$ when operating on $230-\mathrm{V}$ ac mains.

REGULATION $\pm 0.1 \%$ (typically $\pm 0.05 \%$ ) for \pm 12 and $\pm 24 V$, and $\pm 0.2 \%$ (typically $\pm 0.1 \%$ ) for, $\pm 6 \mathrm{~V}$, over the combined range of zero to full load with specified input range for measurements made within 1 -min period; $\pm 0.3 \%$ for \pm 12 and $\pm 24 \mathrm{~V}$, and $\pm 0.6 \%$ for $\pm 6 \mathrm{~V}$, over any $24-\mathrm{hr}$ period at constant ambient temperature for same load and input ranges after a 60 -min warmup.

INSTABILITY $< \pm 0.5 \%$ after a 60 -min warmup over a 6-month period at constant load. line, and ambient temperature.

OUTPUT IMPEDANCE $<0.15 \Omega$ for $\pm 6 \mathrm{~V}$ and $<0.3 \Omega$ for all others at any frequency up to $100 \mathrm{kHz}$.

TEMPERATURE COEFFICIENT $<0.02 \%$ / ${ }^{\circ} \mathrm{C}, 0$ to $60^{\circ} \mathrm{C}$.

NOISE AND RIPPLE $<3 \mathrm{mV}$ peak-to-peak for any output as observed on $50-\mathrm{MHz}$ bandwidth oscilloscope.

VOLTAGE ADJUSTMENTS $\pm 2 \%$ min. range; resettability $\pm 0.05 \%$ of supply voltage.

RECOVERY TIME $<100 \mu$ s to return to within $\pm 0.1 \%$ of rated voltage for all 6 outputs for any change in rated input voltage and load current from $10 \%$ to $100 \%$ of full load.

CIRCUIT PROTECTION Both input power lines fused: Power Supply is automatically cut off by an internal switch if the temperature exceeds a maximum safe limit; also electronic output current foldback limiting with automatic recovery when demand is removed; over-voltage protection for $\pm 6 \mathrm{~V}$ prevents these outputs from exceeding $\pm 7.5 \mathrm{~V}$ $\max$.

ORDERING INFORMATION

\begin{tabular}{l|ccc|c|c|c}
\hline \multirow{4}{*}{$4001 \mathrm{C}$} & \multicolumn{3}{|c|}{ Dimensions (in.) } & \multicolumn{2}{c}{ Weight (approx.) } \\
\cline { 2 - 7 } & $\mathrm{H}$ & $\mathrm{W}$ & $\mathrm{D}$ & \multicolumn{2}{c}{ Shipping } & Net \\
\cline { 2 - 7 } & $8-3 / 4$ & 19 & $10-3 / 4$ & $18 \mathrm{lb}$ & $11 \mathrm{lb}$ \\
& & & & $8.2 \mathrm{~kg}$ & $5.0 \mathrm{~kg}$ \\
4002A Power Supply & $3-3 / 8$ & $16-7 / 8$ & $5-1 / 2$ & $22 \mathrm{lb}$ & $15 \mathrm{lb}$ \\
$\pm 12 \mathrm{~V}, \pm 24 \mathrm{~V}$ & & & & $10.0 \mathrm{~kg}$ & $6.8 \mathrm{~kg}$ \\
4020 Power Supply & 5 & $16-7 / 8$ & $7-1 / 2$ & $29 \mathrm{lb}$ & $22 \mathrm{lb}$ \\
$\pm 6 \mathrm{~V}, \pm 12 \mathrm{~V}, \pm 24 \mathrm{~V}$ & & & & $13.2 \mathrm{~kg}$ & $10.0 \mathrm{~kg}$ \\
4001C/4002A & $8-3 / 4$ & 19 & 16 & $34 \mathrm{lb}$ & $26 \mathrm{lb}$ \\
(assembled) & & & & $15.9 \mathrm{~kg}$ & $11.8 \mathrm{~kg}$ \\
4001C/402D & $8-3 / 4$ & 19 & 18 & $41 \mathrm{lb}$ & $33 \mathrm{lb}$ \\
(assembled) & & & & $18.6 \mathrm{~kg}$ & $15.0 \mathrm{~kg}$ \\
909A Bin Cover & $9-3 / 4$ & $19-1 / 2$ & $21-5 / 8$ & $29 \mathrm{lb}$ & $21 \mathrm{lb}$ \\
& & & & $13.2 \mathrm{~kg}$ & $9.5 \mathrm{~kg}$ \\
\hline
\end{tabular}


APPENDI X B 
BACKGROUND DATA

SPATIAL MODE - NO LEAD

\begin{tabular}{|c|c|c|c|c|c|c|c|c|c|c|}
\hline \multirow[b]{2}{*}{ DATE } & \multirow{2}{*}{$\begin{array}{c}\text { COUNT } \\
\text { TINE } \\
\end{array}$} & \multicolumn{2}{|c|}{ WEST } & \multicolumn{2}{|c|}{ NORTH } & \multicolumn{2}{|c|}{ EAST } & \multicolumn{2}{|c|}{ SOUTH } & \multirow[b]{2}{*}{ TOTAL } \\
\hline & & INNER & OUTER & INNER & OUTER & INNER & OUTER & INNER & OUTER & \\
\hline $12 / 2 / 83$ & $13 \mathrm{~min}$. & 6,968 & 8,554 & 6,678 & 8,597 & 10,407 & 11,537 & 7,667 & 8,362 & 68,770 \\
\hline
\end{tabular}




\section{CALIBRATION DATA}

SPATIAL MODE - NO LEAD

\begin{tabular}{|c|c|c|c|c|c|c|c|c|c|c|c|}
\hline \multirow[b]{2}{*}{ DATE } & \multirow{2}{*}{$\begin{array}{l}\text { COUNT } \\
\text { TIME }\end{array}$} & \multirow{2}{*}{$\begin{array}{l}\text { CAL IBRATION } \\
\text { STANDARD } \\
\end{array}$} & \multicolumn{2}{|c|}{ WEST } & \multicolumn{2}{|c|}{ NORTH } & \multicolumn{2}{|c|}{ EAST } & \multicolumn{2}{|c|}{ SOUTH } & \multirow[b]{2}{*}{ TOTAL } \\
\hline & & & INNER & OUTER & INNER & OUTER & INNER & OUTER & INNER & OUTER & \\
\hline $11 / 3 / 83$ & $10 \mathrm{~min}$. & $244 \mathrm{Cm}$ Drum & & & & & & & & & 57,002 \\
\hline $12 / 2 / 83$ & $1 \mathrm{~min}$. & $78.1 \mathrm{mCi} 244 \mathrm{~cm}$ & 19,830 & 15,619 & 19,221 & 15,267 & 22,080 & 15,008 & 21,947 & 14,713 & 143,685 \\
\hline $12 / 2 / 83$ & $1 \mathrm{~min}$. & $\mathrm{PuO}_{2-\mathrm{B}}$ & 21,043 & 16,549 & 20,333 & 16,595 & 23,046 & 16,317 & 22,911 & 15,935 & 152,729 \\
\hline
\end{tabular}




\section{BACKGROUND DATA}

\section{COINCIDENCE MODE - W/LEAD SHIELD}

\begin{tabular}{|c|c|c|c|c|c|c|c|c|c|c|c|c|c|}
\hline & COIN. & COUNT & \multicolumn{10}{|c|}{ SCALER NUMBER } & \multirow[b]{2}{*}{ TOTAL } \\
\hline DATE & TIME & TIME & 1 & 2 & 3 & 4 & 5 & 6 & 7 & 8 & 9 & 10 & \\
\hline $12 / 5 / 83$ & 101 us & $10 \mathrm{~min}$. & 81,922 & 14,157 & 5,558 & 2,387 & 1,442 & 672 & 375 & 227 & 138 & 190 & 107,068 \\
\hline$"$ & 210 us & $"$ & 76,931 & 15,494 & 7,004 & 3,654 & 2,347 & 1,261 & 725 & 486 & 346 & 998 & 109,246 \\
\hline$"$ & 295 us & $"$ & 73,502 & 16,033 & 7,433 & 3,922 & 2,595 & 1,417 & 857 & 600 & 440 & 1,406 & 108,204 \\
\hline
\end{tabular}




\section{CALIBRATION DATA}

\section{COINCIDENCE MODE - W/LEAD SHIELD}

\begin{tabular}{|c|c|c|c|c|c|c|c|c|c|c|c|c|c|c|c|c|}
\hline \multirow[b]{2}{*}{ DATE } & \multirow{2}{*}{\multicolumn{2}{|c|}{$\begin{array}{l}\text { COIN. } \\
\text { TIME }\end{array}$}} & \multirow{2}{*}{\multicolumn{2}{|c|}{$\begin{array}{c}\text { CAL IBRATION } \\
\text { STANDARD }\end{array}$}} & \multirow{2}{*}{$\begin{array}{l}\text { COUNT } \\
\text { TIME }\end{array}$} & \multicolumn{10}{|c|}{ SCALER NUMBER } & \multirow[b]{2}{*}{ TOTAL } \\
\hline & & & & & & 1 & 2 & 3 & 4 & 5 & 6 & 7 & 8 & 9 & 10 & \\
\hline $12 / 5 / 83$ & 101 & HS & 6.254 & $\mathrm{mC}$ i $244 \mathrm{Cm}$ & $10 \mathrm{~min}$. & 173,415 & 29,750 & 7,286 & 2,678 & 1,578 & 731 & 395 & 244 & 150 & 256 & 216,483 \\
\hline$"$ & 210 & us & & $"$ & $"$ & 161,671 & 35,878 & 10,062 & 4,156 & 2,517 & 1,275 & 766 & 486 & 330 & 855 & 217,996 \\
\hline$"$ & 295 & us & & $"$ & $"$ & 155,642 & 38,633 & 11,456 & 4,779 & 2,825 & 1,503 & 903 & 603 & 422 & 1,400 & 218,165 \\
\hline$"$ & 101 & us & & PuBe & $"$ & 186,906 & 18,304 & 5,966 & 2,594 & 1,581 & 702 & 386 & 240 & 139 & 185 & 217,002 \\
\hline " & 210 & us & & $"$ & " & 177,922 & 22,082 & 7,601 & 3,749 & 2,415 & 1,270 & 757 & 486 & 331 & 844 & 217,457 \\
\hline $12 / 6 / 83$ & 295 & us & & $"$ & $"$ & 166,691 & 24,223 & 8,280 & 4,179 & 2,607 & 1,382 & 861 & 592 & 409 & 1,117 & 210,341 \\
\hline$"$ & 380 & us & & $"$ & $"$ & 163,213 & 26,586 & 8,901 & 4,467 & 2,899 & 1,536 & 927 & 618 & 426 & 1,715 & 211,289 \\
\hline$"$ & 470 & is & & $"$ & $"$ & 160,566 & 29,291 & 9,653 & 4,853 & 3,149 & 1,685 & 1,036 & 680 & 475 & 1,812 & 213,200 \\
\hline$"$ & 380 & us & 6.254 & $\mathrm{mC}$ i $244 \mathrm{~cm}$ & $"$ & 148,297 & 40,145 & 12,175 & 5,230 & 3,218 & 1,661 & 1,011 & 695 & 460 & 1,499 & 214,392 \\
\hline$"$ & 470 & $\mu s$ & & $"$ & $"$ & 147,023 & 42,413 & 13,166 & 5,606 & 3,385 & 1,842 & 1,140 & 779 & 548 & 1,847 & 217,749 \\
\hline
\end{tabular}


BACKGROUND DATA

SPATIAL MODE - W/LEAD SHIELD

\begin{tabular}{|c|c|c|c|c|c|c|c|c|c|c|}
\hline \multirow[b]{2}{*}{ DATE } & \multirow{2}{*}{$\begin{array}{l}\text { COUNT } \\
\text { TIME } \\
\end{array}$} & \multicolumn{2}{|c|}{ WEST } & \multicolumn{2}{|c|}{ NORTH } & \multicolumn{2}{|c|}{ EAST } & \multirow{2}{*}{\multicolumn{2}{|c|}{$\frac{\text { SOUTH }}{\text { TUNIDD }}$}} & \multirow[b]{2}{*}{ TOTAL } \\
\hline & & INNER & OUTER & INNER & OUTER & INNER & OUTER & & OUTER & \\
\hline $12 / 16 / 83$ & $10 \mathrm{~min}$. & 15,370 & 13,299 & 14,864 & 12,900 & 17,771 & 15,076 & 15,505 & 13,694 & 118,479 \\
\hline
\end{tabular}


CALIBRATION DATA

SPATIAL MODE - W/LEAD SHIELD

\begin{tabular}{|c|c|c|c|c|c|c|c|c|c|c|c|}
\hline & COUNT & CALIBRATION & & & NO & & & & & ITH & \\
\hline DATE & TIME & STANDARD & INNER & OUTER & INNER & OUTER & $\begin{array}{l}\text { INNER } \\
\end{array}$ & OUTER & $\begin{array}{l}\text { INNER } \\
\end{array}$ & OUTER & TOTAL \\
\hline $12 / 16 / 83$ & $1 \mathrm{~min}$. & $\begin{array}{l}78.1 \mathrm{mC} \text { i } 244 \mathrm{Cm} \\
\text { w/metal in } \\
19 \text { l bucket }\end{array}$ & 23,951 & 15,650 & 24,002 & 15,452 & 23,613 & 15,076 & 22,851 & 15,632 & \\
\hline " & $10 \mathrm{~min}$. & $\begin{array}{l}\text { Add } \mathrm{H}_{2} \mathrm{O} \text { to } \\
\text { above }\end{array}$ & 84,514 & 48,589 & 85,562 & 48,327 & 85,886 & 49,520 & 81,797 & 48,188 & \\
\hline
\end{tabular}

